\title{
3 Der Weg des österreichischen Skisports in den Nationalsozialismus
}

\subsection{Das „radikale“ Moment im österreichischen Skisport}

Der verlorene Erste Weltkrieg und eine Erste Republik, die für breite Bevölkerungskreise wenig Identifikationsmöglichkeiten bot, sowie andauernde politische und ökonomische Krisen begünstigten eine Hinwendung $\mathrm{zu}$ den Bergen, im Speziellen zu den Alpen. Sie dienten in den 1920er- und 1930er-Jahren als Projektionsfläche und Orientierungshilfe für Generationen von BergsteigerInnen wie SkiläuferInnen. ${ }^{1}$ Auch der ÖSV leitete daraus seine deutschnationale, völkische Grundhaltung ab, die in weiterer Folge bis 1938 auf radikale Weise zum Ausdruck kam. ${ }^{2}$ Wie in anderen alpinen Vereinen und Verbänden kamen die Bestrebungen jüdische SportlerInnen auszuschließen nach dem Ersten Weltkrieg immer deutlicher zur Geltung. ${ }^{3}$

\subsubsection{Die national-völkische Tradition. Antisemitismus und Ausgrenzungs- politik im ÖSV}

Die Geschichte des ÖSV ist eng mit der Geschichte des „Arierparagraphen“ verknüpft. Die personellen Verbindungen zu den völkisch gesinnten Turnern lassen sich bis zur Gründungsgeschichte des ÖSV im November 1905 zurückverfol-

1 Die Historikerin Gertrud Pfister skizziert diese Hinwendung zu den Alpen und ideologische Verengung für die deutschen und österreichischen Bergsteigerkreise in den 1920er-Jahren. Das kann ebenso für die deutschösterreichischen Skikreise gelten. Vgl. Gertrud Pfister, Sportfexen, Heldenmythen und Opfertod: Alpinismus und Nationalsozialismus, in: Claudio Ambrosi/Wolfgang Weber (Hg.), Sport und Faschismen. Geschichte und Region, Innsbruck/Wien/München/ Bozen 2004, S. 21-59, hier S. 28.

2 Folgendes Kapitel über die Ausgrenzungspolitik im ÖSV findet sich in gekürzter Fassung in dem Sammelband „Images des Sports in Österreich“. Vgl. Andreas Praher, „Skifahren ist für uns Deutsche in den Alpenländern mehr als nur ein Sport.“ Der österreichische Skisport als politische Kampfzone der 1930er-Jahre, in: Matthias Marschik/Agnes Meisinger/Rudolf Müllner/Johann Skocek/Georg Spitaler (Hg.), Images des Sports in Österreich. Innensichten und Außenwahrnehmungen, Göttingen 2018, S. 201-218.

3 Vgl. Bernhard Hachleitner, Arierparagrafen und andere Ausschlussmechanismen, in: Bernhard Hachleitner/Matthias Marschik/Georg Spitaler (Hg.), Sportfunktionäre und jüdische Differenz. Zwischen Anerkennung und Antisemitismus, Wien 1918 bis 1938, Berlin/Boston 2019, S. 23-46, hier S. 30. 
gen. Sie hatten Einfluss auf den späteren deutschnationalen Kurs des ÖSV. ${ }^{4}$ Der ÖSV wurde ebenso wie der DSV am 4. November 1905 im Augustinerbräu in München gegründet. Beide Verbände bestritten von Beginn an gemeinsame Wege und veranstalteten gemeinsame Skirennen im Namen des „deutschen Skilaufes“. 1925 wurden die „Ersten Großdeutschen Skimeisterschaften“ in Kitzbühel abgehalten. ${ }^{5}$ In der Frage des „Arierparagraphen“ agierte der ÖSV aber radikaler als sein deutscher „Bruderverband“ und führte diesen 1923, zehn Jahre vor der Machtübernahme der Nationalsozialisten in Deutschland und ohne äußeren Druck ein.

Im Unterschied zum Turnen hatte der Skisport ebenso wie der Alpinismus einen geografisch klar definierten Betätigungsraum zur Verfügung, den er für sich beanspruchen konnte. Die Alpen wurden von führenden männlichen Protagonisten in Alpin-, Ski- und Berggemeinschaften als deutscher Kulturraum begriffen. Diese Geisteshaltung hatte nicht nur eine Abgrenzung, sondern gleichzeitig eine Ausgrenzung bestimmter Bevölkerungsgruppen zur Folge. Rainer Amstädter beschreibt die Entwicklung in seiner Gesellschaftsgeschichte des österreichischen und deutschen Alpinismus als „Faschisierung des Alpinismus“6. Ähnliches traf auch auf den österreichischen Skisport zu, man könnte analog von einer „Faschisierung des Skilaufs“ sprechen. So interpretierten völkisch gesinnte Vertreter in Skivereinen von Wien bis Vorarlberg die Alpen nicht nur als heile Welt, sondern begriffen diese als deutsches Terrain. Ziel war die Durchsetzung einer deutschnationalen Hegemonie im Alpin- und Skisport. Die Vorherrschaft sollte durch eine politische und symbolische Besetzung des Naturraumes sowie den Ausschluss „nichtarischer“ Mitglieder erreicht werden. Der spätere Begründer und Leiter des Salzburger Landesverkehrsamtes Hans HofmannMontanus $^{7}$ verdichtete die von einer Natur- und Heimatromantik getriebenen

$4 \mathrm{Vgl}$. Andreas Brugger, The Influence of Politics on the Development of Turnen, Mountaineering and Skiing in Western Austria, in: The International Journal of the History of Sport, 30 (2013) 6, S. 674-691, hier S. 680.

5 Vgl. Walter König/Gustl Berauer, Handbuch des Schilaufs, Innsbruck 1943, S. 30-31.

6 Amstädter, Der Alpinismus, 267.

7 Der Fremdenverkehrsfachmann Hans Hofmann-Montanus, geboren am 12. Juli 1889 in Wien, war zunächst in Wien und im Burgenland tätig, bevor er vom Salzburger Landeshauptmann Franz Rehrl nach Salzburg berufen wurde. Im Ersten Weltkrieg diente er als Bergführer an der italienischen Front und danach war er einer der Mitbegründer des niederösterreichischen Landesskiverbandes. Er begründete das Salzburger Landesverkehrsamt und leitete dieses von 1926 bis 1938 sowie nach 1945 bis zu seinem Tod am 24. Mai 1954. Hofmann-Montanus war nicht nur Alpinist, Höhlenforscher und Bergsteiger, sondern auch Skiläufer. Er schrieb mehrere Bücher, unter anderem über das Bergsteigen und setzte sich in den 1930er-Jahren als Touristiker für den Ausbau der skisportlichen Infrastruktur ein. Vgl. Hans Hofmann-Montanus, Berge einer Jugend, Wien 1948, S. 111-117; Friederike Zeisberger/Reinhard R. Heinisch (Hg.), Leben über 
reaktionären Anschauungen im März 1919 in einem Vorbericht zur ersten Vertreterversammlung des ÖSV nach dem Ersten Weltkrieg, in dem er festhielt:

\begin{abstract}
Alpenländisch - da sind wir wieder auf den Kern unserer Pläne und Hoffnungen gestossen. Eine nahezu rein alpenländische, deutschalpenländische Vereinigung war der Oesterreichische Skiverband schon vor dem Kriege, und er war es längst, als vom alten deutschen Oesterreich erst der Umsturz des Jahres 1918 den Anhang der slawischen Nationen losschüttelte. ${ }^{8}$
\end{abstract}

Geprägt von einer „narzisstischen Kränkung“, wie Gertrud Pfister schreibt, ${ }^{9}$ die durch die militärische Niederlage im Ersten Weltkrieg hervorgerufen wurde, entwickelte sich im ÖSV über die Jahre eine „Null-Toleranz-Politik“ gegenüber allem, was nicht „deutschstämmig“ war. Der verlorene Krieg und die als ungerecht empfundenen Friedensschlüsse wurden als Vorwand genommen, um deutschnationale Herrschaftsansprüche im Skilauf geltend zu machen. Der ÖSV sah sich kurz nach Kriegsende zunächst als der rechtmäßige Verband, in dem alle „deutschen Skivereine in der ehemaligen Monarchie“10 zusammengefasst werden sollten, musste aber mit dem Abschluss der Friedensverträge 1919 erkennen, dass dies nicht mehr möglich war. Mit der politischen Neuordnung Europas verlor der ÖSV deutsche Mitgliedsvereine in Böhmen, Mähren, im heutigen Slowenien und Südtirol sowie in den Karpaten. Kompensiert wurden die Verluste durch eine Hinwendung zum DSV und mittels einer stärker werdenden deutschnational und völkisch ausgerichteten Verbandspolitik. ${ }^{11}$ Statutarisch untermauert wurde die Geisteshaltung mit der Einführung von „Arierparagraphen“. Diese bildeten den gemeinsamen Nenner für einen politischen Kampf innerhalb der Skiriegen im Österreich der 1920er- und 1930er-Jahre, wobei sich zu den bis 1918 vorwiegend antislawischen Ressentiments sehr schnell antisemitische dazugesellten, ${ }^{12}$ welche immer heftiger in Erscheinung traten. Wie tief verwurzelt der Antisemitismus im österreichischen Sport und vor allem im Skisport

den Tod hinaus. Prominente im Salzburger Kommunalfriedhof, Mitteilungen der Gesellschaft für Salzburger Landeskunde (Band 23), Salzburg 2006, S. 366.

8 Vorwort von Hans Hofmann-Montanus zur bevorstehenden Vertreterversammlung 1919 des Oe. S.V, in: Sportblatt am Mittag, 5.3.1919, S. 4.

9 Pfister, Sportfexen, S. 28.

10 Ignaz Karl Gsur, Konzept zur Geschichte des Skilaufes und 20 Jahre Oe. S.V 1905-1925 (unveröffentlichtes Manuskript), Skihistorisches Archiv des ÖSV, Kopie im Besitz des Verfassers, S. 29.

11 Vgl. Gsur, Konzept zur Geschichte des Skilaufes, S. 29-34; Salzburger Volksblatt, 3.11.1919, S. 5.

12 Ich teile hier die Einschätzung von Gerd Falkner, der feststellt, dass es zunächst ,nicht um direkten Antisemitismus“ ging, sondern um „Zurückdrängung nichtdeutscher, insbesondere slawischer Einflüsse“. Falkner, Der Arierparagraph, S. 9. 
war, zeigen unter anderem die bereits zum Teil veröffentlichten Briefe des ehemaligen Kommandeurs der österreich-ungarischen Skitruppen im Ersten Weltkrieg Georg Bilgeri, der in den 1920er- und 1930er-Jahren als Skilehrer und Skipädagoge im In- und Ausland äußerst geschätzt war. ${ }^{13}$ Seine politische Einstellung, selbst wenn er 1934 noch festhält, dass es seine Überzeugung sei, „daß der Nationalsozialismus an uns Österreichern zerschellen wird und muß“, ${ }^{14}$ ist zumindest im Kontext seiner späteren Schreiben zu hinterfragen. So vertrat er den „Arierparagraphen“ im Skiverband, um den Frieden zu bewahren. ${ }^{15}$ Der spätere zivile Skilehrer Bilgeri war mit seinen Ansichten nicht allein. Das geht beispielsweise aus dem Jahresbericht des Salzburger Landesskiverbandes für das Verbandsjahr 1933/34 hervor. Darin schreibt der Vorstand:

Wenn unser Salzburger Skiverband heute in der Skigeschichte Oesterreichs einen so hervorragenden Anteil nimmt, so verdanken wir dies jenen nationalen Patrioten der Vor- und Nachkriegszeit, die damals schon im Gemeinsinn des völkischen Aufbaues dieses Werk gründeten und immer weiter ausbauend, ob bekannt oder unbekannt, eine wahre selbstlose Tat vollbrachten. Und es ist die Pflicht eines jeden einzelnen deutschfühlenden Skikameradens, dieses Erbe zu bewahren und zu schützen. ${ }^{16}$

\subsubsection{Antisemitismus im österreichischen Sport der Ersten Republik}

Die lange und latent vorhandene Tradition des Antisemitismus im ÖSV, die ab Mitte der 1920er-Jahre in Form von Ausgrenzung und öffentlicher Diffamierung einzelner Personen zum Ausdruck kam, muss vor dem Hintergrund des Antisemitismus der Ersten Republik gesehen werden. „Ein radikaler Deutschnationalismus und ein rassischer Antisemitismus, Ideen, welche später im Nationalsozialismus voll zum Durchbruch kamen, hatten ein halbes Jahrhundert davor bereits begeisterte Anhänger gefunden“, schreibt Konrad Jekl in seinen Betrachtungen über die Republik Österreich. ${ }^{17}$ Jekl geht in seinen Schlussfolgerungen

13 Der Alpinist und Skiläufer Georg Bilgeri war seit Oktober 1894 Berufsoffizier und wurde nach seinem Kriegsdienst im Ersten Weltkrieg 1920 zum Oberstleutnant ernannt. Am 23. Dezember 1925 erhielt er aufgrund seiner skilehrenden Tätigkeit im militärischen und zivilen Bereich ehrenhalber den Titel eines Regierungsrates verliehen. Vgl. Österreichisches Staatsarchiv (OeStA)/AdR, HBbBUT BMfHuV Präs Auszeichnungsanträge Bilgeri Georg Zl. 16026/1925 Kt. 147.

14 Brief von Georg Bilgeri vom 30.7.1934 zit. nach Gudrun Kirnbauer/Friedrich Fetz, Skipionier Georg Bilgeri, Graz/Feldkirch, 2001, S. 43.

15 Vgl. Kirnbauer/Fetz, Skipionier, S. 43-44.

16 Jahresbericht Salzburger Landes-Skiverband 1933/34, S. 3.

17 Konrad Jekl, Auf den Spuren der Republik Österreich. Aufsätze zur österreichischen Zeitgeschichte, Frankfurt am Main 1995, S. 81. 
ebenso auf die Sport- und Turnvereine ein und betont, dass diese im nationalen Lager eine immer größere Bedeutung erfahren hätten. ${ }^{18}$ Was für die deutschnationalen TurnerInnen galt, kann ebenso für die Bergsteiger- und SkifahrerInnenzunft festgestellt werden. Generell war der Antisemitismus innerhalb der österreichischen Gesellschaft vor 1938 in verschiedenen Formen und Ausprägungen vorhanden, sodass die nationalsozialistische Ideologie und die Verfolgung der jüdischen Bevölkerung auf breite Akzeptanz stoßen konnten. Oder wie der Salzburger Historiker Ernst Hanisch in seinen Reflexionen zum ersten Sammelband der Buchreihe Die Stadt Salzburg im Nationalsozialismus schreibt: „Die latenten Ängste wurden nach außen projiziert und bekamen ein Gesicht und einen Namen, die man vernichten konnte."19 Ausgrenzung und An-denPranger-Stellen jüdischer SportlerInnen war eine erste Vorstufe zu dem was folgen sollte. Albert Lichtblau betont, dass der Ausschluss von Jüdinnen und Juden in der Ersten Republik aus gesellschaftlichen Teilbereichen wie Sport- und Tourismusvereinen neben der parteipolitischen antisemitischen Agitation, die jüdische Bevölkerung isoliert und zu „apartheidähnlichen Zuständen“ geführt hat. Gleichzeitig bildete das „Rote Wien“ mit seinem ausgeprägten jüdischen Gemeinschaftsleben bis 1934 einen Gegensatz zur Provinz, in der jüdische BewohnerInnen den antisemitischen Feindseligkeiten stärker ausgesetzt waren. ${ }^{20}$ Dieser Gegensatz kann besonders auch auf sportlicher Ebene festgemacht werden.

Was den Antisemitismus im österreichischen Sport in der Ersten Republik betrifft, stellt Michael John fest, dass 1923 als Wahljahr ein „besonders ereignisreiches Jahr“ gewesen war, mit gehäuft auftretenden antisemitischen Ausschreitungen. ${ }^{21}$ Das würde auch erklären, warum der „Arierparagraph“ im ÖSV 1923 eingeführt wurde. Zumindest kann eine Zuspitzung der Diskussion nachgewiesen werden und somit decken sich die Beobachtungen Johns, dass politische Auseinandersetzungen ihr Äquivalent im Sportgeschehen fanden mit den Rechercheergebnissen im Rahmen dieser Forschungsarbeit. Grundsätzlich kann

18 Vgl. Jekl, Auf den Spuren der Republik, S. 83.

19 Ernst Hanisch, Warum die Geschichte des Nationalsozialismus nicht vergeht. Reflexionen eines alten Historikers, in: Peter F. Kramml/Ernst Hanisch (Hg.), Hoffnungen und Verzweiflung in der Stadt Salzburg 1938/39. Vorgeschichte - Fakten - Folgen. Die Stadt Salzburg im Nationalsozialismus (Band 1), Salzburg 2010, S. 10-31, hier S. 16.

20 Vgl. Albert Lichtblau, Integration und Desintegration am Beispiel der jüdischen Bevölkerung Österreichs. Innen- und Außenperspektiven, in: Manfred Oberlechner (Hg.), Die missglückte Integration? Wege und Irrwege in Europa, Wien 2006, S. 81-100, hier S. 88-89.

21 Michael John, Ein kultureller Code? Antisemitismus im österreichischen Sport der Ersten Republik, in: Michael Brenner/Gideon Reuveni (Hg.), Emanzipation durch Muskelkraft. Juden und Sport in Europa, Göttingen 2006, S. 121-142, hier S. 121-122. 
für die 1920er-Jahre eine gesteigerte antisemitische Haltung in der österreichischen Gesellschaft festgestellt werden. Diese kumulierte 1918 mit dem Zerfall der Habsburgermonarchie und mit der damit einhergehenden Identitätskrise sowie der politischen und wirtschaftlichen instabilen Situation der Ersten Republik. ${ }^{22}$ Da ideologische Barrieren zwischen den politischen Lagern wegbrachen und die jüdische Minderheit politisch schutzlos geworden war, „konnte in der Ersten Republik der extreme Flügel der Deutschnationalen an Integrationskraft gewinnen - und mit ihm der ausgeprägtere, radikale Antisemitismus“"23, schreibt Albert Lichtblau. Dieser von Lichtblau beschriebene ausgeprägtere, radikale Antisemitismus äußerte sich besonders in deutschnationalen Sportverbänden und -vereinen und ließ Worten Taten folgen.

John nennt einige steirische Fußballvereine, die 1923 ebenso wie der ÖSV den „Arierparagraph“ eingeführt haben, unter anderem der Grazer Athletiksportklub (GAK). ${ }^{24}$ Auch Walter Iber verweist in seiner Studie über den steirischen Fußball darauf, dass der GAK am „Arierparagraphen“ festhielt, dieser jedoch in der Praxis nicht immer eingehalten wurde. ${ }^{25}$ Auch für Salzburg lassen sich im Fußballsport, zumindest für den SAK, die Einführung eines „Arierparagraphen" und der darauffolgende Ausschluss jüdischer Mitglieder für die 1920er-Jahre nachweisen. ${ }^{26}$ Der Antisemitismus durchdrang also auch den ansonsten international ausgerichteten Fußballsport. Dennoch bildeten Fußballvereine, die bereits vor 1938 einen „Arierparagraphen“ in den Statuten führten, eine Minderheit. ${ }^{27}$ Das lag sicher an der multiethnischen und multikonfessionellen Zusammensetzung des Mannschaftssports Fußball und auch an der starken sozialdemokratischen Durchdringung des Fußballsports bis 1934. Bei alpinen Vereinen, die primär Einzelsportarten betrieben, sah dies anders aus. Die Fokussierung auf einzelne AthletInnen erlaubte eine Ideologisierung der Körper sowie eine nationale Aufladung dieser. Hier bot der in vielen alpinen Vereinen vorhandene radikale Deutschnationalismus mit seinen antisemitischen Vorstellungen passende Konzepte für ein Sportideal, das sich in den 1930er-Jahren im-

22 Vgl. John, Ein kultureller Code?, S. 121; Albert Lichtblau, Antisemitismus - Rahmenbedingungen und Wirkungen auf das Zusammenleben von Juden und Nichtjuden, in: Emmerich Tálos/Herbert Dachs/Ernst Hanisch/Anton Staudinger (Hg.), Handbuch des politischen Systems Österreichs. Erste Republik 1918-1933, Wien 1995, S. 454-471, hier S. 460-461.

23 Lichtblau, Antisemitismus, S. 458.

24 Vgl. John, Ein kultureller Code?, S. 123.

25 Vgl. Iber, Erst der Verein, S. 46.

26 Vgl. Andreas Praher, Politische Radikalisierung im Salzburger Fußballsport in der Zwischenkriegszeit, in: Siegfried Göllner/Albert Lichtblau/Christian Muckenhumer/Andreas Praher/Robert Schwarzbauer (Hg.), Zwischen Provinz und Metropole. Fußball in Österreich. Beiträge zur 1. Salzburger Fußballtagung, Göttingen 2016, S. 105-124, hier S. 112.

27 Vgl. John, Ein kultureller Code?, S. 123. 
mer mehr der Rassenideologie der Nationalsozialisten annäherte. Eine ähnliche Entwicklung nahm das deutsche Turnen bzw. der Deutsche Turnerbund in Österreich, auch dieser näherte sich dem Nationalsozialismus an. ${ }^{28}$ Der Österreichische Alpenverein agierte mit seinen Beschlüssen der Sektion Austria im Oktober 1921, keine Jüdinnen und Juden mehr als Mitglieder aufzunehmen, ${ }^{29}$ als Vorbild für den ÖSV und seine Mitgliedervereine. Der ÖSV zog zwei Jahre später nach. ${ }^{30}$

\subsubsection{Die Protagonisten}

Wer hatte nun die Grundlagen für die Ausgrenzungspolitik innerhalb des Österreichischen Skiverbandes geschaffen und $\mathrm{zu}$ verantworten? Wer waren die Akteure ${ }^{31}$ hinter dem Beschluss, der Jüdinnen und Juden eine Mitgliedschaft innerhalb des ÖSV und seiner Mitgliedervereine ab 1923 verweigerte? „Ein Konzept zur Geschichte des Skilaufes“ gibt Aufschluss darüber. Das maschinengetippte Protokoll wurde 1925 von ÖSV-Funktionär Ignaz Karl Gsur verfasst bzw. herausgegeben, das Vorwort dazu schrieb Alexander Rödling. ${ }^{32}$ Gsur wurde im September 1921 zum Vorsitzenden des ÖSV gewählt, war Vorsitzender des Wiener Landesskiverbandes und bekleidete daneben das Präsidentenamt des deutschnationalen Ersten Wiener Amateur-Schwimmklubs (EWASK). Er war zudem Vi-

28 Vgl. John, Ein kultureller Code?, S. 130; Praher, Sport und Körperkultur, S. 279-280 und Siegfried Göllner, „Illegal“ - Sportliche Überläufer und Grenzgänger, in: Salzburgs Sport in der NS-Zeit. Zwischen Staat und Diktatur, Salzburg 2018, S. 73-86, hier S. 73.

29 Vgl. dazu Martin Achrainer/Nicholas Mailänder, Der Verein, in: Berg Heil! Alpenverein und Bergsteigen 1918-1945, Köln/Weimar/Wien, 2011, S. 193-318, hier S. 228-229 und Lichtblau, Antisemitismus, S. 467.

30 Albert Lichtblau behauptet in seiner Darstellung über die Rahmenbedingungen und Wirkungen des Antisemitismus in der Ersten Republik, dass die Einführung des „Arierparagraphen“ im ÖSV wenig Erfolg hatte, weil sie die österreichischen Skisportbegeisterten nicht vereinnahmen konnte und zu einer Spaltung führte. Vgl. Lichtblau, Antisemitismus, S. 468. Wie neuere Forschungserkenntnisse zeigen, ging der ÖSV allerdings gestärkt aus dieser Auseinandersetzung hervor. Vgl. hier vor allem die folgenden Kapitel der vorliegenden Forschungsarbeit.

31 Hier wird bewusst die männliche Form verwendet, weil der Vorstand des ÖSV in der Zwischenkriegszeit rein männlich besetzt war und die Entscheidungen bezüglich der geltenden Statuten ausschließlich von Männern bestimmt und mitgetragen wurden.

32 Vgl. Gsur, Konzept zur Geschichte des Skilaufes. Das Vorwort zur Geschichte des Österreichischen Skiverbandes ist zwar von Alexander Rödling verfasst, der nach dem Rücktritt von Gsur ab 1925 das Amt des 1. Vorsitzenden des ÖSV bekleidete. Es ist aber davon auszugehen, dass Gsur den Großteil der knapp 50 Seiten selbst geschrieben hat. 
zepräsident des Hauptverbandes für Körpersport. ${ }^{33}$ Der EWASK war einer der Hauptkonkurrenten des jüdischen Schwimmklubs Hakoah Wien und betrieb ab den 1920er-Jahren eine offen antisemitische Politik. ${ }^{34}$ Es ist daher davon auszugehen, dass Gsur diese maßgeblich mitgestaltete. Seine antisemitische Haltung schimmert jedenfalls im ÖSV-Protokoll aus dem Jahr 1925 durch. In der nachträglich erstellten Niederschrift brachte Gsur die Diskussionen und Beschlüsse der ÖSV-Vollversammlungen zu Papier. Als eine der wenigen schriftlichen Originalquellen des ÖSV gibt das Dokument die Stimmungslage innerhalb des Skiverbandes wieder. Gleichzeitig dokumentiert das Protokoll die politische Ausrichtung einzelner Landesverbände. So steht darin zu lesen:

Die Frage des nationalen Aufbaues des Ö.S. V. war durch ein Schreiben der Schneeschuhriege des akad. Turnvereines (A.T. V.) Graz, vom 28. Oktober 1920 an die V. V. Salzburg angeschnitten worden. In diesem Schreiben [...] wurde der Anschluß des Ö.S. V. an den D.S. V. unter Wahrung der vollsten Autonomie des Ö.S. V. gefordert und der Wunsch ausgesprochen, daß der Ö.S.V. den sogenannten Arierparagraphen in seine Satzungen aufnehmen und daß der österr. Skimeistertitel nur Österreichern zuerkannt werden möge. ${ }^{35}$

Demnach war es also die Schneeschuhriege, sprich die Skilaufabteilung des Akademischen Turnvereins Graz, die im Jahr 1920 als Verbandsmitglied die Forderung nach einem „Arierparagraphen“ aufstellte. Bis dato fehlen weitere Quellen, die das belegen. Jedoch kann das von Gsur 1925 verfasste Protokoll durchaus als zuverlässig angesehen werden. Jedenfalls war bereits bei der ersten Vertreterversammlung des ÖSV nach dem Ersten Weltkrieg im November 1919 der „Zusammenschluß aller skilaufenden Deutschen zu einer mächtigen Vereinigung“36 begrüßt worden. Ein Sonderausschuss sollte für ein „inniges gemeinsames Zusammengehen“ zwischen ÖSV und DSV sorgen und die „engste Fühlung“ $\mathrm{zu}$ den deutschen Skivereinen in den vorwiegend deutschsprachigen

33 Der Alpinist Ignaz Karl Gsur (1888-1960) war seit November 1919 stellvertretender Vorsitzender und wurde im September 1921 zum Vorsitzenden des ÖSV gewählt. Gsur war gleichzeitig erster Vorsitzender des Wiener Landesskiverbandes und seit 1913 Vorsitzender des damals gebildeten Ausschusses der Wiener Ski-Vereine, der am 25. Jänner 1921 als Wiener Landesskiverband (W.L.S.V.) neu gegründet wurde. Zudem war Gsur in den 1920er-Jahren stellvertretender Vorsitzender des Deutschen Skiverbandes. Vereinsakt Landes-Ski-Verband für Wien und Niederösterreich. Wiener Stadt- und Landesarchiv (WStLA), M.Abt. 119, A32 - Gelöschte Vereine: 5500/1922 - 5500/1922; Gsur, Konzept zur Geschichte des Skilaufes, S. 41; Gruber/ Metzger, Es begann in Wien, S. 222.

34 Vgl. William D. Bowman, Hakoah Vienna and the International Nature of Interwar Austrian Sports, in: Central European History 44 (2011), S. 642-668, hier S. 643.

35 Gsur, Konzept zur Geschichte des Skilaufes, S. 32.

36 Zit. nach Falkner, Der Arierparagraph, S. 15. 
Gebieten der ehemaligen Monarchie aufrechterhalten. ${ }^{37}$ Der „Arierparagraph“ wurde hierbei noch nicht erwähnt, zumindest nicht in den Überlieferungen. Allerdings drängte die Skiläuferschaft der Steiermark, die seit Oktober $1920 \mathrm{im}$ steirischen Landesskiverband organisiert war, auf die Einführung des „Arierparagraphen“. Grund dafür war, dass der Steirische Skiverband seit seiner Gründung auf „arischer Grundlage“ stand. Gleichzeitig wollte der Landesverband die sich stellende Anschlussfrage an den Deutschen Skiverband mit der „Arierfrage“ verknüpft sehen. Somit manifestierte sich innerhalb des ÖSV kurz nach dem Ende des Ersten Weltkriegs ein ,großdeutscher Gedanke“, der deutschvölkisch ausgerichtet und durchwegs antisemitisch geprägt war. ${ }^{38}$

Der „Arierparagraph“ wurde schließlich im Oktober 1923 im gesamten ÖSV beschlossen, nachdem schon im Jahr 1921 alle Mitgliedsvereine in einem „vertraulichen Rundschreiben“ aufgefordert worden waren, eine bindende Erklärung abzugeben und im Februar 1923 bei der deutschvölkischen Skimeisterschaft [sic] in Bad Gastein der Antrag auf Abänderung der Satzungen gestellt wurde. ${ }^{39}$ Dass der Antrag auf Abänderung der Satzungen akkurat bei den Skibewerben in Bad Gastein erfolgte, war kein Zufall. Die deutschvölkische und akademische Skimeisterschaft vom 14. bis 15. Februar 1923 in Bad Gastein sollte die politische Ausrichtung des ÖSV auf sportlicher Ebene unterstreichen. ${ }^{40}$ Die Beschlussfassung erfolgte bei der Vertreterversammlung am 6. und 7. Oktober 1923 im oberösterreichischen Bad Ischl. Der Antrag auf Satzungsänderung wurde mit einer deutlichen Mehrheit von $675 \mathrm{zu} 174$ Stimmen angenommen. ${ }^{41}$ Gsur wurde im Rahmen der Vertreterversammlung erneut zum ersten Vorsitzenden des ÖSV gewählt. ${ }^{42}$ Die Konsequenz war eine Verbandsspaltung, einzelne Vereine aus dem Salzkammergutverband sowie dem Tiroler Skiverband traten in den Folgejahren aus dem ÖSV aus. ${ }^{43}$ In der 1969 herausgegebenen Steirischen Skigeschichte wurde über 40 Jahre später das zweifelhafte Resümee gezogen: „Damit war der ÖSV rassenrein [...]“..44

37 Salzburger Volksblatt, 3.11.1919, S. 5.

38 Der Sporthistoriker Gerd Falkner beschreibt die Entwicklung als „Radikalisierung einer sich deutschvölkisch bzw. deutscharisch empfindenden Bewegung innerhalb der deutschen TurnSport- und Skivereine“. Diese reichte laut Falkner bis in die Donaumonarchie zurück, in den 1920er-Jahren kam die antisemitische Facette hinzu. Falkner, Der Arierparagraph, S. 5.

39 Vgl. Salzburger Volksblatt, 3.10.1923, S. 6; Gsur, Konzept zur Geschichte des Skilaufes, S. 33 und S. 41.

40 Vgl. Salzburger Volksblatt, 16.2.1923, S. 7.

41 Vgl. Alexander Rödling, Zur Geschichte des Österreichischen Ski-Verbandes, in: Der Skilauf in Österreich. Jahrbuch des Österreichischen Skiverbandes, Wien 1927, S. 13-107, hier S. 80. 42 Vgl. Gsur, Konzept zur Geschichte des Skilaufes, S. 42.

43 Vgl. Falkner, Der Arierparagraph, S. 18-21; Salzburger Wacht, 31.5.1926, S. 5.

44 Theodor Hüttenegger/Max Pfliger, Steirische Skigeschichte, Graz 1968, S. 121. 
Der Ausschluss von „Nicht-Ariern“ war aber bereits vor der Einführung eines verbandsweiten „Arierparagraphen“ im Jahr 1923 in vereinzelten Vereinen gelebte Praxis. In der Weihnachtswoche 1920 untersagte die Wintersportvereinigung St. Johann im Pongau „nichtarischen“ Interessierten die Teilnahme an einem Anfänger-Skikurs. ${ }^{45}$ Zwei Monate später organisierte der ÖSV in St. Johann im Pongau den Hauptverbandswettlauf. Doch auch andernorts gab es Vorzeichen. So berichtete die Zeitschrift Alpenland in seinem Morgenblatt am 7. Oktober 1921, dass der 50 Mann starke Wintersportverein Kitzbühel aufgrund seiner „deutschvölkischen Gesinnung“ dem neugegründeten Deutschvölkischen Skiverband beigetreten sei. ${ }^{46}$ Dieser verfolgte ab 1921 eine antisemitische und rassistische Politik. ${ }^{47}$

Gsur war nicht der einzige Vertreter, der seinen deutschnational-antisemitischen Standpunkt durchzusetzen vermochte. Neben ihm gab es andere einflussreiche Personen innerhalb des ÖSV, die ihre Machtpositionen ausbauen konnten. Der Unterschied zu Gsur war ihre Nähe zum aufkeimenden Nationalsozialismus. Diese Nähe war durchaus hilfreich und entwickelte sich später zum Karrieremotor.

Skifahren ist für uns Deutsche in den Alpenländern mehr als nur ein Sport. Es [...] gehört zu uns wie jeder andere Ausdruck unseres Wesens. So fest und notwendig ist es mit dem ganzen Volke verbunden [...] Wir Deutsche in Österreich haben dabei eine ganz besondere Aufgabe für das ganze deutsche Volk zu erfüllen. ${ }^{48}$

Diese Zeilen von Karl Springenschmid, geschrieben am Vorabend des „Anschlusses“, zeigen jene Entwicklungen, die im ÖSV und in österreichischen Skivereinen vor 1938 vonstattengingen. Sie verdeutlichen, wie die „Blut und Boden-Ideologie“ ihre Entsprechung im Skisport finden konnte. Springenschmid teilte diese Anschauung mit anderen führenden GesinnungsgenossInnen der Berg- und Skiriege. Er war, wie andere auch, eine zentrale Figur in der illegalen NS-Bewegung. Springenschmid war einer jener Demagogen, die sich vor dem „Anschluss“ offen zum Nationalsozialismus bekannten. Der Lehrer war ein begeisterter Alpinist, Turner, Skiläufer und sowohl im Alpenverein als auch im Skiverband führend tätig.

45 Vgl. Deutsches Volksblatt, 28.11.1920, 17.

46 Vgl. Alpenland. Morgenblatt, 2 (1921) 473, S. 7.

47 Vgl. das Kapitel „Verortung des ,österreichischen“ Skisports im Kontext des Nationalsozialismus“ in dieser Forschungsarbeit.

48 Karl Springenschmid, Ein Volk fährt Ski, in: Skileben in Österreich, Wien 1938, S. 11 und 18. 


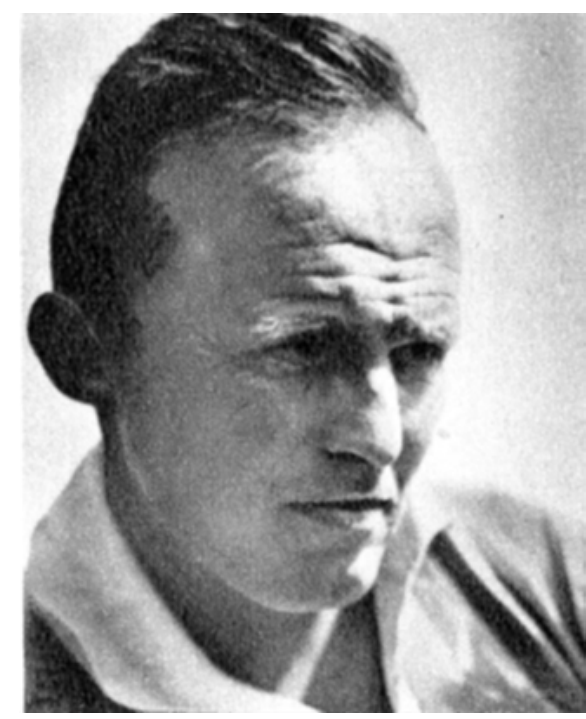

Abb. 11: Karl Springenschmid war einer der führenden Verfechter des „Arierparagraphen“ im ÖSV, Stadtarchiv Salzburg/ Bergland 1933.

Springenschmid wurde 1897 in Innsbruck geboren und legte 1921 die Lehramtsprüfung ab. 1925 fand er eine Anstellung als Lehrer im Salzburger Bergdorf Wagrain. Er war zudem Schriftleiter beim Salzburger Landeslehrerverein. Im September 1934 wurde er wegen NS-Betätigung aus dem Schuldienst entlassen bzw. „in den dauernden Ruhestand“ versetzt. Danach war er als freier Schriftsteller tätig. Als NSDAP-Mitglied wurde er seit 1932 geführt. ${ }^{49}$ Unter anderem schrieb Springenschmid für die ÖSV-Zeitschrift Skileben. Im Frühjahr 1934 veröffentlichte er seine Österreichischen Geschichten zum „illegalen Kampf“. ${ }^{50}$ Darin beschreibt Springenschmid die Aktivitäten einer illegalen SA-Schar auf der Lärchriedlalm in den Kärntner Nockbergen..$^{51} \mathrm{Im}$ selben Bundesland führte er gemeinsam mit dem späteren Sportführer der „Ostmark“ und Salzburger Gauleiter Friedrich Rainer Wehrertüchtigungslager des Deutschen Turnvereins durch..$^{52}$ Der Skilauf sollte ebenso wie der Bergsport für die politischen Ziele des Nationalsozialismus genutzt werden. Das war die Botschaft Springenschmids im März 1938. Eineinhalb Monate später, am 30. April 1938 initiierte er die erste Bücherverbrennung auf österreichischem Boden auf dem Salzburger Residenz-

49 Vgl. BArch (ehem. BDC), PK, Springenschmid, Karl, 19.3.1897 und BArch R/1501/209067. 50 Karl Springenschmid, Österreichische Geschichten aus der ersten Zeit des „illegalen“ Kampfes, München 1935.

51 Springenschmid, Österreichische Geschichten, S. 47.

52 Vgl. Der Turner. Wochenblatt des Deutschen Turnerbundes, 18 (1937) 38, S. 2; Praher, Sport und Körperkultur, S. 290. 
platz und war anschließend im Gauapparat von Salzburg als Leiter des NS-Lehrerbundes führend tätig. ${ }^{53}$ Dass ausgerechnet Springenschmid eine Autobiografie des österreichischen Nachkriegsskistars und Olympiasiegers von 1956 Toni Sailer verfasste, ist eine weitere Facette in der Biografie des führenden NSFunktionärs und der österreichischen Sportgeschichte..$^{54}$

Eine andere treibende Kraft für den antisemitischen Kurs war der Obmann des steirischen Landesskiverbandes Franz Martin. Nachdem er 1920 dem Steirischen Landesskiverband vorgestanden war, dürfte Martin maßgeblich an der Einführung des „Arierparagraphen“ beteiligt gewesen sein und damit eine Grundlage für die ausgrenzende Politik des ÖSV mitgeschaffen haben. ${ }^{55}$ Geboren 1893, war der Tierarzt ab Juli 1932 NSDAP-Mitglied der Ortsgruppe Wien-Favoriten ${ }^{56}$ und saß wegen Parteitätigkeit für kurze Zeit in Haft. 1936 kam die Bundespolizeidirektion Wien bei der Überprüfung führender ÖSV-Funktionäre zu dem Schluss, dass es „bisher keine nachteiligen Wahrnehmungen“ gegen Franz Martin gebe. ${ }^{57}$ Im März 1938 wurde der Sportwart des ÖSV in den leitenden Verwaltungsausschuss der noch bestehenden Österreichischen Sport- und Turnfront berufen ${ }^{58}$ und unmittelbar nach dem „Anschluss“ zum Gaufachwart für Skilauf ernannt.

Ebenso wie Franz Martin war Alexander Rödling führend an der ausgrenzenden Politik des ÖSV beteiligt. Er hatte diese zudem als Präsident zu verantworten. Rödling wurde am 30. November 1886 im heutigen slowenischen Celje (zu Deutsch: Cilli) geboren..$^{59}$ Im Ersten Weltkrieg diente er für 30 Monate in der Feldartillerie und war danach Oberleutnant der Reserve. Für seine militärischen

53 Vgl. Karl Müller, Die Vernichtung des „undeutschen“ Geistes. Theater und Literatur im Dienste des Nationalsozialismus, in: Sabine Veits-Falk/Ernst Hanisch (Hg.), Herrschaft und Kultur. Instrumentalisierung, Anpassung, Resistenz. Die Stadt Salzburg im Nationalsozialismus (Band 4), Salzburg 2013, S. 400-459, hier S. 413-414; Helmut Uitz, Erziehung und Schule in der NS Zeit in Salzburg. Weichenstellung für Generationen, in: Peter F. Kramml/Christoph Kühberger (Hg.), Inszenierung der Macht. Alltag, Kultur und Propaganda. Die Stadt Salzburg im Nationalsozialismus (Band 2), Salzburg 2011, S. 186-279, hier S. 253.

54 Vgl. Toni Sailer, Mein Weg zum dreifachen Olympiasieg, Salzburg 1956; Matthias Marschik, Sportdiktatur. Bewegungskulturen im nationalsozialistischen Österreich, Wien 2008, S. 8.

55 Vgl. Hüttenegger/Pfliger, Steirische Skigeschichte, S. 119-120.

56 Vgl. BArch (ehem. BDC), PK, Martin, Franz, 6.5.1893.

57 Vereinsakt des Österreichischen Skiverbandes 1933-1936, Schreiben der Bundespolizeidirektion Wien an das Bundeskanzleramt (BKA), Generaldirektion für öffentliche Sicherheit, Staatspolizei vom 22. April 1936, OeStA/AdR, BKA/BPD Wien, Vereinsbüro XVIII-11.336.

58 Vgl. Vereinsakt des Österreichischen Skiverbandes 1933-1936, Bescheid der kommissarischen Führung der Österreichischen Sport- und Turnfront vom 12.3.1938, OeStA/AdR, BKA/ BPD Wien, Vereinsbüro XVIII-11.336.

59 Vgl. Meldezettel Dr. Alexander Rödling, Stadtarchiv Graz. 
Leistungen erhielt er mehrere Auszeichnungen, unter anderem das Signum Laudis mit Schwertern sowie die silberne Tapferkeitsmedaille. 1919 beteiligte er sich freiwillig am „Kärntner Abwehrkampf“. Rödling kehrte aus dem Ersten Weltkrieg als Kriegsversehrter zurück. Er zog nach Graz, um dort Rechtswissenschaften zu studieren. Nach Abschluss des Studiums arbeitete er als Beamter bei der steirischen Finanzlandesdirektion und als Referent für das Obergericht in Graz. ${ }^{60}$ In dem 1969 vom Steirischen Landesskiverband herausgegebenen Band zur Steirischen Skigeschichte wird Rödling in seiner Rolle als ÖSV-Präsident rückblickend als „der Geschobene“ bezeichnet, der „manchmal gern anders gehandelt hätte“. ${ }^{61}$ Im Personalfragebogen der NSDAP vom Mai 1938 schildert Rödling die Sachlage ein wenig anders. Unter seiner Führung sei der „7 jährige Kampf um die Einführung d. Ariersatzes (1926) zu einem siegreichen Ende gebracht worden““.62 Rödling buhlte also ein gutes Jahrzehnt später bei den nationalsozialistischen Machthabern um Aufmerksamkeit und verwies in diesem Zusammenhang besonders auf seinen Einfluss in Sachen Antisemitismus innerhalb des ÖSV. Er datierte das Datum der Einführung des „Arierparagraphen“ allerdings fälschlicherweise auf 1926 und nicht auf 1923.

Sein Sohn versuchte noch 1990 in einem Brief an den damaligen Leiter des Wintersportmuseums in Mürzzuschlag die (Mit-)Verantwortung seines Vaters an der Einführung des „Arierparagraphen“ zu schmälern. Der starke Grazer Turnerbund sei militant großdeutsch und extrem antisemitisch orientiert gewesen und die Skiriegen der Turner hätten den ÖSV beeinflusst, so die Argumentation. ${ }^{63}$ Diese geht allerdings bei näherer Betrachtung der Quellen ins Leere. Denn Rödling war nicht nur im Verband der Steirischen Skiläufer organisiert und 1923, als der „Arierparagraph“ beschlossen wurde, im Vorstand des ÖSV aktiv und saß diesem ab 1925 vor, ${ }^{64}$ sondern gleichzeitig stand er als Obmann-Stellvertreter dem Deutschen Turnerbund Graz vor. ${ }^{65}$ Rödling selbst brachte demnach eine antisemitische Grundhaltung in den ÖSV ein, mit der er bereits im

60 Vgl. BArch (ehem. BDC), PK, Rödling, Alexander, 30.11.1886.

61 Hüttenegger/Pfliger, Steirische Skigeschichte, S. 136.

62 BArch (ehem. BDC), PK, Rödling, Alexander, 30.11.1886.

63 Vgl. Brief von Herbert Rödling an Hans Heidinger, 9.5.1990, Archiv Wintersportmuseum Mürzzuschlag, Briefe Pioniere, Sektion R, Kopie im Besitz des Verfassers.

64 Rödling hatte ab 1925 das Amt des 1. Vorsitzenden im Hauptausschuss des ÖSV über und wurde ab der Saison 1927/28 zum 2. Vorsitzenden gewählt sowie 1930 bestätigt, gleichzeitig war er Vorsitzender des steirischen Skiverbandes. Vgl. BKA, Generaldirektion für Sicherheit, Verein ÖSV, Vereinssitzverlegung, OeStA/AdR, BKA 15/4 331.062/1936; Vereinsakt des Österreichischen Skiverbandes 1933-1936, Hauptverband des ÖSV, Beschluss der Vertreterversammlung vom 8./9.10.1927 und vom 31.8.1930, OeStA/AdR, BKA/BPD Wien, Vereinsbüro XVIII11.336.

65 Vgl. BArch (ehem. BDC), PK, Rödling, Alexander, 30.11.1886. 
Turnerbund infiziert wurde. Kein Geringerer als der einflussreiche Grazer Universitätsprofessor Dr. Karl Holtei hielt im Juli 1926 in der Festzeitung des Deutschen Turnerbundes fest, dass „nicht eine bestimmte Staatsbürgerschaft, sondern eine rassische, geistige und sittliche Volkszugehörigkeit“ für eine Mitgliedschaft beim Deutschen Turnerbund Voraussetzung sei. ${ }^{66}$ Das entsprach dem allgemeinen Leitsatz des Deutschen Turnerbundes (1919) „Rassenreinheit Volkseinheit - Geistesfreiheit“, ${ }^{67}$ an dem sich auch die Grazer Turnriege orientierte. Auf diese Weise wurde das im Turnerbund vorherrschende völkische Gedankengut über handelnde Personen wie Rödling in den ÖSV hineingetragen. ${ }^{68}$ Rödlings ideologische Intention wiederum spiegelt sich etwa in seinem 1927 verfassten Geleitwort zum offiziellen Jahrbuch des ÖSV wider:

Wer unsere Skiläufer in den verschneiten Bergen zu beobachten Gelegenheit hatte, weiß, welch guter deutsche Geist in unseren Reihen lebt, weiß auch, daß unsere Leute nicht aus eitlem Selbstzweck an der Vervollkommnung ihrer Laufart arbeiten, sondern daß Liebe zur Heimat und zu unserer herrlichen Bergwelt und der Gedanke, durch Stählung des eigenen Körpers dem ganzen Volke zu dienen, die Haupttriebfedern ihrer Betätigung sind. ${ }^{69}$

Dass Rödling der nationalsozialistischen Idee nahestand, erschließt sich aus seinem NSDAP-Beitritt, der im Jänner 1933 bei der Ortsgruppe Graz mit der Mitgliedsnummer 1386620 erfolgte. Rödling engagierte sich schon vor seiner NSDAP-Mitgliedschaft für die nationalsozialistische Bewegung. Der Oberfinanzrat der steirischen Landesfinanzdirektion war ab Februar 1932 unter dem Decknamen „Dr. Schulz“ für die NSDAP aktiv und leitete Informationen an das steirische NSDAP-Gauwirtschaftsamt weiter. Laut einem Empfehlungsschreiben von Max Holtei, der im Mai 1938 die Finanzlandesdirektion Graz leitete, genoss Rödling Einfluss auf die nationalsozialistische Beamtenschaft, nahm an nationalso-

66 Zit. nach Wolfgang Duchkowitsch, Medien: Aufklärung - Orientierung - Missbrauch. Vom 17. Jahrhundert bis zu Fernsehen und Video, Wien/Berlin 2014, S. 36. Karl Holtei war ObmannStellvertreter des Deutschen Turnerbundes (1919) in Österreich und überzeugter Antisemit sowie Autor und Herausgeber völkischer Schriften bzw. über das Wehrturnen. Seine Hetzartikel beeinflussten unter anderem die Sportberichterstattung des Völkischen Beobachters in den 1920er-Jahren. Vgl. Bernett, Untersuchungen, S. 10-12.

67 Vgl. Ingolf Wöll, Turnen in Österreich. Von den Anfängen bis zur Mitte des 20. Jahrhunderts, St. Pölten 2017, S. 199.

68 Es gibt noch andere belegte Fälle in denen ÖSV-Funktionäre und Turnerbund-Obmänner in Personalunion aufgetreten sind, wie zum Beispiel jener von Theodor Rhomberg in Dornbirn auf den noch eingegangen wird.

69 Alexander Rödling, Zum Geleite!, in: Der Skilauf in Österreich. Jahrbuch des Österreichischen Skiverbandes, Wien 1927, S. 9-10, hier S. 10. 
zialistischen Demonstrationen teil und galt als „aufrechter Nationalsozialist“. ${ }^{70}$ Holtei, der im Zuge des „Anschluss“ mit der Leitung der Finanzlandesdirektion Graz betraut wurde und später in das Innsbrucker Oberfinanzpräsidium wechselte, ${ }^{71}$ war nicht nur Rödlings Vorgesetzter in der Finanzlandesdirektion, die beiden verband auch das Turnen. Sowohl Holtei als auch Rödling waren führend im Akademischen Turnverein Graz tätig. ${ }^{72}$ Holtei wurde gegen Ende des Ersten Weltkriegs zum Hauptmann befördert, 1920 wurde er von der Großdeutschen Volkspartei in die steirische Parteileitung entsandt. ${ }^{73}$ Rödling war demnach in vielfacherweise in die (illegale) NS-Bewegung in der Steiermark verstrickt und profitierte später beruflich davon, indem er die NS-Finanzbehörde in Graz leiten sollte. ${ }^{74}$

Ein anderer Landesskiverband, der neben dem steirischen zu den vehementen Befürwortern des „Arierparagraphs“ zählte, war der Salzburger. Dieser stand unter der Führung des Notars Fritz Rigele. 1878 in Wolkersdorf geboren, besuchte Rigele in Linz die Mittelschule und studierte im Anschluss an der Wiener Universität Rechtswissenschaften. Er gehörte seit der Mittelschulzeit der Burschenschaft Germania in Oberösterreich an, leitete als Vorsitzender die Schivereinigung [sic] Linz und betrieb in der Linzer Innenstadt eine Kanzlei. Rigele gründete nach seinem Umzug nach Oberndorf bei Salzburg gemeinsam mit dem Vorarlberger Skipionier Georg Bilgeri im Jahr 1910 den Skiclub Salzburg (SCS). Bei der Gründungsversammlung am 9. November 1910 wurde Rigele zum ersten Obmann des SCS gewählt und ein Jahr darauf zum Obmann des Salzburger Landesskiverbandes. Rigele saß zudem im Hauptvorstand des Deutschen und Österreichischen Alpenvereins. ${ }^{75}$ Der begeisterte Alpinist engagierte sich ab Mitte der 1920er-Jahre erneut im Skisport, hielt Skikurse ab und bestritt für den SCS einige Wettrennen. Bei der Wiedergründung des Wintersportvereins Saalfelden

70 Vgl. NSBO Betriebszelle Finanz, Dr. Max Holtei, Leiter der Finanzlandesdirektion Graz, 19.5.1938, BArch (ehem. BDC), PK, Rödling, Alexander, 30.11.1886.

71 Vgl. dazu Christian Kuller, Bürokratie und Verbrechen. Antisemitische Finanzpolitik und Verwaltungspraxis im nationalsozialistischen Deutschland, München 2013, S. 94; Wolfgang Fritz, Fortschritt und Barbarei. Österreichs Finanzverwaltung im Dritten Reich, Wien/Berlin 2011, S. 19.

72 Max Holtei setzte sich 1937 für den Ausbau der Skihütte und des Bergheimes des Akademischen Turnvereines Graz auf der Tauplitz ein und unterstützte diesen finanziell. http:// atvgraz.at/atv-glossar/ (28.2.2019).

73 Vgl. Kriegszeitung des A. T. V. Graz, 27.4.1918, S. 2; Grazer Tagblatt, 30.6.1930, S. 4.

74 Vgl. Brief von Herbert Rödling an Hans Heidinger, 9.5.1990, Archiv Wintersportmuseum Mürzzuschlag, Briefe Pioniere, Sektion R, Kopie im Besitz des Verfassers.

75 Skiclub Salzburg (Hg.), 100 Jahre Skiclub Salzburg 1910-2010 (Festschrift), Salzburg 2010, S. 19-20; Salzburger Volksblatt, 12.10.1937, S. 5; Archiv des österreichischen Alpenvereins (OeAV), SE/117/301. 
(heute SK Saalfelden) nach dem Ersten Weltkrieg übernahm Rigele 1923 den Vorsitz und war maßgeblich an der Errichtung der ersten Skihütte des Vereins beteiligt. Nach seiner Obmannschaft erhielt er 1926 als Erster die Ehrenmitgliedschaft des Vereines. ${ }^{76}$ Im ÖSV übernahm Rigele von 1926 bis 1928 das Amt des 2. Vorsitzenden und von 1928 bis 1931 jenes des 1 . Vorsitzenden. Rigele war mit der Schwester von Hermann Göring Olga verheiratet und hatte mit dieser zwei Kinder. Der Schwager von Hermann Göring pflegte nicht nur aufgrund seiner verwandtschaftlichen Bande eine Nähe zum Nationalsozialismus. In seinem Buch 50 Jahre Bergsteiger (1935) bekannte er sich als Nationalsozialist. Zum „nationalen und kulturellen Gedanken im Sport“ schrieb er Folgendes:

Die Pflicht, möglichst vielen die Berge näherzubringen, habe auch ich schon lange vor Kriegsausbruch gefühlt, und ich glaube richtig erkannt zu haben, daß von allen Formen und Arten des Wanderns im Gebirge gerade der Skilauf besonders zur volklichen [sic] Gesundheitsstählung geeignet war [...] Diese Tätigkeit war formell eine unpolitische und damit, vom Standpunkt des sich seines Deutschtums von jeher bewußten Österreichers aus betrachtet, keine nationale. Denn es wäre nie jemandem eingefallen, den Skiverband als einen politischen oder nationalen Verband zu bezeichnen. Dabei war unsere Tätigkeit in Wirklichkeit viel mehr national und volksfördernd als die mancher sogenannter politischer Vereine. ${ }^{77}$

1933 setzte sich Rigele ins Deutsche Reich ab. Zuvor soll er noch gemeinsam mit Göring, der ihn später bei sich in Berlin wohnen ließ, ${ }^{78}$ auf einer Bergtour im Watzmann-Massiv unterwegs gewesen sein. Gesichert ist, dass er 1934 bei den Deutschen Skimeisterschaften in Berchtesgaden anwesend war. Auf einem Foto, aufgenommen während des Skispringens, ist Rigele neben Hermann Göring und dem Reichssportführer Hans von Tschammer und Osten abgelichtet. ${ }^{79}$ Als Alpinist gelang Rigele die Erstbesteigung der Großen Wiesbachhorn-Nordwestwand und der Lyskamm-Nordwand. 1936 wurde er zum Leiter des reichsdeutschen Sektionentages des Deutschen und Österreichischen Alpenvereins berufen. ${ }^{80}$ Ebenso wie Springenschmid betrachtete Rigele die Alpen als „deut-

76 Vgl. 100 Jahre Schiklub Saalfelden, Saalfelden 2012, S. 10-11.

77 Fritz Rigele, 50 Jahre Bergsteiger, Erlebnisse und Gedanken, Berlin 1935, S. 132-133.

78 Hanno Bayr, Berlin trifft Mauterndorf. Eine Reise mit Epenstein und Göring, Mariapfarr 2017, S. 166-167.

79 Der Winter, 30 (1934/35), S. 169. Hans von Tschammer und Osten, geboren am 25. Oktober 1887 in Dresden, trat 1929 in die NSDAP ein und stieg 1930 zum SA-Führer in Dresden auf. Im April 1933 übernahm er das Reichssportkommissariat im Reichsinnenministerium und im Juli 1933 wurde er zum Reichssportführer ernannt. Vgl. Ernst Klee, Das Personenlexikon zum Dritten Reich. Wer war was vor und nach 1945, Frankfurt am Main 2005, S. 631.

80 Vgl. Helmuth Zebhauser, Alpinismus im Hitlerstaat. Gedanken, Erinnerungen, Dokumente, München 1998, S. 111. 
schen Kulturraum“ und betonte weiters ganz im Sinne der Rassenpolitik des NS-Regimes:

Und auch die Tatsache muß als bekannt vorausgesetzt werden, daß jede solche Leibesübung nicht etwa zur Erhaltung erbkranken Nachwuchses, sondern zur Kräftigung von Körper und Gesundheit des heranwachsenden Geschlechts dient. ${ }^{81}$

1935, im selben Jahr, in dem Rigele diese Zeilen verfasste, wurde er damit betraut, eine deutsche Gebirgsbrigade aufzustellen und deren Ausbildung zu übernehmen. Bei einer Übung des 100. Gebirgsjägerregiments in den Berchtesgadener Bergen verunglückte Rigele im Oktober 1937 tödlich. ${ }^{82}$ Bei der Beisetzung am Parkfriedhof in Berlin-Lichterfelde war Ministerpräsident Göring persönlich anwesend. In einem Nachruf wurde Rigele als „Vertrauensmann gegenüber höchsten Regierungsstellen des Reiches“ bezeichnet. ${ }^{83}$

Analog zu anderen Landesskiverbänden in Österreich stand auch der Verband Vorarlberger Skiläufer laut Statuten vom 4. April 1930 auf ,arischer Grundlage“. Aufgenommen würden nur jene Skivereinigungen, die Mitglieder im ÖSV oder DSV sind oder werden wollen. ${ }^{84}$ Damit war „nichtarischen“ und Nichtmitgliedsvereinen der Weg versperrt. Hinter dieser Politik stand der Verbandsobmann, Vize-Präsident des ÖSV und illegale Vorarlberger NSDAPGauleiterstellvertreter Theodor Rhomberg. Der teilhabende Geschäftsführer des Textilunternehmens Herrburger \& Rhomberg und Obmann des Deutschen Turnvereins war maßgeblich am Aufbau eines deutschnationalen, völkisch geprägten Netzwerkes in Dornbirn und Vorarlberg beteiligt und trat öffentlich für den nationalsozialistischen Kampf ein. Im Februar 1934 musste er wegen seiner öffentlichen Auftritte das Amt im ÖSV aufgeben. 1938 wurde Rhomberg von den Nationalsozialisten als Vereinsführer des lokalen Skiklubs in Dornbirn wiedereingesetzt sowie zum Kreisorganisationsleiter und NS-Landessportführer ernannt. ${ }^{85}$

81 Rigele, 50 Jahre Bergsteiger, S. 128-129.

82 Vgl. Bayr, Berlin trifft Mauterndorf, S. 168; Salzburger Volksblatt, 12.10.1937, S. 5.

83 Nachruf Fritz Rigele, OeAV, ZV/5/1251.

84 Akten der Sicherheitsdirektion, Vorarlberger Landesarchiv (VLA), Sicherheitsdirektion, Sch. 42, Nr. 40149, 1930.

85 Stadtarchiv Dornbirn (StAD), Nr. 570, Dornbirns Kampf um die Befreiung 1933-1938 und StAD, Verwaltungsarchiv, Akz.-Nr. 125/2000, Ordner 1938-1945 NSDAP Akten, Nr. V; Ingrid Böhler, Dornbirn in Kriegen und Krisen 1914-1945, Innsbruck 2005, S. 128-129; Andreas Praher, Zwischen Anpassung, Vereinnahmung und Mittäterschaft - Zur Rolle des österreichischen Skisports zwischen den Kriegen und in der NS-Diktatur, in: Rudolf Müllner/Christof Thöny (Hg.), Skispuren. Internationale Konferenz zur Geschichte des Wintersports, Bludenz 2019, S. 235247, hier S. 238. 


\subsubsection{Die Elite im Hauptverband des ÖSV}

Wie soeben dargestellt, handelte es sich bei den verantwortlichen Funktionären im Hauptverband des ÖSV um einflussreiche Persönlichkeiten im österreichischen Alpin- und Skisport, die getrieben von einer antisemitischen Grundhaltung eine deutschnationale Verbandspolitik betrieben. Vergleicht man die Biografien miteinander, ergibt das ein aufschlussreiches Bild bezüglich Geburtsjahrgängen, Berufs- bzw. Bildungsstand, NSDAP-Zugehörigkeit und Beitrittsdatum.

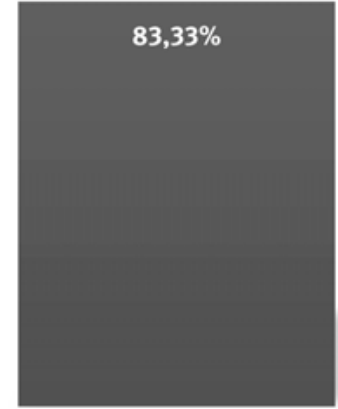

NSDAP-Zugehörigkeit

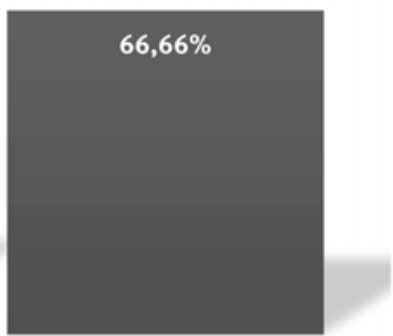

Parteieintritt vor Juni 1933

Grafik 1: Führende Funktionäre im ÖSV-Hauptausschuss nach NSDAP-Zugehörigkeit und Parteieintritt vor Juni 1933.

Quelle: Eigene Zusammenstellung aus unterschiedlichen Beständen. Datenbank Praher, n=12.

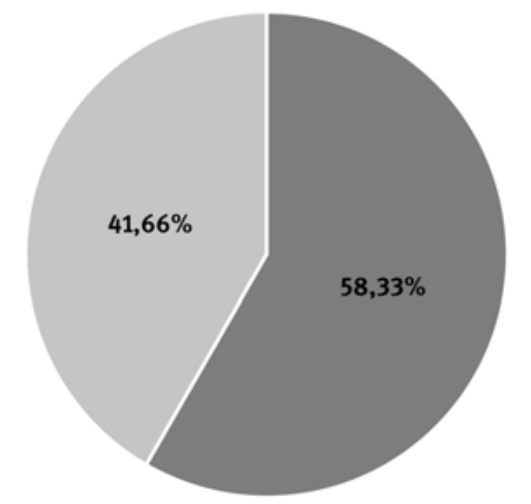

= Akademische Ausbildung $=$ Fachausbildung

Grafik 2: Führende Funktionäre im ÖSV-Hauptausschuss nach Bildungsstand.

Quelle: Eigene Zusammenstellung aus unterschiedlichen Beständen. Datenbank Praher, $n=12$. 
Von den zwölf führenden ÖSV-Funktionären, die in den 1930er-Jahren eine Vorstands- bzw. leitende Funktion innerhalb des Verbandes ausübten, konnte bei zehn eine NSDAP-Mitgliedschaft nachgewiesen werden. Wobei bei einem weiteren der Verdacht auf eine illegale nationalsozialistische Betätigung besteht, dieser konnte von den austrofaschistischen Behörden aber nicht erhärtet werden. ${ }^{86}$ Von den zehn Parteimitgliedern waren acht der NSDAP vor dem Parteiverbot 1933 beigetreten, ein weiterer trat der Partei nach dem „Anschluss“ im Jahr 1939 bei. Bei einem Funktionär konnte die NSDAP-Mitgliedschaft, aber kein Beitrittsdatum eruiert werden. Alle zwölf Vorstandsmitglieder wurden vor 1900 geboren. Zwei Drittel erlebten den Ersten Weltkrieg als junge Männer im Alter zwischen 16 und 28 Jahren. Der verlorene Krieg und der Zerfall der HabsburgerMonarchie bildeten den gemeinsamen Erfahrungshorizont dieser Generation und machte diese offensichtlich empfänglich für radikale deutschnationale Ideen. Sechs der zwölf Funktionäre schlossen ihre akademische Ausbildung mit einem Doktorrat ab. Neben fünf Juristen gab es einen Tierarzt. Vier weitere hatten eine Diplomausbildung absolviert und arbeiteten als Beamte oder Unternehmer. Ein weiterer hatte eine Anstellung als Lehrer und war daneben als Schriftsteller tätig und ein Funktionär verdiente als akademisch ausgebildeter Kunstmaler seinen Lebensunterhalt. Aus den ausgeübten Berufen lässt sich schließen, dass alle zwölf Funktionäre dem Bildungsbürgertum zuzurechnen waren. Sie können also durchaus als Opinion-Leader für die damals im ÖSV heranwachsende SportlerInnen-Generation gesehen werden. Für die meisten bedeutete der „Anschluss“ im März 1938 einen Karrieresprung oder zumindest ein Comeback auf der sportpolitischen Bühne. Sie übten ein sportpolitisches Amt aus und/oder besetzten einen parteipolitischen Posten. Dazu aber mehr in einem späteren Kapitel.

\subsubsection{Die Umsetzung in den Vereinen}

Wie schnell und vor allem mit welcher Vehemenz der „Arierparagraph“ in die Tat umgesetzt wurde, geht aus verschiedenen Vereinsakten hervor. So verfügte der Wiener Landesskiverband in der Hauptversammlung vom 24. Oktober 1924

86 Der bei der ordentlichen Vertreterversammlung des ÖSV am 31. August 1930 in Kitzbühel zum ersten Vorsitzenden gewählte Karl Merz wurde im August 1933 von den austrofaschistischen Behörden strafrechtlich überprüft. 1934 ermittelte die Bundespolizei erneut wegen Verdachts auf „nationalsozialistische Umtriebe“, konnte aber keine Beweise erbringen. Vgl. Vereinsakt des Österreichischen Skiverbandes 1933-1936, Schreiben der Bundespolizeidirektion Wien an das BKA, Generaldirektion für öffentliche Sicherheit, Staatspolizei, Wien, 22. April 1936, OeStA/AdR, BKA/BPD Wien, Vereinsbüro XVIII-11.336. 
in seinen Satzungen, dass „[...] als Mitglieder nur Personen arischer Abstammung und germanischer Volkszugehörigkeit aufgenommen werden können.“87 Der Wiener Landesskiverband folgte damit dem Beschluss des ÖSV. In den vorgeschriebenen Statuten des ÖSV hieß es konkret:

Die Satzungen der Einzelvereine und Verbandsvereine müssen die Bestimmungen enthalten, daß als Mitglieder nur Personen arischer Abstammung und germanischer Volkszugehörigkeit aufgenommen werden können. Den Vereinen steht es jedoch frei, für die Mitgliedschaft engere Grenzen zu ziehen. ${ }^{88}$

$\$ 6$.

Aufnahme in den Verband.

1. In den Oe.S.V. können nur Vereine oder fest abgegrenzte Unterverbande, in der Regel Landesverbände, welche in Oesterreich inren Sitz haben und deren Satzungen als Vereinszweck "Skilauf" oder "hauptsăchlich Skilauf" betonen, aufgonormen werden. Die Satzungen der $3 i n z e l v e r e i n \theta$ und Verbandsvereine $m$ if $s$ s $n$ die $B e-$ stimmur.gen enthelten, dass als Mitglieder nur Personen arischer Abstammung und germanischer Volkszugehörigkelt aufgenommen werden können/Den Vereinen steht es Jedooh frei, für die Mitgliedschaft engere Grenzen zu ziehen.

Abb. 12: Auszug aus den Verbandssatzungen des ÖSV bezüglich der Aufnahme von Mitgliedern in den Mitgliedsvereinen, OeStA.

Der Wiener Landesverband übernahm 1924 auch den letzten Passus im Originalwortlaut: „Den Vereinen steht es jedoch frei, für die Mitgliedschaft engere Grenzen zu ziehen.“89 Damit verschärfte der Verband die „Spielregeln“, wer in den einzelnen Mitgliedsvereinen aufgenommen werden darf. Außerdem waren laut den neu aufgesetzten Statuten für eine Aufnahme mindestens zwei Drittel der Stimmen in der Vorstandssitzung oder Hauptversammlung notwendig. Dieser Passus bedeutete für „nichtarische“ BewerberInnen eine unüberwindbare Barriere. Die Statuten, die Gsur am 24. Oktober 1924 als Vorsitzender des Wiener Landesskiverbandes unterzeichnete, wurden am 14. November 1924 genehmigt. Damit war der Ausschluss unerwünschter Mitglieder nach den völkischen Kriterien des ÖSV zur Realität geworden. ${ }^{90}$ Warum Gsur im Dezember 1924 seinen

87 Vereinsakt Landes-Ski-Verband für Wien und Niederösterreich. WStLA, M.Abt. 119, A32 Gelöschte Vereine: 5500/1922 - 5500/1922.

88 Vereinsakt des Österreichischen Skiverbandes 1933-1936, Satzungen des Österreichischen Skiverbands, OeStA/AdR, BKA/BPD Wien, Vereinsbüro XVIII-11.336.

89 Vereinsakt Landes-Ski-Verband für Wien und Niederösterreich. WStLA, M.Abt. 119, A32 Gelöschte Vereine: 5500/1922 - 5500/1922.

90 Der ÖSV selbst benutzte den Bergiff völkisch in seinen Satzungen und legte fest, dass im Falle der Auflösung des Verbandes das Vermögen „nach Möglichkeit für wintersportliche, tou- 
Rücktritt als Vorsitzender des ÖSV einem Bericht im Sport-Tagblatt zu Folge mit der Einführung des „Arierparagraphen“ begründete, ${ }^{91}$ erschließt sich aus den bisherigen Quellen nicht. Jedenfalls trat Gsur mit Anfang des Jahres 1925 von seinem Vorsitz zurück. Ihm folgte Alexander Rödling.

Auch der Skiklub Innsbruck, dessen Jahresversammlung am 7. November 1923 im Innsbrucker Gasthof „Zum Bären“ stattfand, bekannte sich nicht einmal ein Monat nach der Beschlussfassung im ÖSV zum „Arierparagraphen“.92 Obmann des Innsbrucker Skiklubs war zum damaligen Zeitpunkt kein Geringerer als Carl Rasim, ÖSV-Vizepräsident und Vorsitzende des Gewerbegerichts Innsbruck. Rasim wurde bei der Wiedergründung des Tiroler Skiverbandes im Jahr 1921 zum Vorsitzenden gewählt und war von 1919 bis 1925 Vizepräsident des ÖSV. ${ }^{93}$ Der 1876 in Wien geborene und in Innsbruck wohnhafte Richter trat ab April 1938 als förderndes Mitglied der SS in Erscheinung. ${ }^{94}$ Der bereits erwähnte Innsbrucker Jurist Anton Tschon war im Skiklub Innsbruck für den Jugendskilauf zuständig. Tschon war nachweislich ab 1938 Parteianwärter und ab 1939 Mitglied der NSDAP, wurde aber laut einem Vermerk der austrofaschistischen Sicherheitsbehörden bereits im Jänner 1937 mit der illegalen NSDAP in Verbindung gebracht. ${ }^{95}$ Sowohl Rasim als auch Tschon unterstützten also spätestens ab 1938 die nationalsozialistische Bewegung. Die völkisch ausgerichtete Zeitschrift Alpenland goutierte den Schritt des Innsbrucker Skiklubs, den „Arierparagraphen“ einzuführen, im November 1923 mit folgenden Zeilen:

Der Klub beschloß auch im Sinne einer Bestimmung des österreichischen Schiverbandes seine Satzungen zu ändern und von nun ab nur mehr Mitglieder arischer Abstammung und germanischer Volkszugehörigkeit aufzunehmen. Dieser einmütig gefaßte Beschluß wird in den Kreisen aller deutschen Schneeschuhläufer vollen Beifall finden. So vollzieht sich naturnotwendig in immer weiteren Kreisen die Abkehr vom Judentum, dessen zersetzende Wirkungen die Nachkriegszeit in erschreckender Weise offenbarte. Recht so! ${ }^{96}$

ristische oder völkische Zwecke verwendet werden“ sollte. Vereinsakt des Österreichischen Skiverbandes 1933-1936, Satzungen des Österreichischen Skiverbands, OeStA/AdR, BKA/BPD Wien, Vereinsbüro XVIII-11.336.

91 Unter dem Titel „Die Krise im Oesterreichischen Skiverband“ berichtete das Sport-Tagblatt am 16. Dezember 1924 vom bevorstehenden Rücktritt Gsurs. Laut dem Bericht habe Gsur die Einführung des „Arierparagraphen“ mit seinen Ansichten nicht vereinbaren können. Er gab seinen Rücktritt mit 1. Jänner 1925 auf der Vorstandssitzung in Kitzbühel bekannt. Vgl. Sport-Tagblatt, 16.12.1924, S. 4.

92 Vgl. Alpenland, 4 (1923) 47, S. 5.

93 Vgl. Lässer, 100 Jahre Fremdenverkehr, S. 130.

94 Vgl. Stadtarchiv Innsbruck (StAI), NS-Registrierungsakt Carl Rasim.

95 Vgl. StAI, NS-Registrierungsakt Anton Tschon.

96 Alpenland, 4 (1923) 47, S. 5. 
Auch im vorarlbergischen Montafon folgte man dem Grundsatzbeschluss des ÖSV. Der „Arierparagraph“ wurde sowohl in den Statuten des Skiclubs Gargellen (1929) verankert als auch im Skiverein Vandans (1933). ${ }^{97}$ Ein widersprüchliches Bild ergibt sich bei näherer Betrachtung bei der Wintersportsektion des Kitzbüheler Sportklub (K.S.C.). Diese war ebenso wie der Skiklub Arlberg von Beginn an international ausgerichtet. ${ }^{98}$ Das geht aus den Gründungssatzungen der vom Stammverein unabhängigen Sektion hervor, die im Juni 1926 ins Leben gerufen wurde. ${ }^{99}$ Die ordentliche Mitgliedschaft war an keine Herkunft gebunden, wenn auch ortsansässige Kitzbüheler bevorzugt aufgenommen wurden. Ebenso legte die Wintersportsektion des K.S.C. Wert darauf, dass es sich bei Neu-Mitgliedern, die nicht aus Kitzbühel kamen, um prominente Wintersporttreibende handelte. ${ }^{100}$ Das erklärt sich aus der Geschichte des Vereins, der großbürgerlich geprägt war und obere gesellschaftliche Schichten bis zur Aristokratie anlockte. ${ }^{101}$ In den Vereinsstatuten erfolgte aber keine Unterscheidung zwischen „arisch“ und „nicht-arisch“. Das unterschied den neu formierten Zweigverein von anderen Skivereinen in der Ersten Republik. Dennoch gab es bereits in der Entstehungsgeschichte des Vereins radikale Tendenzen, die aber ab Mitte der 1920er-Jahre entgegen dem allgemeinen Trend im ÖSV ad acta gelegt wurden. Außerdem war im Vorgängerverein eine Nähe zum völkischen Gedankengut festzustellen. Was die Gründe für die spätere Öffnung des Vereins waren, lässt sich nur vermuten. Aber wahrscheinlich dürfte das große internationale Standing des K. S. C. bei den Überlegungen, den „Arierparagraph“ nicht aufzunehmen, eine Rolle gespielt haben. Im Jänner 1930 erweiterte die Skiriege des K.S.C. die Aufnahmebestimmungen dahingehend, dass nicht mehr nur

97 Vgl. Brugger, Vom Pioniergeist, S. 201-202; Michael Kasper, „Kreuzzug auf dem Piz Buin“. Die Gipfelkreuzerrichtung als politische Machtdemonstration, in: Michael Kasper/Martin Korenjak/Robert Rollinger/Andreas Rudigier (Hg.), Alltag - Albtraum - Abenteuer. Gebirgsüberschreitung und Gipfelsturm in der Geschichte, Wien/Köln/Weimar 2015, S. 297-316, hier S. 304. 98 Der Skiklub Arlberg erklärte sich in seinen Statuten aus dem Jahr 1924 als unpolitisch. Vgl. Statuten des Skiklub Arlberg, TLA, Abt. I, XVI 78c, ex 1924, Zl. 1321.

99 Die Wintersportsektion wurde am 8. Juni 1926 ins Leben gerufen und operierte unabhängig vom Stammverein. Wintersportwettbewerbe und Skisportveranstaltungen, die verbandsmäßig ausgetragen wurden, durften ohne Rücksprache mit dem K.S.C. selbstständig durchgeführt werden. Vgl. Satzungen Wintersportsektion des Kitzbüheler Sportklubs (K. S. C.), TLA, Abt. I, XVIII 93b, ex 1926, Zl. 3066.

100 Vgl. Satzungen Wintersportsektion des Kitzbüheler Sportklubs (K. S. C.), TLA, Abt. I, XVIII 93b, ex 1926, Zl. 3066.

101 Ein prominentes Mitglied des Kitzbüheler Skiclubs war die Gräfin und Skispringerin Paula von Lamberg. Sie sprang bereits 1908 bei Skisprungbewerben. Vgl. 50 Jahre Kitzbüheler Skiclub. Arbeit und Erfolg Wintersportverein Kitzbühel, Kitzbühel 1955, S. 8. 
„prominente Wintersportreibende“ ordentliche Mitglieder werden konnten, sondern „auswärtige Wintersportreibende“ generell. ${ }^{102}$

Das im ÖSV und den Mitgliedervereinen vorhandene völkische Gedankengut entsprang nicht selten einer übertriebenen Liebe zur Bergheimat, die zur Idylle verklärt wurde. Ähnlich wie schon Rigele beschreibt der Abfahrtsweltmeister von 1939 Hellmut Lantschner diese Liebe in seiner 1935 verfassten Autobiografie Die Spur von meinem Ski in den Zeilen über seine Cousine Trude folgendermaßen: „Daß auch in ihr - wie in uns allen - eine über alles gehende Liebe zu Volk, Heimat und Bergen lebt, ist selbstverständlich." ${ }^{103}$ Das völkische Gedankengut blieb aber nicht auf einer theoretischen Ebene verhaftet, sondern wurde für viele zur Handlungsanleitung.

\subsection{Rituale der Anpassung}

Österreichische Skisportvereine waren ebenso wie die Turn- oder Alpenvereine bereits in den frühen 1930er-Jahren von Nationalsozialisten unterwandert. Das stellt Matthias Marschik fest, der sich in seiner Analyse hauptsächlich auf Angaben in der Sekundärliteratur stützt. ${ }^{104}$ Ein Blick in erhaltene Vereins-, NSDAPsowie Entnazifizierungs- und Nachkriegsprozess-Akten verdeutlicht diese Tatsache. An der Spitze saßen nicht selten deutschnational gesinnte Obmänner und Vorstandsmitglieder, die von einer „großdeutschen Idee“ beseelt waren. Sie stammten wie dargestellt meist aus dem Bildungsbürgertum, waren Ärzte, Rechtsanwälte oder Lehrer, hatten ein Gewerbe oder waren Industrielle. Diese Männer schufen Vereinsstatuten, durch die „Nichtarier“ ab den 1920er-Jahren vom Sportbetrieb ausgeschlossen waren. Diese Statuten waren ein Nährboden für die Radikalisierung innerhalb der Skiriege. Auf diese Weise machte ein erheblicher Anteil späterer NS-Spitzensportler aus Österreich über „Vorfeldorganisationen“ wie den deutschnationalen Skiklubs nicht nur Bekanntschaft mit der NS-Ideologie, sondern betätigte sich auch für die NS-Bewegung. Nicht selten schlossen sich junge Sportler - meist die Generation der im Ersten Weltkrieg Geborenen - einem nationalsozialistischen Wehrverband an. In einigen Fällen war der Weg vom völkischen Skiverein zur SA aber auch zur SS ein kurzer. ${ }^{105}$

Die großteils auf „arischen“ Grundsätzen stehenden Skivereine und eine weit verbreitete deutschnationale Geisteshaltung erleichterten dieser jüngeren

102 Vgl. Satzungen des K.S. C., TLA, Abt. I, XVIII 93b, ex 1930, Zl. 938.

103 Hellmut Lantschner, Die Spur von meinem Ski, Berlin 1935, S. 154-155.

104 Vgl. Marschik, Sportdiktatur, S. 38-39.

105 Vgl. Praher, „Skifahren ist für uns“, S. 213. 
Sportlergeneration das spätere Hineinwachsen in die NS-Gesellschaft und -Ideologie. ${ }^{106}$ So setzte der einfache SA-Mann von 1936 und spätere SA-Scharführer Andreas Krallinger seine berufliche Karriere 1941 als Angestellter der Kriminalpolizei beim Sicherheitsdienst der SS fort ${ }^{107}$ und Josef Bradl, der ebenfalls schon vor 1938 in der illegalen SA aktiv war, schulte in den Kriegsjahren als Ausbildner die HJ. ${ }^{108}$ Gleichzeitig waren beide Salzburger Skisportler ab 1938 Mitglied der reichsdeutschen Nationalmannschaft.

Der junge Bergführer und Skilehrer Franz Pichlsberger schildert die Sehnsucht nach dem „Anschluss“ in seinen Aufzeichnungen, die 1939 vom Deutschen Alpenverlag herausgegeben wurden, folgendermaßen:

Drei Jahre haben wir uns nicht mehr gesehen. Sechs Jahre sind wir zusammen in den schönsten Gebieten Tirols von Gipfel zu Gipfel gezogen. [...] Kameraden! Drei Jahre klagt ihr in den Briefen euer Heimweh, und glücklich seid ihr in diesem Schmerz. [...] Ihr seht, die weichen, flimmernden Schneehänge durchziehend, eine aufwärts strebende Skispur, sich anpassend den Formen des Bodens, quer über Kämme und Mulden ziehen. [...] Nun sind wir wieder beisammen, wie früher im Herzen der Alpen. ${ }^{109}$

In diesen poetisch formulierten Zeilen schwingt nicht nur Pichlsbergers tiefe $\mathrm{Zu}$ neigung zur Bergwelt mit. In ihr manifestiert sich auch eine gemeinsame Identität, die von österreichischer wie deutscher Seite immer wieder betont wurde. Die Alpen wurden in diesem Zusammenhang als das verbindende Element gesehen, welches eine kulturelle, politische und gesamtgesellschaftliche Zusammengehörigkeit von Österreich und Deutschland nach außen hin sichtbar machen sollte. Tatsächlich wurde die Alpenregion seit Jahrzehnten als gemeinsames Gebiet erschlossen. Genau aus diesem Grund wurden die Gipfel, Täler und weißen Hänge immer wieder als Symbol des gemeinsamen politischen Kampfes herangezogen, sie waren für Deutschnationale das offene Glied in der Kette, die geschlossen werden sollte.

In der ersten Jänner-Ausgabe 1935 berichtete die ÖSV-Verbandsschrift Der Ski unter der Rubrik „Skisport in anderen Ländern“ über die Neuordnung des reichsdeutschen Skisports unter der NS-Sportführung ohne die damit verbundenen politischen Implikationen zu erwähnen. Die Auflösung des DSV und Eingliederung seiner Mitgliedsvereine in das nationalsozialistische Fachamt für

106 Vgl. Falkner, Skipersönlichkeiten im Dritten Reich, S. 101.

107 Vgl. OÖLA, LG Linz, Sondergerichte, VgVr 190/49 (503) und BArch (ehem. BDC), RS, Krallinger, Andreas, 6.12.1914.

108 Vgl. u. a. Praher, SportlerInnen für den Krieg, S. 271.

109 Franz Pichlsberger, Die Unentwegten. Aus Tirols Befreiungskampf von 1933-1938, Innsbruck 1939, S. 171-172. 
Skilauf wurde mit den Worten: „womit endlich eine einheitliche Führung des gesamten deutschen Skisports gesichert ist“ begrüßt. ${ }^{110}$

\subsubsection{Der Weg in die (illegale) SA und SS}

Aktive Sportler wie der aus Wasserburg am Inn stammende und in Mühlbach am Hochkönig aufgewachsene Skispringer Josef Bradl oder der Bischofshofener Skiläufer Andreas Krallinger waren bereits vor 1938 in illegal geltenden Wehrverbänden wie der SA organisiert, andere Sportkameraden in der SS. Der im Dezember 1914 geborene Krallinger trat 1936 der SA bei, ${ }^{111}$ zur selben Zeit stieß auch der um gut drei Jahre jüngere Bradl zum SA-Sturm 1/59 in der Stadt Salzburg. Er wurde im Sommer 1937 im Zuge einer Hausdurchsuchung verhaftet und wegen illegaler Betätigung für die NSDAP in das Polizeigefängnis Salzburg eingeliefert und später in das Salzburger Gefangenenhaus überstellt. ${ }^{112}$ In einem Brief, den Bradl aus seiner Untersuchungshaft an den Salzburger Landeshauptmann Rehrl schrieb, beteuert der Skispringer seine Unschuld. Er sei über Sportkontakte in falsche Kreise geraten. Bradl war zu diesem Zeitpunkt 19 Jahre alt und wusste durchaus sein sportliches Potenzial als Argument einzusetzen. Dieses dürfte schließlich auch ausschlaggebend gewesen sein für seine Freilassung. Bradl wurde aus der Untersuchungshaft entlassen und durfte Anfang des Jahres 1938 wieder bei Wettbewerben starten. Zu einer Verhandlung kam es nicht. ${ }^{113}$ Bradls sportliche Heimat war ab 1936 der Skiclub Salzburg. Dort engagierten sich ab den 1920er-Jahren die Brüder Hermann und Siegfried Amanshauser. Beide galten als überzeugte Nationalsozialisten und waren im Skiverein führend tätig. Hermann Amanshauser trat im Mai 1933 der NSDAP bei und suchte 1934 um die Aufnahme in die SS an. In dieser bestätigte er sich als Geldverwalter zweier SS-Stürme und organisierte unter anderem Rücktransporte von inhaftierten Nationalsozialisten aus dem Internierungslager Wöllersdorf. Hermann Amanshauser stieg am 1. Dezember 1934 zum SS-Sturmmann auf und mit 1. März 1935 zum SS-Scharführer. Noch vor dem „Anschluss“ wurde Amanshauser laut SS-Stammkarten-Abschrift zum Hauptscharführer befördert. ${ }^{114}$ Amanshauser verfasste darüber hinaus theoretische Schriften zum alpinen Skilauf, wie das 1929 erschienen Buch Das Wunder in Weiss und Alpine Skifahrtechnik

110 Der Ski, Nr. 5, 6.1.1935, S. 68.

111 Vgl. BArch (ehem. BDC), RS, Krallinger, Andreas, 6.12.1914.

112 Vgl. SLA, Landesgericht Salzburg (LGS), Vr 1937 1261/I, 13 Vr 1261/37.

113 Vgl. SLA, Landesgericht Salzburg (LGS), Vr 1937 1261/I, 13 Vr 1261/37.

114 Vgl. OÖLA, LG Linz Sondergericht, Sch. 422, VgVr 453/48. 
(1933). Er gehörte dem Alpenverein an und war dort für die Schulung der Jugend zuständig. Im Skiclub Salzburg trat sein Bruder Siegfried Amanshauser ebenso vor 1938 der NSDAP bei (1932) und 1937 der illegalen SS. ${ }^{115}$

\subsubsection{Zell am See als Beispiel des nationalsozialistischen Machtvakuums im Skilauf}

Die Gemeinde Zell am See und die umliegende Region entwickelten sich mit der Inbetriebnahme der Schmittenhöhebahn im Dezember 1927 und der infrastrukturellen Erschließung zu einer bedeutenden Tourismus- und Skisportdestination. ${ }^{116}$ Die Stadt verzeichnete mit knapp 46 Prozent der Beschäftigten im tertiären Sektor im Jahr 1934 einen hohen Dienstleistungsanteil, ${ }^{117}$ vorwiegend im Tourismus. Die Wirtschaftskrise sowie die im Mai 1933 verhängte „TausendMark-Sperre" trafen Zell am See besonders hart und hatten einen Einbruch der Gästezahlen zur Folge. Von Anfang November 1932 bis Ende Oktober 1933 gingen die Gästezahlen in Zell am See von 32444 auf 18718 zurück. ${ }^{118}$ Mit dem Juliabkommen 1936 entschärfte sich die wirtschaftliche Lage mit dem Zustrom deutscher TouristInnen wieder. Von den insgesamt 53806 gemeldeten Gästen bildeten die knapp 7000 reichsdeutschen Gäste im Tourismusjahr 1936/37 den größten Teil der gemeldeten BesucherInnen aus dem Ausland in der Salzburger Tourismusgemeinde im Südwesten des Landes. Sie verzeichneten mit rund 15000 Übernachtungen auch die meisten Nächtigungen. Damit beherbergte Zell am See im Berichtsjahr 1936/37 die meisten Gäste aus dem „Altreich“ im Bundesland Salzburg nach der Landeshauptstadt. ${ }^{119}$ Die Akademischen Weltwinterspiele in Zell am See im Februar 1937 waren gemessen an der Einwohnerzahl der Kleinstadt ${ }^{120}$ ein Sportfest der Superlative. Die internationalen Wettbewerbe, an denen Teams aus 18 Nationen teilnahmen, gestalteten sich auch zu

115 Vgl. BArch (ehem. BDC), SSO, Amanshauser, Siegfried, 15.5.1895.

116 Vgl. Georg J. Daxer, Sehnsucht nach Aussicht. Die Geschichte der Schmittenhöhebahn in Zell am See, Goldegg 2018, S. 50-51.

117 Vgl. Laurenz Krisch, Die Wahlerfolge der Nationalsozialisten in der Spätphase der Ersten Republik im Pongau und Pinzgau. Eine empirische Analyse zur Struktur der NSDAP-Wählerschaft, in: Mitteilungen der Gesellschaft für Salzburger Landeskunde, Salzburg 2000, S. 215267, hier S. 255.

118 Vgl. Statistisches Handbuch für den Bundesstaat Österreich, hrsg. vom Bundesamt für Statistik, 15. Jg., Wien 1935, S. 48.

119 Vgl. Statistisches Jahrbuch für Österreich 1938, hrsg. vom Österreichischen Statistischen Landesamt, Wien 1938, S. 44-45.

120 Die Wohnbevölkerung von Zell am See zählte laut Volkszählung aus dem Jahr 1934 knapp 3000 Einwohner. Vgl. Krisch, Die Wahlerfolge, S. 255. 
einer Demonstration der Zusammengehörigkeit im Sinne der „großdeutschen Idee“. Die reichsdeutschen SportlerInnen wurden am Bahnhof mit einer überdimensionalen Hakenkreuzfahne willkommen geheißen und die Gassen der Altstadt waren ebenso mit Hakenkreuzfahnen beflaggt. Der Salzburger Landeshauptmann Franz Rehrl begrüßte die deutsche Abordnung bei ihrem Einzug mit dem Deutschen Gruß. Die Stadt selbst war ab Beginn der 1930er-Jahre eine Hochburg österreichischer Nationalsozialisten, diese lieferten sich mit Anhängern der Sozialdemokratie teils blutige Kämpfe. ${ }^{121}$ Bei der Salzburger Landtagswahl 1932 errang die NSDAP in Zell am See 37,07 Prozentpunkte. ${ }^{122}$

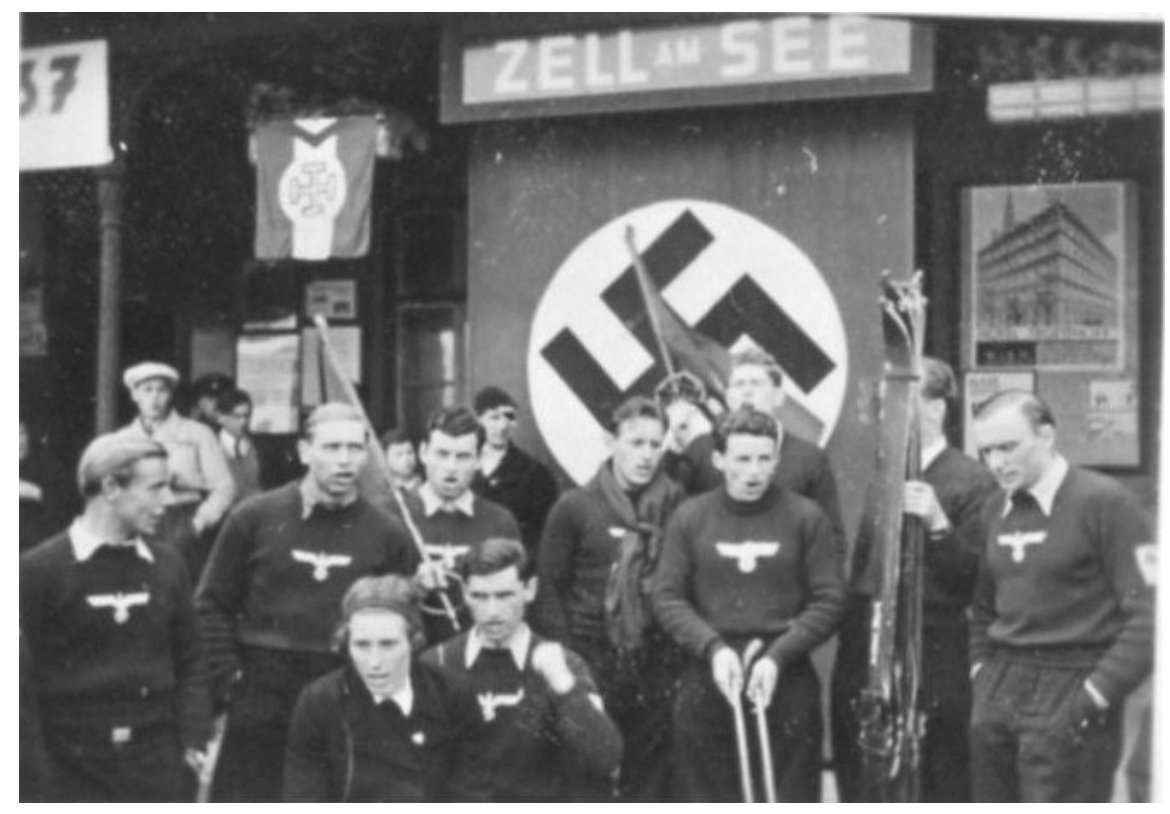

Abb. 13: Das reichsdeutsche Skinationalteam wurde bei den Akademischen Weltwinterspielen im Februar 1937 in Zell am See mit einer überdimensionalen Hakenkreuzfahne am Bahnhof willkommen geheißen, Bezirksarchiv Zell am See.

Analog dazu mutierte der hiesige Skiklub in den 1930er-Jahren zu einem Sammelbecken deutschnationalen Gedankenguts. Im 1919 wiedergegründeten Skiklub Zell am See, dessen Obmänner aus großbürgerlichen Verhältnissen

121 Vgl. Rudulf Leo, Der Pinzgau unterm Hakenkreuz. Diktatur in der Provinz, Salzburg 2013, S. $15-17$.

122 Vgl. Krisch, Die Wahlerfolge, S. 225. 
stammten, ${ }^{123}$ trafen nationalsozialistische Gesinnungsbrüder zusammen. $\mathrm{Zu}$ den führenden Vertretern zählte der in Zell am See praktizierende Arzt Josef Heiß. Der Obmann des Skiklubs Zell am See war seit 1935 Mitglied der SS und wurde beim Juliputsch 1934 wegen nationalsozialistischer Gesinnung für einen Monat in Schutzhaft genommen und für zweieinhalb Jahre seiner Stellung als Sprengelarzt enthoben. Nach dem „Anschluss“ machte Heiß Karriere innerhalb der SS und der Partei sowie als Arzt. Er leitete ab 1939 das Kreisamt für Volksgesundheit und war ab 1940 als Kreisbeauftragter für Rasse- und Bevölkerungspolitik zuständig für NS-Euthanasiefragen. ${ }^{124}$ Heiß wurde am 19. Februar 1900 in Mittersill geboren und wuchs als Sohn des Arztehepaares Stefan und Anna Heiß auf. Nach dem Gymnasium ging er an die Universität Innsbruck und inskribierte dort Medizin. Seine Promotion legte er im Alter von 24 Jahren am 31. Mai 1924 ab. Nach Abschluss des Studiums fand er eine Anstellung als Spitalsarzt im St. Johann-Spital in Salzburg (heute Landeskrankenhaus) und arbeitete in dem Krankenhaus bis Jahresende 1927. Im Juni 1928 machte sich Heiß als praktischer Arzt selbstständig und eröffnete in Zell am See eine Praxis, ließ sich dort nieder, heiratete und gründete eine Familie. Heiß sei „ein überaus angesehener und beliebter Arzt gewesen [...] den die nationalsozialistischen Parteistellen in ihre Dienste zu stellen bestrebt gewesen seien“, hieß es nach dem „Anschluss“ von Seiten der SS, als es um die Rückdatierung seiner Mitgliedschaft ging. ${ }^{125}$ Seine „nationale Gesinnung“ galt als allgemein bekannt, hieß es später in einer Überprüfung des Nachkriegsurteils im Rahmen des Volksgerichtsverfahrens am Landesgericht Linz. Als Ausschussmitglied im Skiklub Zell am See bestimmte Heiß in der Zwischenkriegszeit die Politik des Vereins mit. Obwohl sich dieser offiziell als unpolitisch deklarierte, können Verbindungen von Vorstandsmitgliedern und Funktionären zur nationalsozialistischen Bewegung nicht geleugnet werden. Als Jugendwart agierte ab 1934 Fritz Vogl im Skiklub Zell am See. Vogl wurde am 30. Juli 1899 in St. Michael im Lungau geboren und besuchte nach dem Gymnasium die Hochschule für Bergbauwesen. Im Ersten Weltkrieg hatte er sich die kleine und große Tapferkeitsmedaille sowie das Kärntnerkreuz erkämpft und war zuletzt Leutnant der Reserve. Nach Abschluss seines Hochschulstudiums fand Vogl eine Stelle als Hauptschullehrer und zog nach Zell am See. Er trat im November 1931 in die NSDAP, Ortsgruppe Zell am See, ein und

123 Der Vorstand des Skiklubs Zell am See setzte sich in der Zwischenkriegszeit aus Ärzten, Kaufleuten, Hoteliers und selbstständigen Unternehmern zusammen. Vgl. Ski-Klub Zell am See, Festschrift zum 75-Jahr-Jubiläum 1906-1981, Zell am See 1981, S. 8.

124 Vgl. OÖLA, LG Linz Sondergericht, Sch. VgVr 5457/47 (335).

125 Vgl. Protokoll über nicht öffentliche Sitzung, Oberster Gerichtshof Wien, 14.5.1949, OÖLA, LG Linz Sondergericht, Sch. VgVr 5457/47 (335). 
besuchte in der illegalen Zeit mehrere Schulungslager des NS-Lehrerbundes. ${ }^{126}$ Vogl leitete aber nicht nur die Jugendabteilung des örtlichen Skiklubs, er übte gleich mehrere Funktionen aus. So war der als Fachlehrer der Hauptschule Zell am See tätige ausgebildete Bergbau-Ingenieur ehrenamtlicher Landesjugendführer des ÖSV für den Skilauf im Salzburger Landesskiverband sowie Jugendund Jungmannenwart der Alpenvereinssektion Pinzgau. ${ }^{127}$ Vogl hatte also wesentlichen Einfluss auf die Ausbildung des Alpin- und Skinachwuchses im Bundesland Salzburg. Der Salzburger Landesschulrat sprach dem Nationalsozialisten Vogl in seiner Sitzung vom 22. März 1933 die Anerkennung „für sein verdienstvolles Wirken und sein vorbildliches Verhalten der Skijugend gegenüber als Landesjugendführer von Salzburg des ÖSV“ aus. ${ }^{128}$

Der Skiklub Zell am See gab am 14. November 1934 zu Protokoll, dass der Klub „im Sinne der Verbandsstatuten und der eigenen Anschauungen stets unpolitisch geführt wurde und diesen strengen Standpunkt auch bei allen seinen Zusammenkünften und Veranstaltungen genauest eingehalten hat."129 Dieses Schreiben ist vor allem vor dem Hintergrund der Verfolgung durch Behörden des austrofaschistischen Ständestaates zu betrachten. Ab 1934 standen die Mitgliedsvereine des ÖSV unter verstärkter Beobachtung.

Der Bergsteiger und spätere NS-Expeditionsteilnehmer aus Hüttenberg Heinrich Harrer gewann bei den eben schon erwähnten Akademischen Weltwinterspielen die Abfahrt und die reichsdeutsche Skiläuferin aus Freiburg im Breisgau Christl Cranz siegte bei den Damen. ${ }^{130}$ Der gebürtige Innsbrucker Gerhard Lantschner startete damals bereits für das reichsdeutsche Skiteam. Er war in das Deutsche Reich ausgewandert und am 24. Februar 1936 von den österreichischen Behörden ausgebürgert worden. ${ }^{131} \mathrm{Ob}$ er aus Gründen der politischen Verfolgung geflohen ist, lässt sich aus den bisherigen Quellen nicht erschließen. Es liegt aber nahe, dass er Österreich aus politischen Motiven verlassen hat. Die Flucht seines Cousins Hellmut Lantschner 1934 und seines Bruders

126 BArch (ehem. BDC) PK, Vogl, Fritz, 30.07.1899.

127 Vgl. Der Ski, Nr. 2, 15.11.1933, S. 26; Salzburger Volksblatt, 8.10.1937, S. 5.

128 Vgl. Der Ski, Nr. 2, 15.11.1933, S. 26.

129 Protokoll des Skiklub Zell am See (unveröffentlichtes Manuskript), Kopie im Besitz des Verfassers.

130 Vgl. Gabriele Steinacher, Die Entwicklung des Skilaufs am Beispiel des Skiklub Zell am See, Diplomarbeit, Salzburg 1988, S. 34. Steinacher nennt in ihrer Diplomarbeit 16 Nationen, die an den Akademischen Weltwinterspielen teilgenommen hätten, in zeitgenössischen Berichten ist von 18 Nationen die Rede.

131 Vgl. TLA, Bundespolizeidirektion Innsbruck, NS-Dokumentationsmaterial, 3/5 Ausbürgerungsverzeichnis, Gerhard Lantschner. 
Fritz Lantschner jun. lassen diesen Schluss zu. ${ }^{132}$ Mitglieder der Familie Lantschner waren jedenfalls in Innsbruck für ihre nationalsozialistische Gesinnung bekannt und einige betätigten sich auch am „illegalen Kampf“. Diesen führten sie ab Mitte der 1930er-Jahre von Deutschland aus fort. So wie Hellmut Lantschner konnte auch Gerhard Lantschner nach seiner Ausbürgerung an seine skisportlichen Erfolge anschließen, allerdings unter der Hakenkreuzfahne. Bei den Akademischen Weltwinterspielen in Zell am See 1937 siegte Gerhard Lantschner im reichsdeutschen Trikot im Slalom und im zusammengesetzten Abfahrts- und Torlauf, sprich in der Kombination. ${ }^{133}$

\subsubsection{Skihütten und -vereine als NS-Tarnorganisationen}

Doch auch andernorts mutierten örtliche Skivereine zu NS-Tarnorganisationen. Im Lungau war es der Skiklub Tamsweg, der unter dem Skilehrer Julius Funcke, Rufname Olo, eine SA-Schar zusammenstellte. Der SA-Truppführer nutzte ab 1932 mit seinen Männern die abgelegene Dr. Josef-Mehrl-Hütte in Schönfeld in den Lungauer Nockbergen an der Grenze zu Kärnten als Versammlungs- und Rückzugsort. Von hier sollte im Sinne des Deutschen Reiches nationalsozialistische Propaganda betrieben werden. Funcke wurde am 26. Dezember 1908 in St. Andrä im Lungau geboren und bestand im April 1932 mit Erfolg die staatliche Skilehrerprüfung. Der staatlich geprüfte Skilehrer war im Dezember 1934 als Hilfsskilehrer bei der Alpinen Skischule Lungau angestellt und organisierte für diese die Skikurse am Prebersee. Inhaber der Skischule war Falko Lainer aus Ramingstein. Sowohl Funcke als auch Gerhard Lainer, der Bruder des SkischulInhabers Falko Lainer, hätten sich laut Erhebungen der Bezirkshauptmannschaft Tamsweg zuvor nationalsozialistisch betätigt, Funcke galt zudem als „fanatischer Anhänger“ der NSDAP. Die Behörde erhob aber keine Einwände, da Funcke und Lainer zum Zeitpunkt der Ermittlung „zu keiner Klage mehr Anlass“ gegeben hätten. Die nachsichtige Entscheidung wurde außerdem damit begründet, dass der Lungau über keine anderen Hilfsskilehrer verfüge. ${ }^{134}$ Die Salzburger Landeshauptmannschaft bemühte sich daher im Namen der Bezirkshauptmannschaft Tamsweg am 17. Dezember 1934 um die Zulassung der beiden

132 Sowohl Hellmut Lantschner als auch Fritz Lantschner jun. finden sich in den Ausbürgerungslisten der Bundespolizeidirektion Innsbruck. Für Hellmut Lantschner ist der 16.5.1934 vermerkt. Vgl. TLA, Bundespolizeidirektion Innsbruck, NS-Dokumentationsmaterial, 3/5 Ausbürgerungsverzeichnis, Hellmut und Fritz Lantschner.

133 Vgl. Steinacher, Die Entwicklung des Skilaufs, S. 38.

134 Vgl. Bezirkshauptmannschaft Tamsweg, Verzeichnis der Hilfsskilehrer der Alpinen Skischule Lungau, 15.12.1934, SLA, PRÄ 1936/47-1620. 
Hilfsskilehrer für die Skischule. ${ }^{135}$ Im Februar 1935 hätte Funcke als Skilehrer zusätzlich zu seiner Hilfsskilehrertätigkeit am Prebersee die Skikurse der Zweigstelle der Alpinen Skischule Lungau auf der Karneralm übernehmen sollen. ${ }^{136}$ Anders als in den Akten erwähnt Der Ski sowohl den staatlich geprüften Skilehrer Funcke als auch den Medizinstudenten Falko Lainer als Leiter der Alpinen Skischule Lungau mit ihrem Sitz auf der Karneralm. Dort hat im Winter 1933/34 erstmals der ÖSV-Rennläuferkurs für Slalom und Abfahrt stattgefunden. ${ }^{137} \mathrm{Da}-$ mit waren die beiden also durchaus mit mehr betraut als nur mit der Heranbildung des regionalen Skinachwuchses.

Neben seiner Lehrtätigkeit nahm Funcke in den 1930er-Jahren als alpiner Skiläufer an lokalen Wettbewerben teil, so wie als Gastläufer beim Abfahrtslauf des Deutschen Turnvereins Tamsweg im Februar 1934. ${ }^{138}$ Im selben Monat startete er außer Konkurrenz beim Abfahrtslauf vom Preber nach Tamsweg und erreichte auf der zehn Kilometer langen Strecke die zweitbeste Zeit. ${ }^{139}$ Im April 1935 übernahm Funcke die Rennleitung des Preber-Torlaufes, der vom Skiklub Tamsweg nach den Wettlauf-Bestimmungen des ÖSV durchgeführt wurde. ${ }^{140} \mathrm{Im}$ März 1938 beteiligte sich Funcke an der gewaltsamen Besetzung der Bezirkshauptmannschaft Tamsweg. ${ }^{141}$ Beim ersten Preber-Torlauf unter nationalsozialistischer Herrschaft, der noch im Mai 1938 durchgeführt wurde, trat Funcke als Redner der NS-Bewegung auf und nahm die Preisverleihung vor. ${ }^{142}$

\subsubsection{Nationalsozialistische Sympathiekundgebungen bei Skirennen}

Bis zum März 1938 hatte der Nationalsozialismus immer breitere Gesellschaftsschichten durchdrungen und der Deutsche Gruß war trotz staatlicher Verfolgung im Austrofaschismus bei Ski-Veranstaltungen nicht nur salonfähig, sondern zu einem ständigen Begleiter geworden. Das zeigt sich mehrheitlich bei

135 Vgl. Landeshauptmannschaft Salzburg an den Herrn Sicherheitsdirektor, 17.12.1934, SLA, PRÄ 1936/47-1620.

136 Vgl. Skischule Falko Lainer, Skischule Karneralm, Zulassung von Lehrkräften, 8.2.1935, SLA, PRÄ 1936/47-1620.

137 Vgl. Der Ski, Nr. 3, 1.12.1933, S. 34.

138 Vgl. Salzburger Volksblatt, 8.2.1934, S. 9.

139 Vgl. Salzburger Volksblatt, 27.2.1934, S. 8.

140 Vgl. Salzburger Volksblatt, 26.4.1935, S. 9.

141 Vgl. Volksgerichtakt Julius Funcke, OÖLA, LG Linz Sondergerichte, Sch. 370 VgVr 6478/ 47.

142 Vgl. Salzburger Volksblatt, 16.5.1938, S. 9. 
einer Aufnahme der Skilaufriege der Dornbirner Turnerschaft beim TurngauSkirennen kurz vor dem „Anschluss“ 1938. Doch zurück zum Jahr 1934.

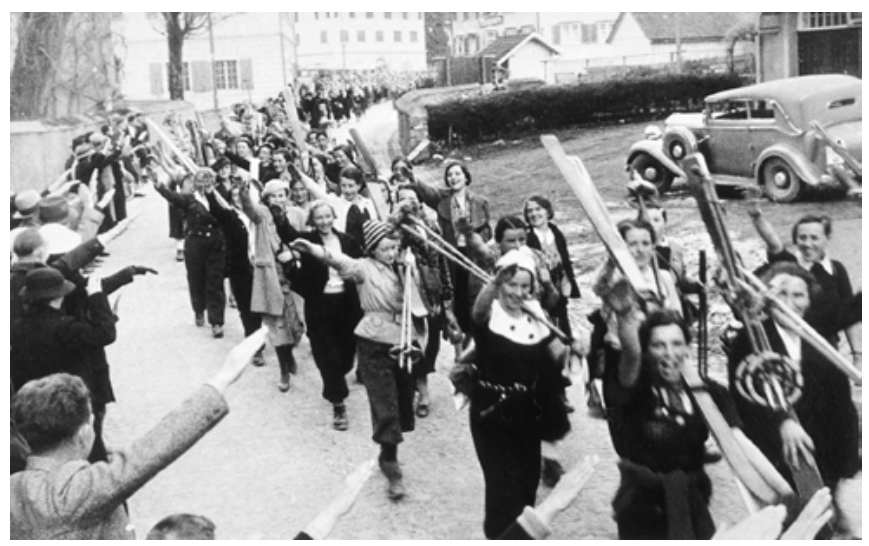

Abb. 14: Skiläuferinnen der Skiriege des Dornbirner Turnvereines im Rahmen des Turngau-Skirennens auf dem Bödele, 6. März 1938, Stadtarchiv Dornbirn.

Ab den 1930er-Jahren, verstärkt ab der Machtübernahme Adolf Hitlers in Deutschland 1933, kam es in (west-)österreichischen Ski-Kreisen vermehrt zu Sympathiekundgebungen für den Nationalsozialismus. Vor allem im Vorfeld des Juli-Putsches 1934 häuften sich nationalsozialistische Kundgebungen bei Wettbewerben und Skisportveranstaltungen. In Kitzbühel wurde das Hahnenkamm-Rennen, welches 1931 ins Leben gerufen wurde, in den Jahren 1933 und 1934 abgesagt. ${ }^{143}$ Die offizielle Website des Hahnenkammrennens gibt über 80 Jahre später politische Gründe für die Absage an. ${ }^{144}$ Einer der Höhepunkte waren die Ausschreitungen bei den Tiroler Skimeisterschaften in Hall am 14. Jänner 1934. Mitglieder des Skiklubs Innsbruck, die den Behörden als Anhänger des Nationalsozialismus bekannt waren, ${ }^{145}$ bekundeten ihre Sympathie zum nationalsozialistischen Regime beim Springen mit dem Deutschen Gruß. Der Wettbewerb wurde daraufhin abgebrochen und das Militär nach Hall entsandt, um die aufgebrachte Menge unter Kontrolle zu bringen. ${ }^{146}$ Laut amtlicher Meldung, die im Tiroler Anzeiger am 15. Jänner 1934 abgedruckt wurde, erging sich eine

143 Vgl. John B. Allen, Politik, Geld und Sport: Der Fall Hannes Schneider, in: Josef Riedmann/Richard Schober (Hg.), Tiroler Heimat. Jahrbuch für Geschichte und Volkskunde (Band 70), Innsbruck 2006, S. 195-200, hier S. 197; Brugger, The Influence of Politics, S. 680. 144 Vgl. https://hahnenkamm.com/wissenswertes/hkr-die-chronik/ (21.5.2019).

145 Vgl. TLA Präs.4163 XII-59 1933 Kart.1220-01.

146 Vgl. u. a. Neueste Zeitung, 16.01.1934, S. 1 und Neueste Zeitung, 08.02.1934, S. 1. 
mehrhundertköpfige Menge in Heil-Hitler-Rufen, demonstrierte den Hitler-Gruß und sang das Deutschlandlied sowie das Horst-Wessel-Lied. Die Bezirkshauptmannschaft Tirol habe daraufhin die Sportveranstaltung sofort abgesagt und in weiterer Folge hatten Gendarmerie und eine Kompanie des Feldjägerbataillons einige der Demonstranten in Gewahrsam genommen. „Mehrere bekannte nationalsozialistische Parteigänger“ wurden in das Anhaltelager nach Wöllersdorf überstellt. ${ }^{147}$ Unter den aktiven Teilnehmern befand sich der Innsbrucker Abfahrer Hellmut Lantschner. Er setzte sich in der Folge ab und floh in das Deutsche Reich. Lantschner reiste laut eigenen Angaben aus dem italienischen Skiort San Martino di Castrozza an, wo er unter anderem als Skilehrer tätig war, um bei den Meisterschaften in Hall zu starten. Von der geplanten Demonstration hätte er im Vorfeld nichts gewusst, behauptete er später bei seinen Aussagen im Entnazifizierungsprozess. ${ }^{148}$ Lantschner war bereits 1932 der SA beigetreten und befand sich nach den Zwischenfällen in Hall im Jänner 1934 auf der Flucht vor den österreichischen Behörden. Der Skiklub Innsbruck musste daraufhin seinen Betrieb einstellen und dem Tiroler Skiverband wurden sämtliche Aktivitäten behördlich untersagt. ${ }^{149}$

Zwei Wochen zuvor war es in Dornbirn zu einem ähnlichen Vorfall im Zuge der Vorarlberger Skimeisterschaften gekommen. Beim Begräbnis des tödlich verunglückten Abfahrers und SS-Mannes Alois Glatzl bekundete der Vize-Präsident des ÖSV und illegale NSDAP-Gauleiterstellvertreter Theodor Rhomberg offen seine nationalsozialistische Einstellung. Der Dornbirner Geschäftsmann und teilhabende Geschäftsführer des Textilunternehmens Herrburger \& Rhomberg, Obmann des Deutschen Turnvereins und Präsident des Verbandes Vorarlberger Skiläufer (VVS) musste daraufhin sein Amt im ÖSV aufgeben. 1938 wurde Rhomberg von den Nationalsozialisten als Vereinsführer des lokalen Skiklubs wiedereingesetzt sowie zum Kreisorganisationsleiter und NS-Landessportführer ernannt. Wie Quellen der NSDAP-Gauleitung für Tirol und Vorarlberg belegen, verfügte Rhomberg aufgrund seiner parteipolitischen Ämter, die er ab 1938 ausübte, über eine beachtliche Machtfülle. ${ }^{150}$ Doch schon in den Jah-

147 Vgl. Tiroler Anzeiger, 15.1.1934, S. 5.

148 Vgl. TLA, LG Innsbruck, 10 Vr 2863/47 Strafverfahren gegen Helmuth Lantschner, geb. am 11.10.1909 in Innsbruck-Igls, vom Beruf Sportlehrer.

149 Vgl. u. a. Tiroler Anzeiger, 8.2.1934, S. 7.

150 Vgl. u. a. StAD, Nr. 570, Dornbirns Kampf um die Befreiung 1933-1938 und StAD, Verwaltungsarchiv, Akz.-Nr. 125/2000, Ordner 1938-1945 NSDAP Akten, Nr. V sowie Ingrid Böhler, Dornbirn in Kriegen und Krisen 1914-1945, Innsbruck 2005. Theodor Rhomberg, geboren am 29.6.1897 in Dornbirn, war seit 24. März 1933 NSDAP-Mitglied und von Jänner 1934 bis Dezember 1934 Gauleiterstellvertreter sowie später Gauschulungsleiter. Unmittelbar nach dem „Anschluss“ wurde er von den Nationalsozialisten zum Landessportführer für Vorarlberg ernannt. 
ren zuvor lässt sich in Dornbirner Ski-Kreisen ein, wie Ingrid Böhler schreibt, „völkisch-nationales Netzwerk“"151 nachzeichnen, dass seine Wurzeln ebenso in der hiesigen Turnbewegung hatte und dessen Mitglieder von den Behörden wegen illegaler NS-Aktivitäten angehalten und angezeigt wurden. Die hohe Konzentration an nationalsozialistischen Turnern, die auch skiläuferisch aktiv waren, erklärt sich auch durch den Einfluss der NSDAP-Ortsgruppe Dornbirn, die sich ab Anfang der 1930er zum Zentrum der nationalsozialistischen Bewegung entwickelte und laut Wolfgang Weber 1932 mit der Übernahme der Landesleitung 78 Mitglieder zählte. ${ }^{152}$ Auch Rhomberg war neben dem illegalen NSDAPGauleiter Anton Plankensteiner Teil dieses Netzwerkes. ${ }^{153}$ Rhomberg und Plankensteiner kannten sich aus der Turnriege und der nationalsozialsozialistischen Bewegung. Der um sieben Jahre ältere Plankensteiner war zunächst ObmannStellvertreter und leitete ab 1930 als Obmann den Turnverein Dornbirn. ${ }^{154}$ Der Bankbeamte trat am 6. November 1930 der NSDAP bei und kandidierte im Oktober 1932 als Spitzenkandidat für die NSDAP bei den Landtagswahlen in Vorarlberg, nahm aber sein gewonnenes Mandat nicht an - Presseberichten zufolge auf „ausdrücklichen Wunsch“ seines Arbeitgebers, der Tiroler Bank. ${ }^{155}$ Planken-

Nach 1938 bekleidete Rhomberg mehrere parteipolitische Ämter. So war er nicht nur Kreisorganisationsleiter der NSDAP, sondern auch Betriebsführer der DAF, Mitglied des NSV und Kreisführer im NSRL. Am 8. November 1938 trat er der SA bei und wurde 1939 zum Obersturmführer befördert. Der Industrielle Rhomberg war teilhabender Geschäftsführer des Dornbirner Textilunternehmens Herrburger \& Rhomberg, Präsident des Verbandes Vorarlberger Skiläufer, Vizepräsident des ÖSV und Obmann des Deutschen Turnvereins TV 1862 sowie des Skivereins Dornbirn. Vgl. u. a. NSDAP Parteipolitische Beurteilung, Gau Tirol-Vorarlberg, Innsbruck, 02.8.1939, StAD, Verwaltungsarchiv, Akz.-Nr. 125/2000, Ordner ohne Titel, Nr. VI/3.

151 Böhler, Dornbirn in Kriegen, S. 128.

152 Vgl. Wolfgang Weber, Von Jahn zu Hitler. Politik- und Organisationsgeschichte des Deutschen Turnens in Vorarlberg 1847-1938, Konstanz 1995, S. 138-139.

153 Böhler, Dornbirn in Kriegen, S. 128-129.

154 Vgl. Weber, Von Jahn, S. 139.

155 Vgl. Feldkircher Anzeiger, 19.10.1932, S. 1; Vorarlberger Volksblatt, 18.11.1932, S. 2; Datenbank der deutschen Parlamentsabgeordneten, Basis: Parlamentsalmanache/Reichstagshandbücher 1867-1938, https://www.reichstag-abgeordnetendatenbank.de/selectmaske.html? pnd=130556556\&recherche=ja (4.6.2019). Anton Plankensteiner, geboren am 13. März 1890 in Bregenz, absolvierte die Realschule in Dornbirn und meldete sich 1909 freiwillig zu einem Jahr bei den Tiroler Kaiserjägern. Ab Februar 1911 war er zunächst als Bankkassier und danach als Korrespondent für die Bank für Tirol und Vorarlberg in den Filialen in Dornbirn und Bludenz sowie in der Zentrale in Innsbruck tätig. Im November 1930 trat er der NSDAP bei und wurde aufgrund seiner späteren illegalen Tätigkeit für die NSDAP in Wöllersdorf inhaftiert und vorübergehend vom Dienst suspendiert. In der NSDAP war Plankensteiner bis 1933 zunächst Ortsgruppenleiter, dann Bezirksverbands- und Kreisleiter sowie illegaler NSDAP-Gaueleiter. Seine Verhaftung und Internierung erfolgten 1934. Nach seiner Internierung in Wöllersdorf wurde Plankensteiner ausgebürgert. 1936 nahm er am NSDAP-Parteitag in Nürnberg teil. Plankenstei- 
steiner wurde später aufgrund seiner illegalen Tätigkeit für die NSDAP von Jänner bis Juli 1934 im Anhaltelager Wöllersdorf inhaftiert und vom Bankdienst suspendiert. ${ }^{156}$ Zum engeren Vertrautenkreis Rhombergs zählten noch der SAStandartenführer Eugen Kölbl, ${ }^{157}$ der NS-Ortsgruppenleiter Josef Luger ${ }^{158}$ und der SS-Blutordensträger und spätere NS-Bürgermeister von Dornbirn Josef Dreher. ${ }^{159}$

Rhomberg musste im Zuge der Neuwahlen des Vorstands des Verbandes Vorarlberger Skiläufer im Juni 1935 ,infolge seiner nationalsozialistischen Einstellung“ sämtliche Funktionen aufgeben und sein Präsidentenamt im VVS zur Verfügung stellen. ${ }^{160}$ Er setzte sich in weiterer Folge ins Deutsche Reich ab. Die Skisportvereine in Vorarlberg standen ab diesem Zeitpunkt ebenso wie andere in Österreich unter verstärkter Beobachtung des austrofaschistischen Ständestaates. Die Sicherheitsdirektion für Vorarlberg forderte 1936 von den einzelnen Gendarmerieposten Berichte über die nunmehr illegale nationalsozialistische Bewegung in Skivereinen. Besonders die Vereine in Dornbirn und Feldkirch standen im Fokus der Ermittlungen. ${ }^{161}$ In einer Meldung des Gendarmeriepostenkommandos Dornbirn hieß es im April 1936, dass der letztmalig gewählte Vorstand des Skivereins Dornbirn ausschließlich aus Nationalsozialisten bestünde - angefangen bei seinem vorbestraften Obmann Otto Weiß, der sich ins Deutsche Reich abgesetzt haben soll. ${ }^{162}$ Weiß, der acht Semester Bodenkultur studierte und 1926 im Fach Landwirtschaft promovierte, trat im Mai 1933 der NSDAP bei und im Februar 1936 der SS. Der gebürtige Dornbirner wurde nach seiner Flucht ins Deutsche Reich am 15. Dezember 1936 eingebürgert und nach einem Schulungskurs für SS-Sturmmänner in Thüringen unter der SS-Nr.

ner kehrte mit dem „Anschluss“ nach Dornbirn zurück und wurde im Juni 1938 als Kreisleiter und Gauinspektor eingesetzt. Vgl. Weber, Von Jahn, S. 139; TLA, BPD Innsbruck, NS-Dokumentationsmaterial, 3/395 Kreis- und Gauamtsleiter, Anton Plankensteiner.

156 Vgl. Brugger, The Influence, S. 676; Datenbank der deutschen Parlamentsabgeordneten, Plankensteiner, Toni, geb. am 16.3.1890 in Bregenz (Vorarlberg), www.reichstag-abgeordnetendatenbank.de (4.6.2019).

157 Vgl. BArch (ehem. BDC), SA, Kölbl, Eugen, 27.06.1898

158 Vgl. Weber, Von Jahn, S. 139.

159 Josef Dreher, geboren am 20. Juni 1896, trat 1932 in die NSDAP und im Oktober 1934 in die SS ein. Vgl. BArch (ehem. BDC), SSO, Dreher, Josef, 20.6.1896.

160 Vgl. Meldung des Gendarmeriepostenkommandos Dornbirn, Bezirk Feldkirch, 16.4.1936, VLA, BH Feldkirch I, Sch. 1425, Fasz. „Nationalsozialistische Tätigkeit“, III-12 (1) 1936; Peter, Turnen fürs Vaterland, S. 203.

161 Vgl. BH Feldkirch an den Sicherheitsdirektor für Vorarlberg und Bregenz, 20.4.1936, VLA, BH Feldkirch I, Sch. 1425, Fasz. „Nationalsozialistische Tätigkeit“, III-12 (2) 1936.

162 Vgl. Meldung des Gendarmeriepostenkommandos Dornbirn, Bezirk Feldkirch, 16.4.1936, VLA, BH Feldkirch I, Sch. 1425, Fasz. „Nationalsozialistische Tätigkeit“, III-12 (1) 1936. 
276179 im Juni 1936 vereidigt. Er machte ab Oktober 1940 Karriere als SS-Führer. ${ }^{163}$ Die österreichischen Behörden ermittelten aber nicht nur im Fall Weiß. Als ebenso verdächtig galten der vorbestrafte Kassier des Skivereins Dornbirn Siegfried Nosko und der wegen Verdacht auf Hochverrat flüchtige sowie zur Verhaftung ausgeschriebene Sportwart Edmund Bösch. Als „vaterländisch“ unzuverlässig eingestuft wurden auch der Obmann-Stellvertreter Alfred Hämmerle und der Schriftführer Karl Hämmerle. ${ }^{164}$

Die Verbundenheit zum nationalsozialistischen Deutschland lässt sich auch an der Berichterstattung in der einschlägigen Verbandspresse des ÖSV ablesen. In einem Vorbericht zu den österreichischen Meisterschaften 1934 im Kärtner Mallnitz stand im Dezember 1933 zu lesen, dass die Sportveranstaltung „ein Ausdruck der Einheit aller deutschen Skiläufer unserer österreichischen Heimat, ein Beweis alpenländischer Sitte und deutschen Fühlens sowie der leiblichen Kraft und Gesundheit unserer Jugend sein soll“. ${ }^{165}$ Als Leiter des Abfahrtslaufes trat der spätere NSRL-Sportfunktionär Alfred Schatz und als „Kenner der Dolomiten“ der spätere Leiter des NS-Lehrerbundes im Gau Salzburg und Initiator der nationalsozialistischen Bücherverbrennung in Salzburg Karl Springenschmid auf.

\subsubsection{Der ÖSV im Visier der austrofaschistischen Behörden}

Die Überprüfung und strafrechtliche Verfolgung von verdächtigen Mitgliedern in Vorarlberg durch die Sicherheitsbehörden war kein Einzelfall. Nachdem die NSDAP im Juni 1933 in Österreich verboten worden war, versuchte die austrofaschistische Regierung, die illegalen Aktivitäten im ÖSV zu unterbinden. Das entsprach der allgemein autoritären Politik der von Kanzler Engelbert Dollfuß installierten Ein-Parteien-Regierung, die bemüht war, „die politische Opposition im Sportbereich auszuschalten“. ${ }^{166}$ Damit standen auch die nationalsozialistischen Aktivitäten in den Mitgliedsvereinen des ÖSV unter permanenter Kontrolle, wenn auch diese weniger drastisch ausfiel als die Ausschaltung und Unterdrückung sozialdemokratischer Sportvereine. ${ }^{167}$ Die österreichische Sportund Turnfront setzte dafür einen eigenen Regierungskommissär ein, der auffäl-

163 Vgl. BArch (ehem. BDC), SSO, Weiss, Otto, 23.5.1903.

164 Vgl. Meldung des Gendarmeriepostenkommandos Dornbirn, Bezirk Feldkirch, 16.4.1936, VLA, BH Feldkirch I, Sch. 1425 Fasz. „Nationalsozialistische Tätigkeit“, III-12 (1) 1936.

165 Der Ski, Nr. 4, 15.12.1933, S. 49.

166 Tálos, Das austrofaschistische Herrschaftssystem, S. 417.

167 Vgl. Tálos, Das austrofaschistische Herrschaftssystem, S. 419; Marschik, Turnen und Sport, S. 380-381. 
lige Mitglieder melden und beobachten sollte. Auf der Liste der Verdächtigen standen vom ÖSV-Direktor Karl Merz abwärts sämtliche Vorstandsmitglieder bis hinein in die Landesverbände. Der Erfolg war bescheiden. In manchen Fällen kam es zu Verfahren, die aber mangels Beweisen sehr schnell wieder eingestellt wurden. ${ }^{168}$ Grundlage für die Überwachung bildete eine Verordnung der Bundesregierung vom 3. März 1934. Nach dieser wurde per Bescheid vom 31. Jänner 1934 der pensionierte Gendarmerie-Oberst Richard Hueber als Überwachungsbeamter des ÖSV bestellt. Hueber nahm daraufhin am 8. Jänner 1935 in der Hauptvorstandssitzung des ÖSV seine Arbeit auf und begab sich anschließend in die Bundesländer, um dort mit den jeweiligen Verantwortlichen in den Landesverbänden Kontakt aufzunehmen. ${ }^{169}$

Die inkonsequente Haltung des austrofaschistischen Systems muss auch vor dem Hintergrund gesehen werden, dass die Sportführung vermeiden wollte, dem nationalen Projekt Skisport zu schaden. Daraus entstand oftmals eine Zwickmühle, in der sich die ermittelnden Instanzen wiederfanden. Denn gleichzeitig war der Skisport nicht nur eine politische Mission, sondern kurbelte den Tourismus und Wintersportbetrieb an. Gerade der Skitourismus war in den Krisenjahren 1933 bis 1936, die von der „Tausend-Mark-Sperre“ gekennzeichnet waren, eine wesentliche Einnahmequelle für Fremdenverkehrsorte, die sich nun bemühten, verstärkt Gäste aus Westeuropa anzusprechen. ${ }^{170}$ Gleichzeitig war die ÖSTF um eine positive Außenwirkung der Nationalsportart Skisport bemüht.

Die Staatspolizei ermittelte weiterhin gegen führende Vertreter des ÖSV. Das geht aus den Aktenbeständen des Bundeskanzleramtes in Wien hervor. So überprüfte die Exekutive ab 1936 die politische Einstellung des ÖSV-Geschäftsführers Franz Mauler. Dieser wurde in der Folge ein Fall der Generaldirektion für öffentliche Sicherheit, da Mauler wegen Betätigung für die NSDAP bereits vorbestraft war. ${ }^{171}$ Mauler war im Februar 1932 der NSDAP beigetreten. ${ }^{172}$ Die Behörden ermittelten zudem gegen den Obmann-Stellvertreter des Wiener akademischen Sportvereins Alfred Bauer, weil dieser laut staatspolizeilichen Akten an einer Besprechung nationalsozialistischer Parteigänger teilgenommen hatte. Das Bundeskanzleramt beschloss daraufhin, dass beide Personen aus ihren

168 Vgl. OeStA/AdR, BKA/BPD Wien, Vereinsbüro XVIII-11.336 Vereinsakt des Österreichischen Skiverbandes 1933-1936.

169 Vgl. Der Ski, Nr. 6, 20.1.1935, S. 84.

170 Vgl. Groß, Beschleunigung, S. 82.

171 Vgl. Bundeskanzleramt, Generaldirektion für die öffentliche Sicherheit, OeStA/AdR, BKA 15/4 331.062/1936.

172 Vgl. BArch (ehem. BDC), PK, Mauler, Franz, 27.3.1889. 
Vorstandsämtern ausscheiden müssen. ${ }^{173}$ Mauler saß im Hauptvorstand des ÖSV und machte keinen Hehl aus seiner völkisch-antisemitischen Einstellung. Im ÖSV-Jahrbuch Skileben, das er gemeinsam mit dem Nationalsozialisten Franz Martin herausgab, schrieb er in der Ausgabe von 1937:

Bei der Naturverbundenheit und der Liebe zu den Schönheiten unserer engeren und weiteren Heimat, die vor allem uns Deutsche in allen Gauen auszeichnet, ist es erklärlich, daß das Skilaufen zu einem wahren Volkssport geworden ist. [...] Aus der Bodenständigkeit, die unseren Sport, seine Vorkämpfer und Anhänger seit je auszeichnet, ist es erklärlich, daß der Ariergrundsatz im Ö.S. V. stets verankert und allen Anstürmen zum Trotz es auch bis heute geblieben ist. ${ }^{174}$

Mauler wurde aber nicht wegen seiner Blut- und Boden-Ideologie von der austrofaschistischen Führung abgesetzt. Er wurde den christlich-sozialen Machthabern wie dem Sportführer Ernst Rüdiger Starhemberg, die selbst eine antisemitische Politik vertraten, ${ }^{175}$ aufgrund seiner nationalsozialistischen Verbindungen zu gefährlich.

\subsection{6 Österreichische SkilehrerInnen auf der Flucht ins Deutsche Reich}

Für staatlich geprüfte Skilehrer aus Österreich, die dem Nationalsozialismus ideologisch nahestanden und darüber hinaus noch Mitglied der SA waren, galt das Deutsche Reich ab 1933 als verheißungsvoller Boden. Vor allem ab Juni 1933 mit dem Parteiverbot bot sich für viele der Ausweg über die Grenze an. Der Hauptfeind der SA, die ihre militanten Mitglieder vielerorts aus den Reihen der deutschnationalen Skivereine rekrutierte, war jetzt nicht mehr der Marxismus, sondern der austrofaschistische Ständestaat. ${ }^{176}$ Das wurde unter anderem bei nationalsozialistischen Demonstrationen rund um Skisportveranstaltungen deutlich, bei denen illegale SA-Skiläufer ihre politische Gesinnung offen-provo-

173 Vgl. Bundeskanzleramt, Generaldirektion für die öffentliche Sicherheit, OeStA/AdR, BKA 15/4 331.062/1936.

174 Franz Mauler, Zweck und Ziele des Ö.S. V., in: Skileben in Österreich, 1937, S. 161.

175 Die Organisation und Ausrichtung des im austrofaschistischen Regime geduldeten Sports, beispielsweise in christlich-sozialen Turnvereinen, war ebenso von einer antisemitischen Note geprägt. Sportführer Ernst Rüdiger Starhemberg sprach sich bei der Einführung des Gesetzes zur ÖSTF im Oktober 1934 gegen die Einbeziehung von Jüdinnen und Juden aus. Vgl. Tálos, Herrschaftssystem, S. 417.

176 Vgl. Hans Schafranek, Söldner für den „Anschluss“. Die Österreichische Legion 19331938, Wien 2011, S. 11. 
zierend dem Dollfuß-Regime entgegensetzten. ${ }^{177}$ Darüber hinaus kämpften Nationalsozialisten mit massiver Gewalt und terroristischen Methoden gegen den Austrofaschismus. ${ }^{178}$ Das machte sich mitunter auch bei Grenzüberschreitungen bzw. bei illegalen Grenzübertritten in Skikreisen bemerkbar.

Zum Ausdruck kam die Fluchtbewegung österreichischer Skilehrer ab 1933 bei den Ansuchen an den Reichsverband Deutscher Turn-, Sport- und Gymnastiklehrer. Dieser hatte ab 1934 mehrere Fälle abzuwickeln, bei denen geflüchtete österreichische Skilehrer um eine Skischulkonzession in den bayerischen Alpen ansuchten. ${ }^{179}$ In der Diskussion war zunächst von einem „Sturm der Entrüstung“ die Rede, würde ein österreichischer Staatsbürger die Genehmigung in Bayern bekommen. ${ }^{180}$

Dass die Fluchtversuche und Grenzübertritte zum Teil blutig ausgingen, zeigt ein Fall im Salzburger Pinzgau. So betätigte sich der aus Saalfelden stammende Skilehrer Georg Fuchslechner bei einem bewaffneten Überfall auf Heimwehrmitglieder im Steinernen Meer, einer Gebirgsgruppe im salzburgisch-bayerischen Grenzgebiet, als Haupttäter. ${ }^{181}$ Fuchslechner wurde 1906 geboren und trat im Alter von 24 Jahren im September 1930 mit der Mitgliedsnummer 300876 der NSDAP bei. ${ }^{182}$ Seit 1928 war er als Berg- und Skiführer im Deutschen- und Österreichischen Alpenverein in der Sektion Saalfelden aktiv. Er war zudem Pächter der Ingolstädter Hütte im Grenzgebiet zu Bayern. Gemeinsam mit dem illegalen SA-Sturmbannführer und Skiläufer Johann Mathoi begab sich Fuchslechner in der Nacht vom 17. Auf den 18. August 1933 nach Saalfelden. Dort gaben die beiden mehrere Schüsse aus einem Hinterhalt auf bewaffnete Heimwehrbeamte ab. Bei dem Schusswechsel wurden zwei Beamte schwer verletzt. Mathoi und Fuchslechner hatten sich zuvor verabredet, weil Mathoi über das Steinerne Meer in das Deutsche Reich flüchten wollte und Fuchslechner als ortskundigen Gehilfen benötigte. Bei dem Fluchtversuch sind sie überrascht worden und Fuchslechner eröffnete zur Ablenkung das Feuer. Während

177 Vgl. hier vor allem die NS-Demonstration bei den Tiroler Landes-Skimeisterschaften in Hall, aber auch bei den österreichischen Skimeisterschaften in Mallnitz, beide 1934. Vgl. Innsbrucker Zeitung, 23. Februar 1934, S. 5.

178 Zum Erstarken der nationalsozialistischen Bewegung in Österreich und zum nationalsozialistischen Terror vor 1938 vgl. u. a. Gerhard Botz, Nationalsozialismus in Wien. Machtübernahme, Herrschaftssicherung, Radikalisierung, Kriegsvorbereitung 1938/39, Wien 2018, S. 2122; Emmerich Tálos/Florian Wenninger, Das austrofaschistische Österreich, 1933-1938, Wien 2017, S. 91.

179 Bayerisches Hauptstaatsarchiv (BayHStA), MK 41585.

180 Schreiben des Staatsministeriums für Unterricht und Kultus an die Regierung, Kammer des Inneren von Oberbayern, München 16. Februar 1934, BayHStA, MK 41585.

181 SLA, LRA 1920-1938 XXXIII 1581; TLA, LG Innsbruck, 10 Vr 4132/47.

182 Vgl. BArch (ehem. BDC), PK, Fuchslechner, Georg, 7.8.1906. 
Mathoi fliehen konnte, verblieb Fuchslechner zunächst in Österreich. ${ }^{183}$ Die Bezirkshauptmannschaft Zell am See stellte am 27. August 1933 fest, dass Fuchslechner der Haupttäter beim bewaffneten Überfall auf Heimwehrmitglieder in Saalfelden und in der Zwischenzeit ebenfalls ins Deutsche Reich geflohen war. Sein genaues Fluchtziel war den Behörden unbekannt. Der staatlich geprüfte Skilehrer Fuchslechner suchte erst im Jänner 1933 um die Errichtung einer Skischule beim Sporthotel Penhab in Saalbach an, im August desselben Jahres wurde ihm die Leitung dieser Skischule per Bescheid entzogen. ${ }^{184}$ Die Bezirksbehörde veranlasste daraufhin, dass ein anderer Skilehrer die Skischule in Saalbach übernehmen sollte. ${ }^{185}$

Der gelernte Schlosser Mathoi, geboren am 20. März 1899 in Wien, trat Ende Oktober 1930 in die NSDAP und SA ein und war führend am Aufbau eines illegalen SA-Sturmbannes in Kitzbühel und drei NSDAP-Ortsgruppen beteiligt. Er flüchtete später ins Deutsche Reich. ${ }^{186}$ Die Überweisung von der österreichischen illegalen NSDAP an eine reichsdeutsche Ortsgruppe wurde am 25. September 1936 in München bestätigt. ${ }^{187}$ Mathoi erhielt zunächst in verschiedenen Lagern der „Österreichischen Legion“ eine militärische Schulung. ${ }^{188}$ Ab Anfang Jänner 1934 führte er einen Sturmbann der „Österreichischen Legion“ und übernahm am 1. März 1935 als Adjutant die Standarte und ein halbes Jahr später als Führer einen anderen Sturmbann. Im Juni 1938 kehrte er als hauptamtlicher Führer der Gebirgsjäger-Standarte 1 mit Sitz in Innsbruck zurück in das nationalsozialistische Österreich. Wie andere Skilehrer und Bergführer diente Mathoi während des Zweiten Weltkriegs für die SA-Gruppe Alpenland als Gebirgsjäger und wurde mit dem Eisernen Kreuz erster und zweiter Klasse ausgezeichnet, ehe er im Dezember 1943 als Oberleutnant „uk“ gestellt wurde. ${ }^{189}$ Der von den österreichischen Behörden steckbrieflich gesuchte SA-Mann Fuchslechner schloss sich nach seiner Flucht in das Deutsche Reich im Februar 1936 dem NSKK-Motorsturm in Berchtesgaden an. In der SA galt Fuchslechner als „erstklassiger Lang-, Abfahrts- und Torläufer““. ${ }^{190}$ Bei den SA-Skimeisterschaften in

183 Vgl. TLA, LG Innsbruck, 10 Vr 4132/47.

184 Vgl. Georg Fuchslechner, Errichtung einer Skischule im Hotel Penhab in Saalbach, Zurücknahme des Bescheids vom 19. August 1933, SLA, LRA 1920-1938 XXXIII 1581.

185 Vgl. Bezirkshauptmannschaft Zell am See, 27. August 1933, SLA, LRA 1920-1938 XXXIII 1581.

186 Vgl. TLA, BPD Innsbruck, NS-Dokumentationsmaterial, 3/5 Ausbürgerungsverzeichnis, Johann Mathoi; TLA, LG Innsbruck, 10 Vr 4132/47.

187 Vgl. BArch (ehem. BDC), PK, Mathoi, Hans, 20.3.1899.

188 TLA, LG Innbsruck Vr 4132/47.

189 Vgl. BArch (ehem. BDC.), SA, Mathoi, Hans, 20.3.1899.

190 Vgl. BArch (ehem. BDC.), SA, Fuchslechner, Georg, 7.8.1906. 
Schreiberhau, die 1936 als NS-Winterkampfspiele durchgeführt wurden, startete Fuchslechner für NSKK-Motorsturm. ${ }^{191}$ Die Nachnennung des geflüchteten Fuchslechner zu den Wettbewerben erfolgte auf ausdrücklichen Wunsch der Motorstandarte 84 Kolbermoor des NSKK-Motorsturms. Als Begründung in dem Schreiben vom 5. Februar 1936 an die Kraftfahrinspektion Süd gab die Motorstandarte 84 an, dadurch „noch einen sehr guten Skiläufer nach Schreiberhau“ entsenden zu können. ${ }^{192}$ Fuchslechner war erst einen Tag zuvor dem Motorsturm beigetreten. Seine Loyalität zur NSDAP und zur nationalsozialistischen Bewegung lässt sich einem Schreiben an den Beauftragten des Führers der NSDAP in Österreich entnehmen. In diesem schreibt Fuchslechner am 29. März 1939: „Mir liegt an meinem alten Parteibuch sehr viel.“" ${ }^{193} \mathrm{Zu}$ diesem Zeitpunkt war Fuchslechner bereits nach Saalfelden zurückgekehrt und wohnte im Ingolstädter Haus am Steinernen Meer, wo er sich als Bergführer betätigte. ${ }^{194}$ Der geflüchtete Alpinsportler kehrte also dorthin zurück, wo seine Flucht den Ausgang genommen hatte. Während des Zweiten Weltkriegs war der Oberjäger Fuchslechner unter anderem als Heeresbergführer in der Gebirgsjäger- und Heereshochgebirgsschule in Fulpmes eingesetzt und schulte dort die Gebirgseinheiten für den Winterkrieg. ${ }^{195}$

Ebenfalls im Jahr 1933 machte sich ein anderer aus Saalfelden gebürtiger Skilehrer auf dem Weg ins Deutsche Reich. Die Motive für seine Flucht waren ähnlich gelagert. Nachdem der Absolvent der Lehrerbildungsanstalt Anton Höttl im Juli 1932 in die SS eintrat und Anfang 1933 der NSDAP-Ortsgruppe St. Johann im Pongau beigetreten war, flüchtete er aufgrund seiner Gesinnung im Juli 1933 nach München und trat dort den aktiven Dienst in der SS im „SS-Hilfswerk Dachau“ sprich im Lager Dachau der „Österreichischen Legion“ an. Dort befand sich Höttl bis zum 23. Oktober 1934. Danach begann er in München ein Studium, das seine spätere Karriere nachhaltig prägen sollte. Er inskribierte im November 1934 an der Akademie der bildenden Künste und machte im Rahmen seines Studiums zum Zeichenlehrer die Ausbildung zum Turnphilologen am In-

191 Vgl. BArch (ehem. BDC.), SA, Fuchslechner, Georg, 7.8.1906.

192 Vgl. Schreiben des NSSK Motortsurmn 15/M84 an die Kraftfahrinsepktion Süd, Berchtesgaden, 5.2.1936, BArch (ehem. BDC.), SA, Fuchslechner, Georg, 7.8.1906.

193 Vgl. Schreiben Georg Fuchslechner an den Beuaftragten des Führers für die NSDAP, Saalfelden, 29.3.1939, BArch (ehem. BDC.), SA, Fuchslechner, Georg, 7.8.1906.

194 Vgl. BArch (ehem. BDC), PK, Fuchslechner, Georg, 7.8.1906.

195 Georg Fuchslechner war einer jener österreichischen Skisportler, die aufgrund ihrer Bergführerausbildung und skiläuferischen Kenntnisse als Ausbildner an die Heereshochgebirgsschule in Fulpmes abkommandiert wurden. Vgl. Broschüre der Heeresbergführer der Deutschen Wehrmacht basierend auf der Bergführerkartei der Heereshochgebirgsschule in Fulpmes, Privatnachlass Alfred Rössner, Sammlung Privatnachlässe, Skimuseum Werfenweng. 
stitut für Leibesübungen. Die Lehramtsprüfung für Turnen legte er im Juli 1937 an der Führerschule des Berliner Hochschulinstituts für Leibesübungen in Neustrelitz mit „sehr gut“ ab. Als der SS-Rottenführer Höttl 1939 nach Bischofshofen zurückkehrte und eine Anstellung als Sport- und Zeichenprofessor an der Oberschule in Kreuzberg bekam, war er nicht nur gut ausgebildet, sondern hatte auch eine nationalsozialistische Hochschulbildung samt wehrsportlicher Ausbildung in diversen Lagersystemen absolviert. Höttl durchlief die Lager der „Österreichischen Legion" in Dachau und Lechfeld sowie die Gelände- und Wintersportlager im Rahmen seiner Turnlehrer-Ausbildung. ${ }^{196}$ Diese Fähigkeiten und erworbenen Kenntnisse gab er bis zu seiner Einberufung 1941 zum Gebirgs-Artillerie-Regiment 111 als Leiter in Skilagern für die Salzburger LehrerInnenschaft sowie an die Jugend im Turn- und Zeichenunterricht weiter. ${ }^{197}$

\subsubsection{Frühe Netzwerke und Seilschaften}

Bei den Deutschen Skimeisterschaften in Berchtesgaden 1934 zeigten sich die enge Bande zwischen Österreich und dem Deutschen Reich nicht nur auf einem sportlichen Level. Die Veranstaltung diente einerseits der NS-Sportpropaganda dazu, Werbung zu machen und die angespannte innenpolitische Lage in Österreich für sich zu nutzen, andererseits wurden bestehende sportpolitische Kontakte vertieft und neue geknüpft.

Der bekannte Skirennfahrer, Bergführer und Vorsitzende des Skiclubs Salzburg Fritz Rigele zeigte sich mitunter in kameradschaftlicher Pose neben NS-Reichssportführer Hans von Tschammer und Osten und Ministerpräsident Hermann Göring. ${ }^{198}$ Göring, selbst ein leidenschaftlicher Skifahrer, war bereits vor dem Ersten Weltkrieg Mitglied des Skiclubs Salzburg (SCS), dem auch seine Schwester angehörte. Der damals in Oberndorf bei Salzburg ansässige Notar Rigele leitete als Obmann den Verein, während Göring als junger Kadett Mitglied des Kadetten-Korps in Berlin-Lichterfelde war. ${ }^{199}$ Hellmut Lantschner, der vor der österreichischen Justiz nach Berchtesgaden geflüchtet war, suchte unter anderem den Kontakt zum Reichssportführer von Tschammer und Osten und dieser bekundete sein Interesse an dem späteren NS-Weltmeister. Nach den

196 Vgl. OÖLA, LG Linz, Sondergerichte, Sch. 417, VgVr 234/48; BayHStA, MK 33117, Anton Höttl, 1.5.1912.

197 Vgl. Salzburger Volksblatt, 3.1.1939, S. 6; OÖLA, LG Linz, Sondergerichte, Sch. 417, VgVr 234/48; WASt, Höttl, Anton, 1.5.1912.

198 Vgl. Der Winter, 30 (1934/35), S. 169.

199 Vgl. Mitglieder-Verzeichnis, Ski-Klub Salzburg Jahrbuch 1912, München 1912, S. 78 und 80. 
Vorfällen in Hall flüchtete Lantschner zunächst von Salzburg aus mit dem Güterzug über Freilassing nach Berchtesgaden, wo er sich bei den Deutschen Skimeisterschaften mit dem Meistertitel in der Abfahrt empfehlen konnte. Danach war er abwechselnd in St. Moritz und Garmisch-Partenkirchen als Skilehrer tätig. In Garmisch soll er enge Kontakte zu Mitgliedern der Österreichischen Legion gehabt haben, die wiederum aus Tiroler Skikreisen kamen, wie sein befreundeter Vereinskollege aus Innsbruck Josef Gumpold. Gumpold, geboren am 3. September 1908 in Jenbach, war ebenso wie Hellmut Lantschner an der nationalsozialistischen Demonstration bei den Tiroler Skimeisterschaften in Hall beteiligt und flüchtete 1934 von Innsbruck ohne Ausreisebewilligung ins Deutsche Reich. Der Skispringer und Kombinationsläufer dürfte dort der Österreichischen Legion beigetreten sein. Gumpold wurde wegen Verdachtes des Verbrechens des Hochverrats von der österreichischen Justiz gesucht. Laut Zeugeneinvernahmen dürfte Gumpold im Lager Bad Aibling stationiert gewesen sein, wo der SABrigadeführer aus Innsbruck Hans Glück das Kommando der Kaserne über hatte. ${ }^{200}$ Der Skilehrer und Skiläufer Gumpold trat 1932 in die SA ein und wohnte 1937 in Garmisch-Partenkirchen, wo er 1935 nach seiner Flucht als SA-Obertruppführer in der SA-Gruppe Hochland seinen Dienst versah und 1937 zum SASturmführer befördert wurde. Gumpold war zweifacher Deutscher Skimeister und Mitglied der reichsdeutschen Olympiamannschaft. Aufgrund seiner ,ausserordentlichen sportlichen Fähigkeiten als österreichischer Flüchtling“ und „seiner nationalsozialistischen Einstellung“ hatte er die deutsche Staatsbürgerschaft erhalten. Er war zudem als skitechnischer Referent für die SA tätig und war bei den Wintersportkämpfen der Gliederungen der NSDAP als Mannschaftsführer der SA-Gruppe Hochland eingesetzt. ${ }^{201}$ Der ebenfalls ins Deutsche Reich geflüchtete Fritz Lantschner, der Cousin von Hellmut Lantschner, stellte seinem Gesinnungsgenossen und Skikameraden ein tadelloses Zeugnis aus. Gumpold sei vor seiner Flucht führend für die nationalsozialistische Propaganda der illegalen Gauleitung Tirol zuständig gewesen und hätte sich durch „,besondere Einsatzbereitschaft“ ausgezeichnet. ${ }^{202}$ Fritz Lantschner wohnte zu diesem Zeitpunkt in München und unterhielt gute Kontakte zum späteren Gauleiter Franz Hofer. Gumpold wurde daraufhin rückwirkend mit 1. April 1933 in die NSDAP aufgenommen. ${ }^{203}$

200 Vgl. SLA, LGS, Vr-1938 151-300, 13Vr 272/38.

201 Vgl. BArch (ehem. BDC), SA, Gumpold, Josef, 3.9.1908.

202 Vgl. Fritz Lantschner an das NSDAP Flüchtlingshilfswerk, Mitgliedschaftamt Berlin, 14.6.1937.

203 Vgl. BArch (ehem. BDC), SA, Gumpold, Josef, 3.9.1908. 
Vom Hilfswerk Nordwest, sprich der Österreichischen Legion, ${ }^{204}$ dokumentiert ist auch ein vorübergehender Aufenthalt von Hellmut Lantschner auf Rügen 1937. Laut eigenen Angaben residierte er dort im Rittergut Karnitz. Im selben Jahr startete er bei den Wintersportkämpfen der Gliederungen der NSDAP im Rang eines SA-Obertruppführers in Rottach-Egern, wo er den ersten Platz belegte. ${ }^{205}$ Im Februar 1938 wurde der Abfahrer Hellmut Lantschner neben seiner deutschen Vereinskollegin Christl Cranz in der Presse als „Deutschlands Skimeister“ gefeiert. ${ }^{206}$ Lantschner startete ab 1937 ebenso wie Cranz für den SC Freiburg und nahm für diesen Anfang April 1937 an den vom Deutschen Reichsbund für Leibesübungen organisierten Internationalen Feldberg-Ski-Wettkämpfen teil. Dort traf er auf seinen Cousin Gerhard Lantschner der damals für den ASC München an den Start ging. ${ }^{207}$ Der Weg über den lokalen Skiverein in die SA war für viele junge männliche Sportler ein kurzer. Das lässt sich nicht nur an der Biografie von Hellmut Lantschner feststellen. Bei den Wintersportkämpfen der Gliederungen der NSDAP in Rottach-Egern im Februar 1937 starteten nachweislich vier aus Österreich stammende SA-Skiläufer, die zuvor ins Deutsche Reich geflüchtet waren. Neben Hellmut Lantschner waren das die bereits erwähnten Gerhard Lantschner und Josef Gumpold sowie Hans Haslwanter. ${ }^{208}$ Während die beiden Lantschner und Haslwanter im Dienst der Österreichischen Legion standen, ging Gumpold für die SA-Gruppe Hochland an den Start. ${ }^{209}$

Im Volksgerichts-Verfahren 1948 vor dem Innsbrucker Landesgericht gab Hellmut Lantschner an, nie ein Interesse an Politik und den Vorgängen innerhalb der NSDAP gehabt zu haben. ${ }^{210}$ Dass sein Verwandter Fritz Lantschner junior, zunächst Gaufachberater im Gau Tirol und Vorarlberg und ab 1935 beim

204 Hilfswerk Nordwest (HWNW) war die Bezeichnung der Österreichischen Legion von 1935 bis März 1938.

205 Vgl. BArch (ehem. BDC), PK, Lantschner, Hellmut, 11.11.1909; Ergebnislisten der Wintersportkämpfe in Rottach-Egern am 20./21.2.1937, Oberste SA-Führung, München, 26.2.1937, BArch, NS 22/915.

206 Vgl. dazu Neueste Sport-Zeitung, 7.2.1938, S. 4.

207 Vgl. Startliste Internat. Feldberg-Ski-Wettkämpfe, Samstag, den 3. April und Sonntag, den 4. April 1937, Original im Besitz des Verfassers.

208 Hans Haslwanter trat 1934 in Österreich der illegalen der SA bei und wurde 1937 aufgrund sportlicher Erfolge zum SA-Sturmführer ernannt. Haslwanter war nach seiner Flucht ins Deutsche Reich Angehöriger der Österreichischen Legion und trat nach dem „Anschluss“ der NSDAP bei. Er leitete 1939 den SA-Sturm in Seefeld. TLA, LG Innsbruck, 10 Vr 1194/46.

209 Vgl. Ergebnislisten der Wintersportkämpfe der Gliederungen der NSDAP in Rottach-Egern am 20./21.2.1937, Oberste SA-Führung, München, 26.2.1937, BArch NS 22/915.

210 Vgl. TLA, LG Innsbruck, 10 Vr 2863/47, Strafverfahren gegen Hellmut Lantschner, geb. am 11.10.1909 in Innsbruck-Igls und Antrag auf Nachsicht der Sühnefolgen nach dem Verbotsgesetz 1947 für Hellmut Lantschner, OeStA, AdR, PK 2Rep AR NS Buchstabe I-Q 14/5.968/1951. 
Kulturbauamt München beschäftigt, gute Kontakte zum späteren Gauleiter von Tirol und Vorarlberg Franz Hofer hatte und mit diesem in München verkehrte, dürfte die spätere Karriere des NS-Weltmeisters von 1939 gefördert haben. Im Sommer 1938 wurde Hellmut Lantschner nach seiner Rückkehr aus dem „Altreich" als Vereinsführer des Skiklubs Sölden eingesetzt und als Skiausbildner gelang es dem Weltmeister von 1939 sich immer wieder vom Frontdienst freizuspielen.

Mit dem Ende der „Tausend-Mark-Sperre“ im Juli 1936 wurden skisportliche Kontakte zwischen Österreich und NS-Deutschland wieder aufgenommen und intensiviert. Im Herbst 1936 nutzte das Reichsfachamt Skilauf unter der Leitung von Josef Maier die Gelegenheit, die Tiroler Skikameraden in Innsbruck zu besuchen. Der mit kolportierten 600 TeilnehmerInnen besetzte Sonderzug sei bei der Ankunft unter Jubel begrüßt worden. Der zweite Vorsitzende des Tiroler Skiverbandes Hans Lenz begrüßte die offizielle reichsdeutsche Skisport-Delegation aus München, die gemeinsam mit einer Tiroler Abordnung vor das Stadttheater zog, wo laut Bericht im Fachamt-Organ Ski-Sport das „Deutschlandlied“ erklang. ${ }^{211}$ Ein Jahr später, im September 1937, war Maier als offizieller Abgeordneter des DSV zur Vertreterversammlung des ÖSV nach Kitzbühel geladen worden. Bei dieser überbrachte er „die besten Wünsche des Reichssportführers von Tschammer und Osten" und betonte das Bestreben von Seiten der Reichssportführung nach einer engeren Zusammenarbeit. ${ }^{212}$

\subsection{Skisport im Schatten des ÖSV}

\subsubsection{Der katholische Skilauf}

Abseits des vom ÖSV organsierten Wintersportbetriebs gab es im Österreich der Zwischenkriegsjahre noch eine Reihe anderer Organisationen, die sich mehr oder weniger erfolgreich um die Verbreitung des Skisports bemühten. Abgesehen von den scheinbar unpolitischen bzw. politisch links positionierten Vereinen und den jüdischen, die sich ab 1923 im Allgemeinen Österreichischen Skiverband (AÖSV) organisierten, waren dies die Skiriegen der katholischen Sportvereine der Österreichischen Jugend Kraft (ÖJK) bzw. des Reichsbundes der katholisch-deutschen Jugend Österreichs. Ab Mitte der 1920er-Jahre nahm der Reichsbund den Skilauf in sein Turn- und Sportprogramm auf und propagierte diesen zunächst noch als „Schneeschuhlauf“. In den frühen 1930er-Jah-

211 Vgl. Ski-Sport, 2 (1936) 1, S. 6.

212 Vgl. Ski-Sport, 3 (1937) 1, S. 20. 
ren veranstaltete der Reichsbund seine ersten Skimeisterschaften, dazu gesellten sich eigene Diözesan-Meisterschaften. ${ }^{213} 1930$ eröffnete der Reichsbund eine eigene Skihütte in den Radstädter Tauern, eine weitere stand der katholischen Jugendorganisation in Dornbirn auf dem Bödele zur Verfügung. ${ }^{214}$ Exemplarisch werden hier einige Aktivitäten einzelner Skiriegen aus dem katholischen bzw. christlich-sozialen Umfeld erwähnt. Der Reichsbund-Landesverband Vorarlberg veranstaltete seit den späten 1920er-Jahren Skirennen auf dem Bödele. Im Februar 1930 fanden in unmittelbarer Umgebung zur Verbandshütte zum zweiten Mal nach 1929 die Skimeisterschaften des Landesverbandes der katholischen Jugendvereine auf dem Dornbirner Hausberg statt. ${ }^{215}$ In Salzburg organisierten die Christlich Deutschen Turner (CDT) regelmäßige Verbandswettläufe im Skifahren, unter anderem in Zell am See. An diesen nahmen ebenso sportlich aktive Mitglieder des katholischen Gesellenvereins (Kolpingvereins) aus der Landeshauptstadt teil. ${ }^{216}$ Darüber hinaus veranstaltete der Landes- und Diözesanverband Salzburg im Februar 1936 auf dem Gaisberg die österreichweite Skimeisterschaft des Reichsbundes der katholisch-deutschen Jugend. Diese wurde zugleich mit der Salzburger Verbandsmeisterschaft der ÖJK ausgetragen. An den Wettbewerben in der Stadt Salzburg sollten auch Jugendliche aus entlegeneren Gebirgsregionen teilnehmen. ${ }^{217}$ Mit dem „Anschluss“ 1938 und der Auflösung der katholischen Vereine endete das kurze skisportliche Kapitel der vorwiegend männlichen katholischen Skiläufer. In Salzburg wurde das Vereinsgebäude des Gesellenvereins nur wenige Stunden nach dem „Anschluss“ am 13. März 1938 von der SA besetzt und verwüstet. Die Gestapo untersagte daraufhin jegliche Vereinstätigkeit. ${ }^{218}$

213 Vgl. Gerhart Schultes, Der Reichsbund der katholischen deutschen Jugend Österreichs. Entstehung und Geschichte, Wien 1967, S. 194.

214 Vgl. Schultes, Der Reichsbund, S. 194.

215 Vgl. Vorarlberger Volksblatt, 24.1.1929, S. 8; Vorarlberger Volksblatt, 12.2.1930, S. 7.

216 Vgl. Handschriftliches Protokoll von Alois Oberhuemer zur Senior-Tagung am 14.1.1935, Kopie im Besitz des Verfassers. Alois Oberhuemer war Vorstandsmitglied des katholischen Gesellenvereins (Kolpingvereins) in Salzburg und leitete diesen als Senior von 1934 bis zur Auflösung durch die Nationalsozialisten im März 1938. Der gelernte Kaufmann wurde am 16. Mai 1910 in Zell am See geboren und engagierte sich nicht nur in der sportlichen Nachwuchsarbeit, sondern war auch aktiver Skiläufer im Gesellenverein. Oberhuemer wurde 1941 zur Luftwaffe eingezogen und war zunächst in Holland und dann an der Ostfront eingesetzt. Er gilt seit Jänner 1945 als vermisst.

217 Vgl. SLA, RehrlSp 1936/0050.

218 Vgl. Festschrift 100 Jahre Katholischer Gesellenverein Salzburg 1852-1952, Salzburg 1952, S. 1. 


\subsubsection{Die Arbeiterskisportbewegung}

Schon vier Jahre vor dem „Anschluss“ waren die Arbeiterskisportler von der austrofaschistischen Sportführung verboten und in die Illegalität gedrängt worden. Damit standen Mitte der 1930er-Jahre hunderte Arbeiter-Skisportler ohne Verein da, mussten sich neue suchen und fanden zum Teil in ÖSV-Vereinen eine neue Heimat. Bis zu diesem Zeitpunkt lieferte die österreichische Arbeiterbewegung wichtige Impulse im Skisport, die auch internationale Beachtung fanden. Im Gegensatz zum Arbeiterfußball ist der Arbeiterskisport in der Ersten Republik bisher noch gänzlich unerforscht. ${ }^{219}$ Es wäre demnach vermessen im Folgenden einen Anspruch auf Vollständigkeit erheben zu wollen. Dennoch möchte ich an dieser Stelle skizzenhaft auf einzelne Stationen im österreichischen Arbeiterskisport hinweisen, die diesen bis zum Verbot durch das austrofaschistische Regime 1934 prägten. Dadurch soll deutlich gemacht werden, dass es im organisierten Skilauf der 1920er- und 1930er-Jahre sehr wohl ein linkes, aus der Sozialdemokratie genährtes, Gegengewicht zum bürgerlich geprägten und deutschnational ausgerichteten ÖSV gab, welches aber schließlich durch die reaktionäre Politik des Austrofaschismus eliminiert wurde. Schon zuvor aber lief der Arbeiterskisport vor allem in Westösterreich Gefahr, sich selbst zu isolieren.

Grundlegend baute der Arbeitersport in der Ersten Republik eigene Strukturen auf und besaß auch im Skisport eine eigenständige Sportorganisation, die sich zwar als Alternative zum bürgerlichen Sport verstand, aber mit diesem nicht in sportliche Konkurrenz trat. ${ }^{220}$ Während Fußball, Radfahren, Schwimmen, Wandern und Turnen zu den am meisten betriebenen Sportarten in der Arbeiterschaft zählten, spielte das Skifahren zunächst eine Nebenrolle. Das lag auch daran, dass sich die meisten Arbeitersportvereine auf Industrieorte und -städte in Ostösterreich konzentrierten und der Arbeitersport in Westösterreich nur bedingt und kleinräumig Fuß fassen konnte.

In Innsbruck sind die ersten Initiativen, auf organisatorischer Ebene einen Arbeiterskisport zu etablieren, auf Dezember 1922 zurückzuführen. Der Arbeiter

219 Während mit der Studie von Matthias Marschik die Geschichte des Arbeiterfußballs in der Ersten Republik zumindest für den Großraum Wien und Niederösterreich aufgearbeitet ist, findet sich für den Arbeiterskisport keine vergleichbare Untersuchung. Auch die von Reinhard Krammer bereits 1981 erschienene Studie zum Arbeitersport geht nicht auf den Skisport in der Arbeiterbewegung ein, sondern konzentriert sich primär auf das Arbeiterturnen, den Arbeiterradsport, die Naturfreunde und den Arbeiterschwimmsport. Vgl. Marschik, „Wir spielen nicht zum Vergnügen“; Krammer, Arbeitersport.

220 Vgl. Gidl/Graf, Skisport, S. 41; John Bunzl, Hakoah Wien: Gedanken über eine Legende, in: Michael Brenner/Gideon Reuveni (Hg.), Emanzipation durch Muskelkraft. Juden und Sport in Europa, Göttingen 2006, S. 111-120, hier S. 113. 
Turnverein Innsbruck gründete zu dieser Zeit eine Skiabteilung und organisierte noch im Jänner 1923 einen ersten alpinen Langlauf. Adolf Putz, der aus diesem als Sieger hervorging, startete 1925 bei der ersten Winter-Olympiade der Arbeiter in Schreiberhau, wo er das Spezialspringen gewinnen konnte. Als der Arbeiterbund für Sport und Körperkultur in Österreich (ASKÖ) ein eigenes übergreifendes Vereins- und Wettkampfwesen organisierte und den Kontakt zum bürgerlichen Sport verweigerte, wechselte Putz zum bürgerlichen Skiklub Innsbruck. ${ }^{221}$ Putz war dabei kein Einzelfall. Noch 1931 präsentierte die Arbeiter-Zeitung unter anderem die Salzburger Skispringer Wilhelm Köstinger und Andreas Krallinger als sportliche Aushängeschilder des Arbeiterskisports. ${ }^{222}$ Beide kehrten kurz darauf der Sozialdemokratie den Rücken und wandten sich der nationalsozialistischen Bewegung zu. Allein diese Beispiele zeigen, wie schwach der Arbeiterskisport im Westen Österreichs war. Im Osten Österreichs konnte der Arbeiterskisport dagegen bis zum Schluss eine große Anhängerschaft mobilisieren. Noch im März 1933 veranstalteten die ArbeiterskifahrerInnen eine ihrer letzten großen Massenkundgebungen auf dem Schneeberg. ${ }^{223}$

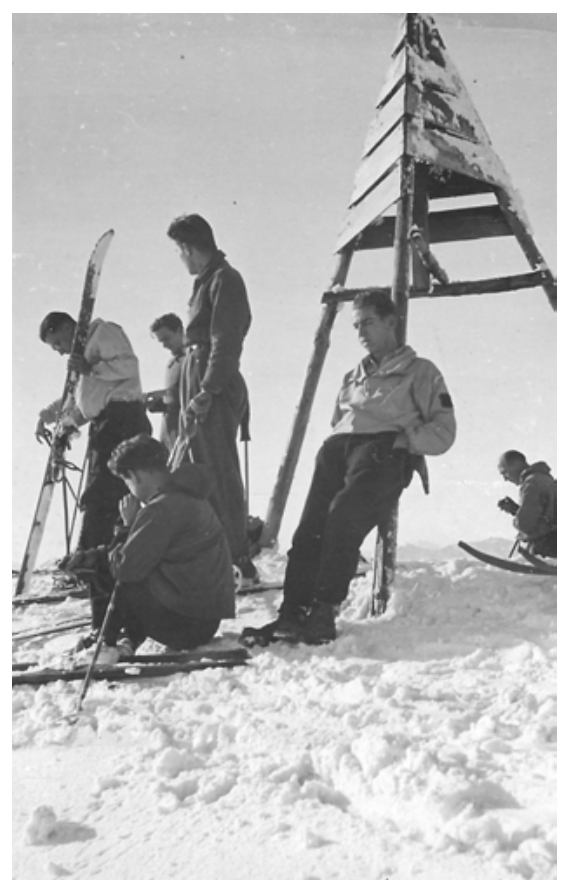

\begin{abstract}
Abb. 15: Skisport als Ausgleich und Flucht vor dem Dollfuß-Schuschnigg-Regime: Arbeitersportler aus Steyr bei einem Abfahrts- und Slalomlauf auf dem Kasberg im April 1937, Privatbesitz.
\end{abstract}

221 Vgl. Gidl/Graf, Skisport, S. 41.

222 Vgl. Arbeiter-Zeitung, 16.2.1931, S. 4.

223 Vgl. Arbeiter-Zeitung, 16.2.1931, S. 4; Arbeiter-Zeitung, 13.3.1933, S. 4. 
Doch auch abseits des Wiener Raums fand der Arbeiterskisport Verbreitung. Eine zentrale Rolle spielte dieser beispielsweise in der industriell geprägten oberösterreichischen Kleinstadt Steyr. Über die sozialdemokratischen Vorfeldorganisationen der Kinder- und Naturfreunde bildeten sich dort ab den 1920erJahren vielversprechende Strukturen heraus, die den proletarisch geprägten Skisport beförderten und SkiathletInnen auf Spitzenniveau hervorbrachten. Zu erwähnen ist hier der erfolgreiche Langläufer, Skispringer, Langstreckenläufer und Arbeiterturner Otto Pensl. Der 1895 in Linz geborene Pensl nahm regelmäßig an Skimeisterschaften des ASKÖ teil und startete 1931 als Skiläufer bei der Arbeiter-Olympiade in Mürzzuschlag. ${ }^{224}$ Wie andere Steyrer Arbeitersportler kämpfte er im Bürgerkrieg auf Seiten des Republikanischen Schutzbundes und engagierte sich ab 1934 und über 1938 hinaus im kommunistischen Widerstand. Als Gegner des Nationalsozialismus wurde Pensl Ende April 1945 im Konzentrationslager Mauthausen ermordet. ${ }^{225}$

\subsubsection{Der Arbeiterskisport aus Perspektive der Winterspiele in Mürzzuschlag}

Der proletarische Skisport fand, wie die Arbeitersportbewegung generell, seine größte Verbreitung in Ostösterreich. Punktuell gab es aber regionale Zentren des Arbeiterskisports in Westösterreich, die aufgrund einer anderen Wirtschaftsstruktur in den sonst bäuerlich-katholisch geprägten Gebieten hervorstachen. Belege hierfür liefert eine Zusammenstellung der skifahrenden TeilnehmerInnen der 2. Arbeiter-Olympiade in Mürzzuschlag 1931. Ein überwiegender Anteil der daran teilnehmenden österreichischen ArbeiterskisportlerInnen (72 Prozent) stammte aus Industrieregionen oder -städten der Bundesländer Steiermark, Oberösterreich und Niederösterreich und der Bundeshauptstadt Wien. Mit 31 StarterInnen stellte Wien die meisten SkiläuferInnen für die alpinen und nordischen Bewerbe, gefolgt von Linz mit zehn und Mürzzuschlag mit sieben. Die Stadt Innsbruck sowie die Eisenbahnergemeinde Saalfelden im Bundesland Salzburg bildeten aus westösterreichischer Sicht die Ausnahme. Beide Orte stellten ebenfalls sieben TeilnehmerInnen. Der Bahnknotenpunkt Bischofshofen und die steirische Landeshauptstadt Graz entsandten sechs, die Arbeitersportvereine in Steyr und am Semmering jeweils fünf TeilnehmerInnen. ${ }^{226}$

224 Vgl. u. a. Tagblatt, 12.2.1929, S. 10; Programm Wintersport-Olympiade Mürzzuschlag, Archiv Wintersportmuseum Mürzzuschlag.

225 Vgl. Digitales Gedenkbuch für die Toten des KZ Mauthausen und seiner Außenlager 19381945, Otto Pensl. https://raumdernamen.mauthausen-memorial.org/ (5.4.2021).

226 Vgl. Programm Wintersport-Olympiade Mürzzuschlag, Archiv Wintersportmuseum Mürzzuschlag, eigene Zusammenstellung der TeilnehmerInnen. 


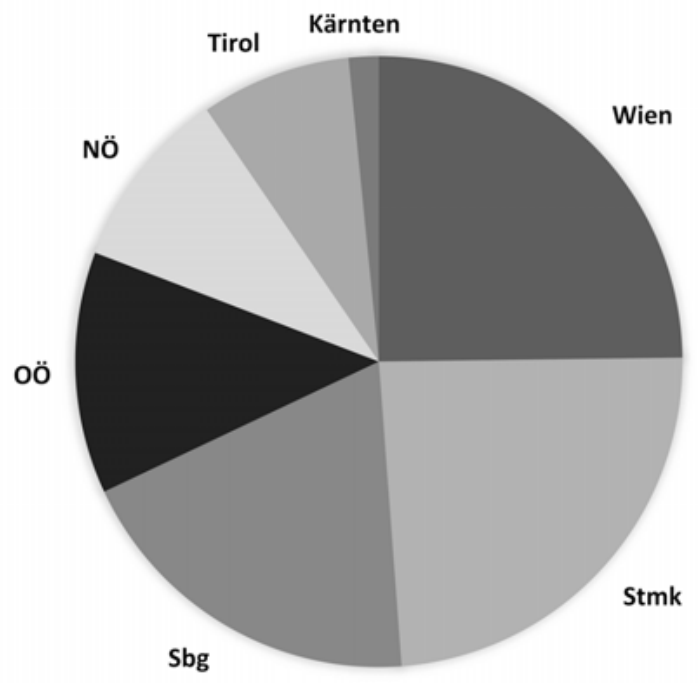

Grafik 3: Prozentueller Anteil der an den Winterspielen in Mürzzuschlag 1931 teilgenommenen 125 Arbeitersportlerlnnen nach Bundesländern.

Quelle: Programm Wintersport-Olympiade Mürzzuschlag, Archiv Wintersportmuseum Mürzzuschlag, eigene Zusammenstellung, $n=125$ (125=100\%).

Aus dem Bundesland Salzburg reisten im Februar 1931 insgesamt 24 ArbeiterskisportlerInnen zur Wintersport-Olympiade nach Mürzzuschlag. Nur Wien (31) und die Steiermark (30) entsandten mehr TeilnehmerInnen. Oberösterreich hatte mit 16 ArbeiterskisportlerInnen um acht weniger aufzuweisen als Salzburg (siehe Grafik). Nimmt man die Herkunftsorte der aus dem Bundesland Salzburg kommenden SkisportlerInnen genauer unter die Lupe, so decken sich diese mit jenen Orten, in denen die Sozialdemokratie nach Ende des Ersten Weltkriegs aufgrund der Beschäftigten bei der Eisenbahn ihre politischen Erfolge feiern konnte. So kamen die meisten ArbeiterskisportlerInnen, nämlich 18, aus den Bahnknotenpunkten Saalfelden, Bischofshofen und Gastein. ${ }^{227}$ Die Landes-

227 Vgl. Leo, Der Pinzgau, S. 62-64. Bischofshofen und Saalfelden zählten bis in die 1930erJahre zu den sozialdeokratischen Hochburgen im Bundesland Salzburg. In Bischofshofen erreichten die Sozialdemokraten bei den Nationalratswahlen 1930 knapp 56 Prozent und bei der Landtagswahl 1932 kamen sie auf die Hälfte der Stimmen. In Saalfelden war die Sozialdemokratie 1930 mit 46,95 Prozent und 1932 mit 43,15 Prozent die stimmenstärkste Fraktion. In Bad Gastein konnten die Sozialdemokraten bei der Nationalratswahl 1930 noch 27,34 Prozent der Stimmen gewinnen, bei der Landtagswahl waren es mit 22,80 Prozent schon deutlich weniger. Vgl. Krisch, Die Wahlerfolge, S. 228 und 256. 
hauptstadt Salzburg spielte mit nur drei TeilnehmerInnen zumindest in Mürzzuschlag eine untergeordnete Rolle. ${ }^{228}$

Abgesehen von der überaus regen Teilnahme österreichischer Arbeiter-SkiläuferInnen aus unterschiedlichen Regionen, insgesamt waren 97 Männer und 28 Frauen im Vorfeld gemeldet, ${ }^{229}$ waren die Arbeiter-Winterspiele vor allem ein internationaler Erfolg, an dem sich SportlerInnen aus sieben europäischen Ländern beteiligten. Nach Österreich entsandte Deutschland mit 36 WintersportlerInnen die meisten Athletinnen nach Mürzzuschlag, gefolgt von der Tschechoslowakei, Ungarn, Finnland, Lettland und der Schweiz. Während die Männer in den vier Disziplinen Langlauf, Torlauf, Abfahrt und Skisprung an den Start gingen, konnten die Frauen nur einen Langlauf absolvieren.

Die Sozialistische Arbeitersportinternationale (SASI) bildete für die Sommerspiele in Wien und die Winterspiele in Mürzzuschlag 13 Fest-Ausschüsse, die mit der Organisation betraut waren. Zum Hauptorganisator für Mürzzuschlag wurde der Wintersportreferent des ASKÖ Theodor Hüttenegger bestimmt. Er leitete auch den technischen Hauptausschuss der Bewerbe und war nach 1945 maßgeblich für den Aufbau des Wintersportmuseums in Mürzzuschlag verantwortlich und der erste Leiter des Museums. ${ }^{230}$

Im Folgenden soll näher auf die jüdischen Vereine und jene Skiklubs, die im AÖSV organisiert waren, eingegangen werden. Zunächst wird noch der Sonderfall des Skiclubs Arlberg beleuchtet, der 1924 ins deutsche Exil ging, um von diesem zehn Jahre später wieder zurückzukehren.

\subsubsection{Der Skiclub Arlberg und das Bestreben einer internationalen Vereinspolitik}

Nicht alle Skivereine waren mit der ausgrenzenden und antisemitischen Politik des ÖSV und seiner mehrheitlich männlichen Vertreter einverstanden. Jene, die 1923 aus dem ÖSV austraten, zogen nicht mit, weil sie nicht wollten oder nicht konnten. Den jüdischen Vereinen war mit der Einführung des „Arierparagra-

228 Vgl. Programm Wintersport-Olympiade Mürzzuschlag, Archiv Wintersportmuseum Mürzzuschlag, eigene Zusammenstellung der TeilnehmerInnen.

229 Hier sind nur die ArbeitersportlerInnen gerechnet, die im Skilauf in den verschiedenen Disziplinen an den Start gingen. Insgesamt nahmen aus Österreich bei den Arbeiter-Winterspielen in Mürzzuschlag 205 Frauen und Männer in allen Sportarten teil. Vgl. Programm Wintersport-Olympiade Mürzzuschlag, Archiv Wintersportmuseum Mürzzuschlag.

230 Vgl. Organisation der Ausschüsse für die 2. Arbeiter-Olympiade der Sozialistischen Arbeiter-Sport-Internationale, Archiv Wintersportmuseum Mürzzuschlag; E-Mail von Hannes Nothnagl, Leiter des Wintersportmuseums Mürzzuschlag, 22.7.2019. 
phen" die Mitgliedschaft im ÖSV sowie die Teilnahme an ÖSV-Wettbewerben verwehrt worden. ${ }^{231}$ Andere Skivereine traten für eine offene Geisteshaltung im Sport ein und lehnten daher diskriminierende Maßnahmen ab.

Widerstand gegen die antisemitische Politik innerhalb des ÖSV regte sich etwa am Arlberg. Der dortige Skiclub Arlberg (SCA) wollte aus Gründen der Internationalität und weil sich der Verein in seinen Prinzipien als „unpolitisch“ verstand nicht länger dem ÖSV angehören. Der SCA trat dem Allgäuer Skiverband als Unterverband des DSV bei. Laut Hannes Schneider geschah dies 1922, ${ }^{232}$ also ein Jahr vor der Einführung des „Arierparagraphen“ im ÖSV. Tatsächlich trat der SCA erst danach, im Jahr 1924, dem Allgäuer Skiverband und damit dem DSV bei. ${ }^{233}$ Gleichzeitig erklärte der SCA in seinen Statuten aus dem Jahr 1924, dass er keine „politische Tendenz“ verfolge. ${ }^{234}$ Schneider, der damals als aktiver Skiläufer im Ausschuss saß, begründete die Entscheidung 1934 in einem Brief an den DSV-Obmann Josef Maier folgendermaßen: „Für unseren Klub, der, wie allerwelts bekannt ist, aus Mitgliedern aller Nationen besteht, war es wohl selbstverständlich, daß wir einen unpolitischen Verband suchten und im DSV auch gefunden haben.“235 Der SCA beherbergte neben österreichischen und reichsdeutschen StaatsbürgerInnen Mitglieder unterschiedlicher Nationalitäten, die unter anderem in New York, London, Zürich, Paris, Prag oder Bukarest gemeldet waren. Nationalität, Herkunft und politische Gesinnung sollten für Aufnahme und Mitgliedschaft keine Rolle spielen. Aus den Aufnahmelisten in den Protokollbüchern geht hervor, dass der Zulauf von Mitgliedern aus unterschiedlichen europäischen Staaten und Milieus bis Mitte der 1930er-Jahre ungebrochen war. ${ }^{236}$ Damit unterschied sich der SCA von deutschnationalen Skivereinen, die den „deutschen Skilauf“ propagierten und laut Statuten nur „arische“ Mitglieder aufnahmen. Die internationale Beliebtheit des SCA ging so weit, dass im Frühjahr 1934 auf Vorschlag eines höherrangigen schwedischen Militärs und unter Zustimmung der Vereinsführung in St. Anton ein schwedischer Ableger des Skivereins gegründet wurde. ${ }^{237}$ Schon sechs Jahre zuvor hatte sich im nordamerikanischen Denver (Colorado) aufgrund der internationalen

231 Vgl. Praher, „Skifahren ist für uns“, S. 210.

232 Vgl. Brief von Hannes Schneider an Josef Maier, St. Anton, 2.5.1934, Sammlung Briefe, Sammlung Lechmuseum.

233 Vgl. Falkner, Der Arierparagraph, S. 20.

234 Vgl. Statuten des Skiklub Arlberg, TLA, Abt. I, XVI 78c, ex 1924, Zl. 1321.

235 Brief von Hannes Schneider an Josef Maier, St. Anton, 2.5.1934, Sammlung Briefe, Sammlung Lechmuseum. Schneider nennt in dem Brief das Jahr 1922 als Beitrittsjahr zum DSV. 236 Vgl. Neuaufnahmen laut Protokollbuch des SCA 1933-1955, Sammlung Lechmuseum. 237 Vgl. Ausschusssitzung des Skiclub Arlberg, 19.4.1934, Protokollbuch des SCA 1933-1955, Sammlung Lechmuseum. 
Ausstrahlung der Arlberg-Schule ein Skisportverein den Namen Arlberg Club gegeben. Die Namensgebung beruhte auf einem regen Austausch, der sich sowohl im sportlichen wie auch im alpenländischen Stil der Ressorts niederschlug. ${ }^{238}$ Der SCA sowie andere europäische Skivereine und ihre BotschafterInnen begründeten damit indirekt eine globale, transnationale Skikultur.

Die liberale Vereinspolitik erklärte sich durch die soziale Herkunft der Mitglieder und war rational dadurch begründet, dass der SCA seine Erfolge und seinen Einfluss im mitteleuropäischen Skisport den internationalen Kontakten verdankte. Nicht wenige Mitglieder des SCA entstammten dem europäischen Adel oder kamen aus dem Großbürgertum. ${ }^{239}$ Diese mit einer antisemitischen Vereinspolitik vor den Kopf zu stoßen, wäre für den Klub fatal gewesen. Abgesehen davon war einer der größten Förderer des Arlberger Skisports und Ehrenobmann des SCA, Rudolf Gomperz, jüdischer Abstammung. Sportlich profitierte der SCA durchaus vom Verbandswechsel zum DSV. So übertrug der DSV die Durchführung der Deutschen Skimeisterschaft im März 1926 an den SCA. Die Wettbewerbe, für die 93 TeilnehmerInnen gemeldet waren, fanden in St. Anton und nicht wie geplant in Garmisch-Partenkirchen statt. Diese Nachricht überraschte selbst den Allgäuer Skiverband. ${ }^{240}$ Für das Vereinsjahr 1928/29 vermeldete der SCA einen Mitgliederzuwachs von über 100 Personen, wobei über die Hälfte auf das Konto des DSV gingen. ${ }^{241}$ Gomperz selbst, der fortan sein Knowhow in den Dienst des DSV stellte und als Hauptausschussmitglied des DSV die Organisation der Deutschen Skimeisterschaften leitete, ${ }^{242}$ übersiedelte nach München. Er beschrieb das Klima im DSV als unparteiisch und genoss noch bis Anfang der 1930er-Jahre hohes Ansehen in deutschen Skikreisen. 1931 erhielt er die Goldene Ehrennadel des DSV und war bis dahin Vorsitzender des Skifachausschusses. ${ }^{243}$ Hannes Schneider gelang es indes, an der neuen Fassung des amtlichen Lehrplans des DSV mitzuwirken und in diesem die Arlberg-Schule zu verankern. ${ }^{244} \mathrm{Ab} 1933$ sollte sich dieses Blatt zum Negativen wenden.

238 Vgl. Dettling/Schoder/Tschofen, Spuren, S. 23.

239 Vgl. Neuaufnahmen laut Protokollbuch des SCA 1933-1955, Sammlung Lechmuseum.

240 Vgl. Innsbrucker Nachrichten, 13.3.1926, S. 6; Graf, Tiroler Sportgeschichte, S. 27.

241 Vgl. Jahresbericht des Ski-Clubs Arlberg über das Clubjahr 1928/29, St. Anton 1929, S. 5., Sammlung Lechmuseum.

242 Vgl. Jahresbericht des Ski-Clubs Arlberg über das Clubjahr 1928/29, St. Anton 1929, S. 6., Sammlung Lechmuseum.

243 Vgl. Falkner, Der Arierparagraph, S. 23.

244 Vgl. Jahresbericht des Ski-Clubs Arlberg über das Clubjahr 1928/29, St. Anton 1929, S. 6., Sammlung Lechmuseum. 


\subsubsection{Der SCA im Fahrwasser der nationalsozialistischen Sportpolitik}

Gegen Mitte der 1930er-Jahre wurde es auch für den SCA vereinspolitisch eng, da sich die politischen Kräfteverhältnisse in Deutschland zugunsten der Nationalsozialisten änderten und in Österreich die austrofaschistische Sportpolitik die Regeln verschärfte. Die ersten Unstimmigkeiten zwischen dem SCA und dem DSV tauchten mit der nationalsozialistischen Machtübernahme in Deutschland 1933 auf. Es ging um die Frage, unter welchen Umständen der SCA im DSV verbleiben konnte, nachdem der DSV-Hauptvorstand im Frühjahr 1933 beschlossen hatte, dass eine Neuaufnahme von „Rassefremden“ in den Unterverbänden zu unterbleiben hätte und diese von den Vorständen grundsätzlich ausgeschlossen seien. ${ }^{245} \mathrm{Um}$ eine weitere Mitgliedschaft des SCA im DSV zu garantieren, wurde im November 1933 eine eigene Gruppe reichsdeutscher SkiläuferInnen im SCA gegründet, die über den Allgäuer Skiverband beim DSV gemeldet werden sollte. ${ }^{246}$ Der SCA konnte vorerst im DSV verbleiben, wurde aber im Frühjahr 1934 aus Gründen der Unvereinbarkeit mit der reichsdeutschen Sportpolitik gedrängt, aus dem DSV auszutreten. Das unfreiwillige Ausscheiden aus dem DSV wurde in der Ausschusssitzung am 16. Mai 1934 zur Kenntnis genommen. ${ }^{247}$

\subsubsection{Die Rückkehr zum ÖSV}

Sechs Monate später trat der SCA dem Tiroler Skiverband und dem ÖSV bei. Die versammelten Vorstandsmitglieder erklärten sich am 24. November 1934 mit dem Beitritt einverstanden. Gleichzeitig bekräftigte der SCA seine unpolitische Haltung. Kein Mitglied sollte „wegen seiner politischen Einstellung aus dem Klub entfernt werden“, gab Schriftführer Walter Schuler zu Protokoll. Jeder könne seine politische Einstellung haben, „die ihm beliebt“. ${ }^{248}$ Der Wechsel zum ÖSV erfolgte einerseits als Folge des Ausscheidens aus dem DSV, andererseits aufgrund der austrofaschistischen Sportpolitik, die es einem österreichischen Sportverein nicht erlaubte einem Verband im nationalsozialistischen Deutsch-

245 Vgl. Der Winter, 26 (1933) 14, S. 543; Gerd Falkner, 100 Jahre Deutscher Skiverband. Chronik des deutschen Skilaufs von den Anfängen bis zur Gegenwart (Band 1), Planegg 2005, S. 118. 246 Vgl. Ausschusssitzung des Skiclub Arlberg, 14.11.1933, Protokollbuch des SCA 1933-1955, Sammlung Lechmuseum.

247 Vgl. Ausschusssitzung des Skiclub Arlberg, 16.5.1934, Protokollbuch des SCA 1933-1955, Sammlung Lechmuseum.

248 Vollversammlung des Skiclub Arlberg, 24.11.1934, Protokollbuch des SCA 1933-1955, Sammlung Lechmuseum. 
land anzugehören. ${ }^{249}$ Warum der AÖSV - siehe nächstes Kapitel - für den SCA keine Option war, geht aus den Protokollen nicht hervor. Vermutlich dürfte aber die sportliche Perspektive dafür ausschlaggebend gewesen sein, warum sich der SCA dem ÖSV anschloss. Zum Zeitpunkt des Verbandswechsels hatte der Skiclub Arlberg immerhin 600 Mitglieder zu betreuen. Der Beitritt zum ÖSV blieb politisch nicht ohne Folgen und so musste der SCA nach einem Jahrzehnt der Verweigerung schließlich doch noch den „Arierparagraph“ in seine Satzungen aufnehmen und durfte demnach keine neuen Mitglieder jüdischer Herkunft aufnehmen. Die Vereinsführung fand allerdings ein juristisches Schlupfloch, wie „nichtarische“ Mitglieder weiterhin im Verein verbleiben konnten. Sie sollten durch den so genannten „Aussterbeparagraphen“ unter Schutz gestellt werden. ${ }^{250}$ Damit konnten jene jüdischen SkiläuferInnen, die vor Jahresende 1934 in den Skiclub Arlberg aufgenommen worden waren, weiterhin für den Verein aktiv sein, obwohl dieser offiziell den Statuten des ÖSV unterstand.

\subsubsection{Die Gründung des Allgemeinen Österreichischen Skiverbandes (AÖSV)}

Als Reaktion auf die Einführung des „Arierparagraphen“ gründete sich der Allgemeine Österreichische Skiverband (AÖSV). $\mathrm{Zu}$ den Gründungsmitgliedern zählten unter anderem die Wintersportsektion der Hakoah und die Skilaufsektion des Österreichischen Touringclubs (ÖTC) Wien. „Die im Jahre 1923 vom Oesterreichischen Skiverband vorgenommene Satzungsänderung veranlaßte die Sektion, aus demselben auszutreten und an der Gründung des Allgemeinen Oesterreichischen Skiverbandes teilzunehmen [...]“, schrieb der ÖTC in einem Rückblick auf 25 Jahre Skilaufsektion in seinen Klubnachrichten im November $1935 .{ }^{251}$ Gegründet hatten den AÖSV der Wiener Rechtsanwalt Gustav Klein-

249 Die Sport- und Turnfront verlangte staatstreues Verhalten. Das zeigte sich mitunter besonders in Auseinandersetzungen mit dem Nationalsozialismus. Vgl. Tálos, Das austrofaschistische Herrschaftssystem, S. 417-418.

250 Vgl. Ausschusssitzung des Skiclub Arlberg, 27.12.1934, Protokollbuch des SCA 1933-1955, Sammlung Lechmuseum.

251 Nachrichten der Skilauf- und Bergsportsektion des Österreichischen Touring-Clubs Wien, 1 (1935) 1, S. 2. Die Skilaufsektion des ÖTC wurde 1910 gegründet und zählte von Beginn an prominente Mitglieder wie den norwegischen Polarforscher Roald Amundsen oder den Skipionier Georg Bilgeri als Ehrenobmann. Sie war vor dem Ersten Weltkrieg maßgeblich an der Gründung des Freiwilligen Skifahrer-Korps beteiligt und wurde im Ersten Weltkrieg vom k. u. k. Kriegsministerium beauftragt, eine Skitruppe der osmanischen Armee aufzubauen. Rudolf Weishäupl war in den 1930er-Jahre Langzeitobmann der Skilaufsektion, die 1934 mit der Bergsportsektion zusammengelegt wurde und damit einen Mitgliederstand von über 1500 Personen erreichen sollte. 
Doppler und der Wiener Mediziner Alexander Hartwich. Für die Mitgliedschaft im AÖSV sollten keinerlei Einschränkungen gelten: „Bei der Aufnahme eines Vereins oder einer Vereinssektion hat ausser [sic] Betracht zu bleiben [...] welcher Abstammung, Volkszugehörigkeit, Religion und Berufsklasse ihre Mitglieder angehören. Der Verein hat keine wie immer geartete politische Tendenz", ${ }^{252}$ hieß es in den Gründungsstatuten vom Oktober 1923. Der AÖSV wurde am 9. November desselben Jahres behördlich genehmigt. Dem neuen Verband traten neben den Skisektionen der Hakoah und des ÖTC der Österreichische Skiverein, die Wintersportsektion des W. A.C., die Skisektion des Wiener Amateur-Sportvereines, die Skivereinigung der Sektion Donauland, der Wintersportverein Payerbach und der Kritzendorfer Sportklub bei.

\subsubsection{Der Kompromiss}

Verwirrung stiftete im November 1927 der Österreichische Skiverein, als dieser ausgerechnet unter der Präsidentschaft von Gustav Klein-Doppler, dem Mitbegründer des AÖSV, den „Arierparagraphen“ mit einer Zwei-Drittel-Mehrheit annahm. Als Argument wurden die bevorstehenden Olympischen Winterspiele 1928 in St. Moritz ins Feld geführt und die mögliche Entsendung von Skiläufern. Im Grunde hatte der Österreichische Skiverein Angst, SportlerInnen an Mitgliedsvereine des ÖSV zu verlieren, und gab dem Druck antisemitischer Sportkreise nach. Ein Teil der Ausschussmitglieder legte daraufhin ihr Mandat nieder. ${ }^{253}$ Klein-Doppler trat in der Folge zurück. Der Österreichische Skiverein blieb weiterhin Mitglied im AÖSV und dieser betonte einmal mehr seine unpolitische Haltung und präsentierte sich nach außen als Verband in dem alle österreichischen StaatsbürgerInnen gleich ihrer Nationalität, Konfession oder Ideologie willkommen seien. ${ }^{254}$

\subsubsection{Ungleicher Wettbewerb}

Der AÖSV fristete bis zu seiner Auflösung im Juli 1939 durch die Nationalsozialisten in sportlicher Hinsicht ein Schattendasein und konnte dem zahlenmäßig größeren und finanzkräftigeren ÖSV wenig entgegensetzen. ${ }^{255}$ Laut eigenen Angaben waren dem ÖSV im Jahr 1937 rund 360 Skivereine angeschlossen, ${ }^{256} \mathrm{im}$

252 Vereinsakt Allgemeiner Österreichischer Skiverband, WStLA, M. Abt. 119, A 32 - Gelöschte Vereine: $11637 / 1923$ - 11637/1923.

253 Vgl. Sport-Tagblatt, 19.11.1927, S. 9.

254 Vgl. Hachleitner, Arierparagrafen, S. 34.

255 Vereinsakt Allgemeiner Österreichischer Skiverband, WStLA, M. Abt. 119, A 32 - Gelöschte Vereine: 11637/1923 - 11637/1923.

256 Vgl. Mauler, Zweck und Ziele, S. 161. 
AÖSV war es dagegen nicht einmal ein Zehntel davon. Der ÖSV-Vorsitzende Gsur kommentierte dies in seinem Konzept zur Geschichte des Skilaufes folgendermaßen: „Der AÖSV bemühte sich eifrigst, bei allen sportlichen und politischen Behörden sich als den für Österreich allein maßgebenden Skiverband durchzusetzen, was ihm jedoch nicht gelang.“257

Der Konkurrenz zum Trotz stellte der AÖSV sein eigenes Wettbewerbsprogramm auf die Beine. Dieses fand ebenso mediale Beachtung in der überregionalen Sportpresse, wenn auch in kleinerem Umfang. Ebenso wie der ÖSV veranstaltete der AÖSV Österreichische Skimeisterschaften. Diese waren offen für alle österreichischen StaatsbürgerInnen. ${ }^{258}$ Im November 1925 gelang es dem AÖSV als einzige allgemein offene Konkurrenz eine „Damenmeisterschaft“ auszuschreiben. Diese wurde für Februar 1926 angesetzt. Das restliche Wintersportprogramm blieb überschaubar. Als interne Verbandswettbewerbe sollten noch ein Langlauf, ein Sprunglauf und ein Geländelauf stattfinden. ${ }^{259}$ Dieses im Vergleich zum ÖSV dürftige Wettbewerbsgeschehen sollte sich auch bis Ende der 1930er-Jahre nicht wesentlich verändern. Trotzdem konnte der AÖSV regelmäßig Meisterschaftsbewerbe abhalten. Das Sport-Tagblatt berichtete am 26. Februar 1937 von den Meisterschaften des Allgemeinen Österreichischen Skiverbandes. Als teilnehmende Vereine finden sich in der Berichterstattung die aus dem Deutschen und Österreichischen Alpenverein ausgeschiedene Sektion Donauland, der ÖTC, die Hakoah und der W. A. C. Die Meisterschaften fanden am 20. und 21. Februar 1937 in Kirchberg in Tirol statt. Neben einem Slalom- und einem Abfahrtslauf wurde eine Kombination aus Slalom, Abfahrt und Langlauf ausgetragen. Peter Benedikt vom Alpenverein Donauland holte in der Allgemeinen Klasse die Tagesbestzeit vor Anton Bergson vom ÖTC und Albert Schapira von der Hakoah. Benedikt kürte sich ebenso zum Verbandsmeister in der Kombination. Verbandsmeisterin bei den Frauen wurde Trude Hasterlik vom ÖTC vor der jüdischen Skirennläuferin Trude Raubitschek von der Hakoah. Der bereits erwähnte Arzt Alexander Hartwich, der den AÖSV 1923 mitbegründete, leitete die Bewerbe als Kampfrichter. ${ }^{260}$ Hartwich stand dem AÖSV in den 1930erJahren als Präsident vor, während der Obmann der Skilauf- und Bergsportsektion des ÖTC Rudolf Weishäupl als Sportreferent die sportliche Leitung im AÖSV über hatte. ${ }^{261}$ Beide waren Anfang 1930 als Vizeobmänner in der Skilauf-

257 Gsur, Konzept zur Geschichte des Skilaufes, 43.

258 Falkner, Der Arierparagraph, S. 20.

259 Vgl. Sport-Tagblatt, 18.11.1925, S. 5.

260 Vgl. Sport-Tagblatt, 26.2.1937, S. 5.

261 Vgl. Sport-Tagblatt, 14.11.1933, S. 5. 
sektion des ÖTC aktiv. Weishäupl übernahm später die Leitung der Sektion im ÖTC als Langzeitobmann.

Der AÖSV beschränkte sich aber nicht nur auf den Wettbewerbsbetrieb, sondern veranstaltete auch regelmäßige Verbandsskikurse, die ebenfalls in Kirchberg in Tirol durch staatlich geprüfte Skilehrer abgehalten wurden. Der Ort bei Kitzbühel wurde als ideales Standquartier beworben, mit der Eisenbahnhaltestelle in der Nähe, dem Auto erreichbar und dem Anschluss an die Hahnenkamm-Seilbahn. „Kitzbühel gehört allen, Kirchberg gehört uns“, ${ }^{262}$ lautete die unmissverständliche Botschaft an die eigenen Mitglieder und den Mitbewerber ÖSV in den offiziellen Nachrichten des ÖTC. Im Leistungssportbereich bot der AÖSV in den 1930er-Jahren eigene Kurse für Wettläufer an. Die sportliche Leitung der Kurse übernahmen die beiden Kitzbüheler Abfahrtsläufer Fritz Huber und Hans Lackner. Jene Skisportler, die sich bei den Trainingskursen empfehlen konnten, waren für das internationale Arlberg-Kandahar-Rennen zugelassen. ${ }^{263}$ Ob diese Kurse auch für Frauen offen waren, ist aus den Quellen nicht ersichtlich.

\subsubsection{Skilauf jüdischer SportlerInnen in der Touristik- und Wintersportsektion}

Ein starkes Lebenszeichen in der Zwischenkriegszeit ging von der Hakoah Wien aus, die schon ab 1909 eine Wintersportsektion betrieb ${ }^{264}$ und diese in den 1920er-Jahren als Touristik- und Wintersportsektion weiterführte. Diese gab regelmäßig bis 1935 eine eigene Zeitschrift heraus, die auf skisportliche Termine und Veranstaltungen hinwies und über Aktivitäten der Sektion berichtete. Die Wintersportsektion, die sich 1923 dem AÖSV anschloss, ${ }^{265}$ sollte „binnen kurzem ein paar hundert Mitglieder“ zählen. ${ }^{266}$ Der langjährige Hakoah-Funktionär Arthur Baar schreibt, dass er selbst kurze Zeit Vorsitzender dieser Sektion gewesen sei. Baar habe bei Hannes Schneider das Skifahren und Unterrichten erlernt

262 Nachrichten der Skilauf- und Bergsportsektion des Österreichischen Touring-Clubs Wien, 1 (1935) 2, S. 3.

263 Vgl. Nachrichten der Skilauf- und Bergsportsektion des Österreichischen Touring-Clubs Wien, 2 (1936) 3, S. 6.

264 Vgl. Neues Wiener Tagblatt, 19.12.1909, S. 44.

265 John Bunzl schreibt, dass der ÖSV 1926 den „Arierparagraphen“ beschlossen hätte, „was zum Austritt jener führte, die sich dagegen aussprachen“. Tatsächlich beschloss der ÖSV den „Arierparagraphen“ 1923 und die Loslösung vom ÖSV ereignete sich schon drei Jahre zuvor, im Jahr 1923. Vgl Bunzl, Hakoah Wien, S. 113.

266 Arthur Baar, 50 Jahre Hakoah 1909-1959, Tel Aviv 1959, S. 254. 
und sei deswegen ein beliebter Skilehrer gewesen. ${ }^{267}$ Tatsächlich veranstaltete die Touristik- und Wintersportsektion der Hakoah ab den frühen 1920er-Jahren gemeinsame Skitouren mit Hannes Schneider in den Tiroler Alpen. Schneider führte beispielsweise eine Gruppe von Hakoah-Skiläufern im April 1923 auf den Peischlkopf am Arlberg. ${ }^{268}$ Neben Skitouren in den Ostalpen und Erstbegehungen im Eis veranstaltete die Touristik- und Wintersportsektion regelmäßig Skikurse für Anfänger und Fortgeschrittene in Mariazell sowie in Mürzzuschlag. Allerdings beschränkten sich die von der Sektion organisierten Skitouren nicht nur auf Ostösterreich, sondern führten die Hakoah-Mitglieder westlich bis in das Hochkönigmassiv ${ }^{269}$ oder wie erwähnt in das Arlberg-Gebiet. Außerdem wurde 1925 ein Hüttenfonds eingerichtet. ${ }^{270}$ Dieser Fonds sollte dazu verwendet werden, um die Finanzierung einer vereinseigenen Schutz- und Skihütte zu ermöglichen. Die Sektion verfügte zwar ab Oktober 1923 über eigene Klubräumlichkeiten im 8. Wiener Gemeindebezirk am Bennoplatz, hatte aber keinerlei Unterbringungs- und Übernachtungsmöglichkeiten in den Bergen. ${ }^{271}$ In skisportlicher Hinsicht beteiligten sich die Hakoah-SkiläuferInnen in der Regel an den Wettbewerben des AÖSV, sofern nicht eigene Vereinsrennen ausgetragen wurden. ${ }^{272}$ „Die Sektion hat durch den Beitritt zum Allgemeinen österreichischen Skiverband auch nach außenhin Anschluß gefunden“, ${ }^{273}$ hieß es in einem Bericht über die Jahresvollversammlung im Februar 1924. Dieser Anschluss an einen Dachverband bedeutete für die Mitglieder neben dem individuellen, finanziellen Vorteil einer Fahrpreisermäßigung, die Möglichkeit an Verbandsrennen teilzunehmen und sich mit anderen AthletInnen außerhalb der Hakoah zu messen. Darüber hinaus steigerte die Mitgliedschaft im AÖSV die öffentliche Wahrnehmung und den allgemeinen Bekanntheitsgrad der Hakoah-SkiläuferInnen. Dessen war sich die Sektionsleitung durchaus bewusst: „Abgesehen davon, daß tüchtige Fahrer ihre Kraft und Geschicklichkeit mit anderen messen wollen, steckt in dieser Tätigkeit ein großer propagandistischer Wert, der nicht

267 Vgl.Baar, Hakoah, S. 254.

268 Vgl. Touristik- und Wintersport im Sportklub Hakoah, 1 (1923) 2, S. 1-2.

269 Vgl. Skitouren-Programm, in: Touristik- und Wintersport im Sportklub Hakoah, 1 (1924) 3, S. 5.

270 Vgl. Touristik- und Wintersport im Sportklub Hakoah, 2 (1925) 14, S. 1-3.

271 Vgl. Touristik- und Wintersport im Sportklub Hakoah, 1 (1923) 2, S. 1.

272 Vgl. Touristik- und Wintersport im Sportklub Hakoah, 1 (1924) 3, S. 1. Das Lexikon jüdischer Sportler schreibt, dass die Hakoah bei Wettbewerben des ÖSV teilgenommen hätte, was nicht sein kann, da jüdische SportlerInnen aus dem ÖSV laut „Arierparagraphen“ ausgeschlossen waren und die Hakoah seit 1923 dem AÖSV angehörte. Vgl. Ignaz Hermann Körner, Lexikon jüdischer Sportler in Wien 1900-1938, hrsg. und editiert von Marcus G. Patka im Auftrag des Jüdischen Museums der Stadt Wien, Wien 2008, S. 212.

273 Touristik- und Wintersport im Sportklub Hakoah, 1 (1924) 3, S. 1. 
ungenützt bleiben darf.“274 Laut dem abgedruckten Bericht zur Vollversammlung hatte sich die Mitgliederzahl bis 1924 mit 252 Personen mehr als verdoppelt. Neben den skisportlichen Aktivitäten, die einen regen Zulauf erlebten, förderte die Touristik- und Wintersportsektion das jüdische Kultur- und Gesellschaftsleben mittels Vorträgen über Palästina oder das „Naturempfinden bei den Juden“. Das zionistische Selbstverständnis kam aber auch in einer internen Gedenkfeier zum Todestag von Theodor Herzl zum Ausdruck. Darüber hinaus sollte bei diesen Anlässen für den Jüdischen Nationalfonds geworben werden. ${ }^{275}$ Die Touristik- und Wintersportsektion hatte sich also ebenso wie der Stammverein Hakoah der zionistischen Idee verschrieben und unterstützte diese im Rahmen gesellschaftlicher Aktivitäten. ${ }^{276}$

Die Entwicklungen im ÖSV wurden von der Hakoah sehr wohl aufmerksam verfolgt und thematisiert. So berichtete die Zeitschrift der Touristik- und Wintersportsektion im Februar 1924 von der Einführung des „Arierparagraphen“ im ÖSV und den daraus resultierenden Diskussionen um die Teilnahme bei internationalen Wettbewerben. ${ }^{277}$ Im Dezember 1924 wies die Zeitschrift auf die Zerwürfnisse hin, die der „Arierparagraph“ verursacht habe, indem der ÖSV dem AÖSV die Teilnahme bei Verbandsmeisterschaften verweigerte und umgekehrt die Sportveranstaltungen des AÖSV nicht beschickte. ${ }^{278}$ In einer weiteren Ausgabe nahm die Zeitschrift nochmals Stellung zu dem Vorwurf, nur ein Gegenstück zu den „arischen“ Vereinen zu sein, weil die Hakoah nur Juden als Mitglieder aufnehme. Der Bericht, der als Reaktion auf den Ausschluss der Sektion Donauland aus dem Deutschen und Österreichischen Alpenverein erschien, wollte deutlich machen, dass der Zusammenschluss jüdischer Mitglieder im Verein dem Ziel dient: ,unserem Volk [dem jüdischen, Anm.] den Weg körperlicher Ertüchtigung zu zeigen, nicht aber - und das ist der Unterschied gegenüber den hakenkreuzlerischen Vereinigungen - uns gegen Andersnationale ab-

274 Touristik- und Wintersport im Sportklub Hakoah, 1 (1924) 3, S. 1.

275 Vgl. Touristik- und Wintersport im Sportklub Hakoah, 1 (1924) 3, S. 1-2.

276 Susanne Helene Betz verweist darauf, dass die Hakoah „ein streng zionistisches Projekt“ war. In diesem Sinne verfolgte und unterstützte der jüdische Sportklub die national-jüdischen Bestrebungen mit dem Ziel einer Staatsgründung in Palästina und untermauerte dies mit dem Konzept des „Muskeljudentums“, das von Max Nordau entworfen wurde und beim 2. Internationalen Zionistenkongress 1898 in Basel vorgestellt wurde. Dieses Verständnis eines starken, körperlich fitten und selbstbestimmten Judenmtums als Reaktion auf den Antisemitismus wurde in die Hakoah hineingetragen. Vgl. Susanne Helene Betz, 1909-2019: 110 Jahre Hakoah Wien. Zur Frage des Zionismus, in: Siegfried Göllner/Andreas Praher/Robert Schwarzbauer/ Minas Dimitriou (Hg.), Zwischenräume. Macht, Ausgrenzung und Inklusion im Fußball. Beiträge zur 2. Salzburger Fußballtagung, Göttingen 2019, S. 25-39, hier S. 27 und 30.

277 Vgl. Touristik- und Wintersport im Sportklub Hakoah, 1 (1924) 3, S. 4.

278 Vgl. Touristik- und Wintersport im Sportklub Hakoah, 1 (1924) 8, S. 2. 
zuschließen und den Versuch $\mathrm{zu}$ machen, deren Bewegungsfreiheit $\mathrm{zu}$ hindern. “279 Ebenso stellte die Hakoah in dem Artikel ihre friedliche Absicht klar und dass sie um einen fairen Wettbewerb bemüht ist. Gleichzeitig appellierte sie an die Vernunft ihrer Gegnerschaft. „Wir wollen keinen Kampf - wohin nationale Feindschaft führt, haben fünf Jahre Krieg jeden denkenden Menschen gezeigt. “280

\subsubsection{Fokus auf den Skisport}

Die Vollversammlung der Touristik- und Wintersportsektion im Jänner 1927 zog einige Änderungen nach sich und der Fokus der Sektion verlagerte sich aufgrund der steigenden Mitgliederzahlen in diesem Bereich auf den Skisport. ${ }^{281}$ Das lässt sich auch von der neuen Namensgebung der Sektion ableiten, denn bei der Neubildung wurde das Wort „Wintersportsektion“ aus dem Vereinsnamen gestrichen und stattdessen das Wort „Ski-Klub“ eingeführt. Treibende Kraft dahinter war Hugo J. Kohn, der im April 1927 um die Genehmigung des Touristik- und Ski-Klubs Hakoah beim Vereinsbüro der Wiener Landesregierung ansuchte. ${ }^{282}$ Kohn, der seit der Wiedergründung 1923 die Sektion leitete, ${ }^{283}$ wurde als deren Obmann bestätigt und Richard Gänsler zu seinem Stellvertreter gewählt. Gänsler saß zudem gemeinsam mit Kohn im Hüttenausschuss der Sektion. ${ }^{284}$ Als Wintersportreferent leitete Gänsler ebenso die Skikurse der Touristikund Wintersportsektion. ${ }^{285}$ Als Vereinszweck wurde bei der Neubildung angegeben: „Der Klub bezweckt die Förderung und Verbreitung der Touristik und des Wintersportes unter den Juden.“286 Mitglied konnte jeder „,volksbewusste Jude (Jüdin) [sic]“ ${ }^{287}$ werden, der oder die das 16. Lebensjahr erreicht hatte. Der neu aufgestellte Touristik- und Ski-Klub strebte keinen professionellen Sportbetrieb an, sondern legte in seinen Statuten von Beginn an fest, dass er auf dem „Amateurstandpunkt“ stehe. Dennoch stand der Verein dem Wettbewerbsgedanken

279 Touristik- und Wintersport im Sportklub Hakoah, 1 (1924) 6, S. 1.

280 Touristik- und Wintersport im Sportklub Hakoah, 1 (1924) 6, S. 1.

281 Vgl. Touristik und Wintersport im Sportklub Hakoah, 4 (1927) 22, S. 1.

282 Vgl. Neubildung Touristik u. Ski-Klub Hakoah, WStLA, M.Abt. 119, A32 - Gelöschte Vereine: 10673/1927 - 10673/1927.

283 Vgl. Bericht über die Jahresvollversammlung vom 25. Jänner 1924. Touristik- und Wintersport im Sportklub Hakoah, 1 (1924) 3, S. 1.

284 Vgl. Wiener Morgenzeitung, 9.6.1927, S. 10.

285 Touristik und Wintersport im Sportklub Hakoah, 4 (1927) 22, S. 1.

286 Neubildung Touristik u. Ski-Klub Hakoah, WStLA, M.Abt. 119, A32 - Gelöschte Vereine: 10673/1927 - 10673/1927.

287 Neubildung Touristik u. Ski-Klub Hakoah, WStLA, M.Abt. 119, A32 - Gelöschte Vereine: 10673/1927 - 10673/1927. 
im Individualfall nicht negativ gegenüber: „Die Erzielung von Höchstleistungen sind dem Klub nur insoweit erwünscht, als sie der Ertüchtigung der einzelnen Mitglieder von Nutzen sein können.“288 Die sportlichen Aktivitäten sollten sich auf Skikurse, Skitouren, Vorträge und den Bau sowie die zukünftige Bewirtschaftung von Hütten konzentrieren. Die Bildung des Touristik- und Ski-Klubs Hakoah wurde am 5. Mai 1927 behördlich genehmigt. Die Namensänderung in Touristik- und Ski-Klub Hakoah sorgte zwar kurzfristig für Unruhe - sie wäre, so die Kritik, ohne Beschluss und Einberufung einer Generalversammlung erfolgt -, die Vereinsbehörde erkannte aber keine Verletzung der Statuten bzw. des Vereinsgesetzes und bekräftigte am 12. Jänner 1928 die Neubildung des Touristik- und Ski-Klubs Hakoah. ${ }^{289}$

Auf der Vollversammlung im Jänner 1927 wurde das Fehlen einer eigenen Vereinshütte erneut thematisiert. Diese konnte 1936 auf dem Semmering errichtet werden. ${ }^{290}$ Gleichzeitig wurde beklagt, dass die SkisportlerInnen der Hakoah im Gegensatz zu großen Skivereinen keine Fahrpreisermäßigung der Bahn bekommen würden. Dabei richtete sich die Kritik ganz klar an den ÖSV, der hier nur seine eigenen Mitgliedervereine unterstützen würde. ${ }^{291}$ Dem Touristik- und Skiklub Hakoah gelang es in Folge, eigene Abfahrtsläufe zu organisieren und durchzuführen, und die Hakoah brachte trotz ihrer nicht professionellen Ausrichtung eine Reihe sehr guter alpiner SkiläuferInnen hervor, die sich auch international einen Namen machen konnten. Unter ihnen das Ehepaar Richard und Gertrude Raubitschek. Richard Raubitschek wuchs als Sohn des Zahntechnikers Alfred Raubitschek in Wien auf. Gemeinsam mit seinem Vater und seinem Bruder Ernst führte er später die Praxis im zwölften Wiener Gemeindebezirk. ${ }^{292}$ Vater Alfred war zudem Vorsitzender der Wiener Zahnärztevereinigung. ${ }^{293}$ Richards älterer Bruder Ernst war ebenso Skiläufer und Vorstandsmitglied in der Wintersportsektion der Hakoah, die beiden führten gemeinsam Erstbegehungen durch und besaßen das bronzene Sportabzeichen der Hakoah. ${ }^{294}$ Die Ehefrau von Ernst, Friederike (Fritzi) Raubitschek, war eine talentierte

288 Neubildung Touristik u. Ski-Klub Hakoah, WStLA, M.Abt. 119, A32 - Gelöschte Vereine: 10673/1927 - 10673/1927.

289 Vgl. Neubildung Touristik u. Ski-Klub Hakoah, WStLA, M.Abt. 119, A32 - Gelöschte Vereine: 10673/1927 - 10673/1927.

290 Vgl. Baar, Hakoah, S. 46.

291 Vgl. Touristik und Wintersport im Sportklub Hakoah, 4 (1927) 22, S. 1.

292 Vgl. Badener Zeitung, 10.8.1935, S. 2.

293 Vgl. Friederike Raubitschek, My husband was a Jew, in: Renate Meissner (Hg.), Erinnerungen: Lebensgeschichten von Opfern des Nationalsozialismus (Band 5), Exil in Australien, Wien 2018, S. 210-223, hier S. 217.

294 Vgl. Wiener Morgenzeitung, 9.6.1927, S. 10; Toursitik- und Wintersport im Sportklub Hakoah, 2 (1925) 14, S. 2; Körner, Lexikon jüdischer Sportler, S. 175. 
Skiläuferin und gleichzeitig Schriftführerin der Sektion. Die beiden lernten sich bei gemeinsamen Berg- und Skitouren der Hakoah kennen und lieben. ${ }^{295}$ Richard Raubitschek, geboren am 25. Oktober 1900 in Wien, war Mitbegründer der Sektion. Er heiratete am 4. Juli 1928 im Wiener Stadttempel Gertrude Eckstein. ${ }^{296}$ Beide betätigten sich sportlich in der Wiener Hakoah und konnten skiläuferische Erfolge feiern. 1933 belegte Richard Raubitschek bei der Makkabiade im polnischen Zakopane im Abfahrtslauf den dritten Platz und 1936 holte er im slowakischen Bistrica den Sieg in seiner Altersklasse. ${ }^{297}$ Neben der Teilnahme an alpinen Skirennen unternahm Richard Raubitschek mit anderen HakoahMitgliedern Skitouren in den österreichischen Alpen und leitete Skikurse der Touristik- und Wintersportsektion. ${ }^{298}$ Er hatte zudem die Leitung der Rettungsstelle in der Sektion über. ${ }^{299}$ Seine 1903 geborene Ehefrau Gertrude war ebenso im Skilauf erfolgreich. ${ }^{300}$

Die Touristik- und Wintersportsektion der Hakoah war Teil des Jüdischen Turn- und Sportverbandes Österreich und damit über den Makkabi-Weltverband international mit anderen jüdischen Sportvereinen sehr gut vernetzt. ${ }^{301}$ Die Wiener Sektion organisierte in verschiedenen Ländern Osteuropas gemeinsame Skisportveranstaltungen bzw. nahm an solchen teil. $\mathrm{Zu}$ einem Fixpunkt im Saisonkalender entwickelten sich die Makkabi-Weltwinterspiele, bei denen immer wieder österreichische SkiläuferInnen starteten. ${ }^{302}$ Daneben organisierte die Wintersportsektion der Hakoah regionale und überregionale Skirennen wie das Abfahrts- und Slalomrennen im niederösterreichischen Türnitz oder die „Goldene Alpenrose“ in Innsbruck. ${ }^{303}$ Die Wintersportsektion pflegte darüber hinaus Kontakte $\mathrm{zu}$ international ausgerichteten Skivereinen in anderen europäischen Staaten wie dem Ski-Club of Great Britain oder dem Schweizer AlpenKlub. ${ }^{304}$ Auch die Hakoah Innsbruck war Mitglied im Makkabi-Weltverband.

295 Baar, Hakoah, S. 245; Raubitschek, My husband was a Jew, S. 217.

296 Vgl. Family Trees, Richard Raubitschek, www.ancestry.com (15.2.2019) Das Lexikon jüdischer Sportler in Wien erwähnt Trude Raubitschek als Schwester von Richard und Ernst Raubitschek. Aus mehreren Quellen sowie aus dem Buch 50 Jahre Hakoah von Arthur Baar geht allerdings hervor, dass Gertrude Raubitschek (geb. Eckstein, kurz genannt Trude) die Ehefrau von Richard war. Vgl. u. a. Baar, Hakoah, S. 245.

297 Vgl. Baar, Hakoah, S. 245.

298 Vgl. Touristik- und Wintersport im Sportklub Hakoah, 2 (1925) 14, S. 1.

299 Vgl. Touristik- und Wintersport im Sportklub Hakoah, 4 (1927) 21, S. 1.

300 Vgl. u. a. Sport-Tagblatt, 26.2.1937, S. 5.

301 Vgl. OeStA, AdR, ZNsZ, Stiko Karton 568, Mappe 31-N 14.

302 Vgl. Sport-Tagblatt, 20.2.1936, S. 5.

303 Vgl. Sport-Tagblatt, 3.3.1934, S. 10 und 8.2.1935, S. 3.

304 Vgl. Touristik und Wintersport im Sportklub Hakoah, 4 (1927) 22, S. 1 


\subsubsection{Jüdisches (Ski-)sportleben aus statistischer Perspektive}

Trotz dieser zahlreichen wintersportlichen Aktivitäten waren die Mitgliederzahlen im Vergleich zu nichtjüdischen Skivereinen in Österreich bescheiden. Wie stark die Zahl der Aktiven bei der Touristik- und Wintersportsektion der Hakoah Wien und der Hakoah Innsbruck tatsächlich war, geht aus einer Mitgliederstatistik aus dem Jahr 1936 hervor. Diese weist für Innsbruck in Summe 44 Mitglieder auf und für die organisierten jüdischen SkisportlerInnen in Wien 183. Die größte Altersgruppe bildete bei der Hakoah Innsbruck die Gruppe der 18- bis 25jährigen mit 20 Mitgliedern. Die zweitgrößte Gruppe war jene der unter 14-jährigen, gefolgt von jener der 14- bis 18-jährigen. ${ }^{305}$ Das zeigt, dass die Hakoah vor allem in der Jugendförderung Impulse setzen konnte. Für die Touristik- und Wintersportsektion liegen leider keine altersspezifischen Zahlen vor.

Tab. 3: Mitgliederstatistik der angeschlossenen Vereine im Jüdischen Turn- und Sportverband Österreich (Stand, 30. Juni 1936, ausgewählte Vereine nach Alter).

\begin{tabular}{lrrrrr}
\hline & $\begin{array}{r}\text { unter 14 } \\
\text { Jahren }\end{array}$ & $\begin{array}{r}\text { 14-18 } \\
\text { Jahre }\end{array}$ & $\begin{array}{r}\text { 18-25 } \\
\text { Jahre }\end{array}$ & $\begin{array}{r}\text { über 25 } \\
\text { Jahre }\end{array}$ & $\begin{array}{r}\text { Mitglieder } \\
\text { insgesamt }\end{array}$ \\
\hline Sportklub Hakoah & 30 & 235 & 350 & 165 & 780 \\
\hline Touristik- und Skiklub Hakoah & k. A. & k. A. & k. A. & k. A. & 183 \\
\hline Hakoah Innsbruck & 12 & 9 & 20 & 3 & 44 \\
\hline Hakoah Graz & 41 & 25 & 55 & 170 & 291 \\
\hline
\end{tabular}

Quelle: OeStA, AdR, ZNsZ, Stiko Karton 568, Mappe 31-N 14, eigene Zusammenstellung.

Tab. 4: Mitgliederstatistik der angeschlossenen Vereine im Jüdischen Turn- und Sportverband Österreich (Stand, 30. Juni 1936, ausgewählte Vereine nach Geschlecht).

\begin{tabular}{lrrr}
\hline & männlich & weiblich & Insgesamt \\
\hline Sportklub Hakoah & 600 & 180 & 780 \\
\hline Touristik- und Skiklub Hakoah & 126 & 57 & 183 \\
\hline Hakoah Innsbruck & 25 & 19 & 44 \\
\hline Hakoah Graz & 205 & 86 & 291 \\
\hline
\end{tabular}

Quelle: OeStA, AdR, ZNsZ, Stiko Karton 568, Mappe 31-N 14, eigene Zusammenstellung.

305 Vgl. Mitgliederstatistik, Stand 30.6.1936, in: OeStA, AdR, ZNsZ, Stiko Karton 568, Mappe 31-N 14. 
Im Vergleich zu Wien und Graz hatte die Hakoah Innsbruck im Jahr 1936 analog zur Größe der jüdischen Gemeinde in Tirol statistisch gesehen die wenigsten Mitglieder, ${ }^{306}$ war aber sportlich dennoch äußerst erfolgreich. Die HakoahSportlerInnen aus Innsbruck konnten fünf österreichische Sportabzeichen in Bronze erwerben, wohingegen der Touristik- und Skiklub mit insgesamt vier Sportabzeichen (drei Bronzenen und einem Goldenen) auf eines weniger kam. In welchen Sportarten die Sportabzeichen errungen wurden, geht zwar aus der Statistik nicht hervor. Bei der Hakoah Innsbruck ist aber anzunehmen, dass diese im Alpin- bzw. Wintersportbereich erzielt wurden, zumindest bildeten der Skilauf und das Bergsteigen einen eindeutigen Schwerpunkt bei den jüdischen SportlerInnen aus Tirol. So ging der Goldene Ski der Hakoah von 1935 bis 1937 drei Mal in Folge nach Innsbruck. ${ }^{307}$ Auffallend ist vor allem, dass das Geschlechterverhältnis in Innsbruck mit 25 Männern und 19 Frauen im Vergleich mit den anderen Hakoah-Vereinen und der Touristik- und Wintersportsektion am ehesten ausgeglichen war.

306 Laut der österreichischen Volkszählung vom 22. März 1934 umfasste die jüdische Wohnbevölkerung in Tirol 365 Menschen. In der Steiermark lebten zum selben Zeitpunkt 2195 Personen jüdischen Glaubens und in Wien waren es 176034 . Vgl. Albert Lichtblau, Integration, Vernichtungsversuch und Neubeginn. Österreichisch-jüdische Geschichte 1848 bis zur Gegenwart, in: Eveline Brugger/Martha Keil/Albert Lichtblau/Christoph Lind/Barbara Staudinger (Hg.), Geschichte der Juden in Österreich, Wien 2006, S. 447-565, hier S. 502. Im März 1938 wurden von den Nationalsozialisten in Tirol und Vorarlberg 460 Jüdinnen und Juden als so genannte „Glaubensjuden erfasst. Vgl. Thomas Albrich, Einleitung, in: Thomas Albrich (Hg.), Wir lebten wie sie..." Jüdische Lebensgeschichten aus Tirol und Vorarlberg, Innsbruck 1999, S. 7-12, hier S. 9.

307 Vgl. Thomas Mayer, Orte der Begegnung und des Kampfes. Hakoah in den Bundesländern, in: Susanne Helene Betz/Monika Löscher/Pia Schölnberger (Hg.), ,...mehr als ein Sportverein“. 100 Jahre Hakoah Wien 1909-2009, Innsbruck/Wien/Bozen 2009, S. 48-64, hier S. 58-59. 